\title{
Genetic background, diet and body fatness : impact on metabolic risk markers and lipid metabolism
}

Citation for published version (APA):

Jellema, A. (2003). Genetic background, diet and body fatness : impact on metabolic risk markers and lipid metabolism. [Doctoral Thesis, Maastricht University]. Datawyse / Universitaire Pers Maastricht. https://doi.org/10.26481/dis.20031121aj

Document status and date:

Published: 01/01/2003

DOI:

10.26481/dis.20031121aj

Document Version:

Publisher's PDF, also known as Version of record

\section{Please check the document version of this publication:}

- A submitted manuscript is the version of the article upon submission and before peer-review. There can be important differences between the submitted version and the official published version of record.

People interested in the research are advised to contact the author for the final version of the publication, or visit the DOI to the publisher's website.

- The final author version and the galley proof are versions of the publication after peer review.

- The final published version features the final layout of the paper including the volume, issue and page numbers.

Link to publication

\footnotetext{
General rights rights.

- You may freely distribute the URL identifying the publication in the public portal. please follow below link for the End User Agreement:

www.umlib.nl/taverne-license

Take down policy

If you believe that this document breaches copyright please contact us at:

repository@maastrichtuniversity.nl

providing details and we will investigate your claim.
}

Copyright and moral rights for the publications made accessible in the public portal are retained by the authors and/or other copyright owners and it is a condition of accessing publications that users recognise and abide by the legal requirements associated with these

- Users may download and print one copy of any publication from the public portal for the purpose of private study or research.

- You may not further distribute the material or use it for any profit-making activity or commercial gain

If the publication is distributed under the terms of Article $25 \mathrm{fa}$ of the Dutch Copyright Act, indicated by the "Taverne" license above, 
Genetic background, diet and body fatness: impact on metabolic risk markers and lipid metabolism 

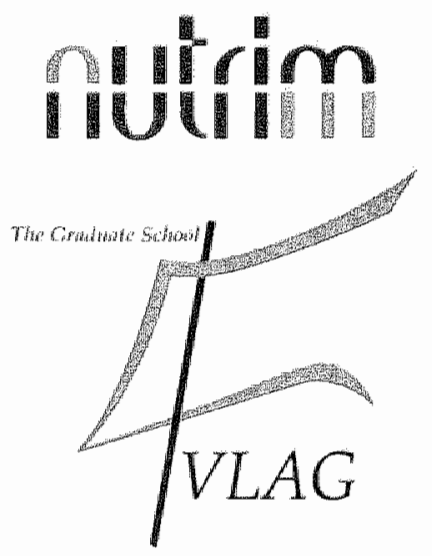

The studies presented in this thesis were performed at the Nutrition and Toxicology Research Institute Maastricht (NUTRIM), which participates in the Graduate School VLAG (Food Technology, Agrobiotechnology, Nutrition and Health Sciences) accredited by the Royal Netherlands Academy of Arts and Sciences. There was a close collaboration with the Centre for Nutrition and Health of the National Institute of Public Health and the Environment in Bilthoven.

Production: Datawyse, Universitaire Pers Maastricht Cover Design: Annemarie Jellema/Leo Vandijck

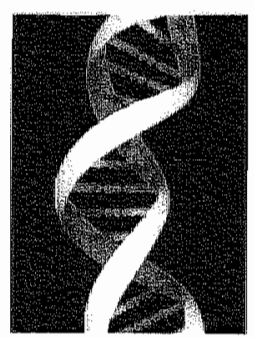

Picture front page

(c) Annemarie Jellema, Amsterdam ISBN 90-5278-392-6 


\section{Genetic background, diet and body fatness: impact on metabolic risk markers and lipid metabolism}

\section{Proefschrift}

ter verkrijging van de graad van doctor

aan de Universiteit van Maastricht

op gezag van de Rector Magnificus

Prof. Dr A.C. Nieuwenhuijzen Kruseman

volgens het besluit wan het College van Decanen

in het openbar te verdedigen op

vrijdag 21 november 2003 om 14.00 uur

door

\section{Annemarie Jellema}

geboren op 16 maart 1975 te Grouw

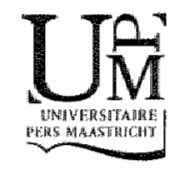


Promotores:

Prof. Dr Ir R.P. Mensink

Prof. Dr Ir W.H.M. Saris

Prof. Dr Ir D. Kromhout (Wageningen Universiteit)

Copromotor:

Dr Ir E.J.M. Feskens (Wageningen Universiteit)

Beoordelingscommissie:

Prof. Dr Ir P.A. wan den Brandt (voorzitter)

Prof. Dr T.W.A. de Bruin

Prof. Dr Ir L.M. Havekes (Universiteit Leiden)

Prof. Dr E.C.M. Mariman

Prof. Dr E. Schouten (Wageningen Universiteit)

The studies described in this thesis were supported by a grant from the Netherlands Organization for Scientific Research (NWO) (grant number $980-$ 10-006).

Financial support by the Netherlands Heart Foundation and the Netherlands Organization for Scientific Research (NWO) for the publication of this thesis is gratefully acknowledged. Printing of this thesis was also possible by the generous support from the Dutch Diabetes Research Foundation. 


\section{Contents}

\section{Chapter 1}

General introduction

\section{Chapter 2}

Metabolic risk markers in an overweight and normal weight population with oversampling of carriers of the IRS-1 972Arg variant

\section{Chapter 3}

Gly972Arg variant in the insulin receptor substrate-1 gene and association with type 2 diabetes: a meta-analysis of 27 studies

\section{Chapter 4}

Impact of polymorphisms in the IL-6 and TNF- $\alpha$ genes on metabolic risk markers and the interaction of overweight

\section{Chapter 5}

Effects of fish oil and weight reduction on subcutaneous adipose tissue lipolysis in the fasting and postprandial state

\section{Chapter 6}

Effects of fish oil and weight loss on inflammatory parameters and PAl-1 antigen concentrations in obese men during the fasting and postprandial state

\section{Chapter 7}

General discussion

\section{Summary}

Samenvatting

\section{Abbreviations}

Nawoord 



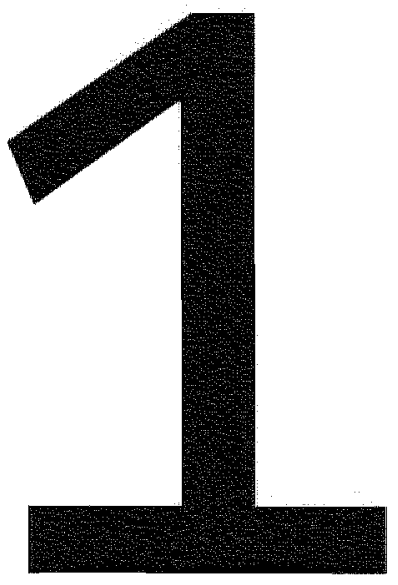

General introduction 
Until recently, adipose tissue was mainly seen as a passive organ for storage of energy in the form of triglycerides (TG) (1). Research of the past decade, however, has shown that adipose tissue plays a central role in lipid and glucose metabolism. It further secretes a variety of endocrine signals, cytokines and hemostatic factors (see table 1.1) (2).

\section{Table 1.1:}

Products of adipocytes

\begin{tabular}{|c|c|}
\hline & Product \\
\hline \multirow[t]{5}{*}{ Metabolites } & Non-esterified fatty acids (3) \\
\hline & Glycerol (4) \\
\hline & Alanine (5) \\
\hline & Glutamine $(6)$ \\
\hline & Lactate (7) \\
\hline \multirow[t]{4}{*}{ Endocrine signals } & Oestradiol (8) \\
\hline & Cortisol (9) \\
\hline & Leptin $(10)$ \\
\hline & Angiotensinogen (11) \\
\hline \multirow[t]{2}{*}{ Cytokines } & Tumor necrosis factor- $\alpha$ (12) \\
\hline & Interleukin-5 (13) \\
\hline Hemostatic factors & Plasminogen activator inhibitor-1 (14) \\
\hline insulin signaling & Insulin receptor substrate-1 (15) \\
\hline \multirow[t]{3}{*}{ Lipid metabollism } & Acylating stimulating protein (16) \\
\hline & Cholesterol ester transfer protein (17) \\
\hline & Lipoprotein lipase (18) \\
\hline
\end{tabular}

In overweight and obesity, a disturbance in lipid and glucose metabolism in adipose tissue has been observed. In this thesis, the effects of genetic and dietary factors on metabolic risk markers are studied, with a special emphasis on the effects in overweight and obese subjects. This introduction should provide the reader with background information to comprehend the studies presented in this thesis. First, the regulation of lipid and glucose metabolism 
and the disturbances seen in overweight and obese subjects will be described. Second, some genetic and dietary factors possibly influencing metabolic risk markers will be reported. Finally, the objectives and an outline of this thesis are given.

\section{Obesity as a multifactorial disease}

Obesity occurs when there is an imbalance between energy intake and energy expenditure (19). The energy surplus is stored in the reserve tissues of which the adipose tissue forms the main component.

There are several definitions of overweight and obesity. The most practical current definitions are the ones of the World Health Organization (WHO) with overweight defined as a body mass index (BMI) between $25-30 \mathrm{~kg} / \mathrm{m}^{2}$ and obesity defined as a BMI of $30 \mathrm{~kg} / \mathrm{m}^{2}$ or greater (20). The prevalence of obesity is progressively increasing worldwide. It has already reached epidemic proportions in the United States (21). The age-adjusted prevalence of obesity in the US based on one of the national surveys from 1999-2000 was $30.5 \%$ (22) compared with $22.9 \%$ in the period $1988-1994$ (23). The prevalence of overweight also increased during this period from $55.9 \%$ to $64.5 \%$. Between 1976 and 1997 , the prevalence of obesity in the Netherlands increased from $4.9 \%$ to $8.5 \%$ among men and from 6.2 to $9.3 \%$ among women (24).

Obesity is determined by many genetic and environmental factors that are incompletely understood. Several twin studies have shown a strong genetic component of BMI $(25,26)$ accounting up to $70 \%$ of variance. With regard to the genetic origin of obesity, it has been suggested that a major - so far unidentified - gene may predispose those patients with extreme obesity, whereas polygenic effects may be involved in the range from thin to fat (27). Genetic predispositions have received great attention, although the underlying cause of the dramatic increase in obesity prevalence in industrialized countries within the last few decades is most likely due to changes in environmental factors, such as changes in the intakes of energy by dietary fat, alcohol, and fiber, and a decrease in the level of physical activity (28). The sensitivity of these environmentall factors however, may vary from person to person because of differences in genetic background (29).

Obesity can be divided into two forms, android obesity, mostly found in men, and gynoid obesity, mostly found in women (30). Android obesity, the form with an accumulation of upper body fat, is more frequently associated with diabetes, hypertension and coronary heart disease (CHD) (31). Especially the accumulation of visceral fat (fat in the abdominal cavity) is an important marker for obesity-related complications. The waist to hip ratio has been accepted as a good proxy variable of body fat distribution (30). 


\section{Regulation of lipid and glucose metabolism}

Lipolysis refers to the process in which TG are broken down in a stepwise fashion via diacylglycerol (DG) and monoacylglycerol (MG) into fatty acids (FA) and glycerol (3). The vast majority of the body's TG is found in adipose tissue stores (1). The turnover of TG in adipocytes is mainly regulated by two enzymes, lipoprotein lipase (LPL) and hormone sensitive lipase (HSL) (see figure 1.1).

\section{Figure 1.1:}

Simplified overview of lipid metabolism

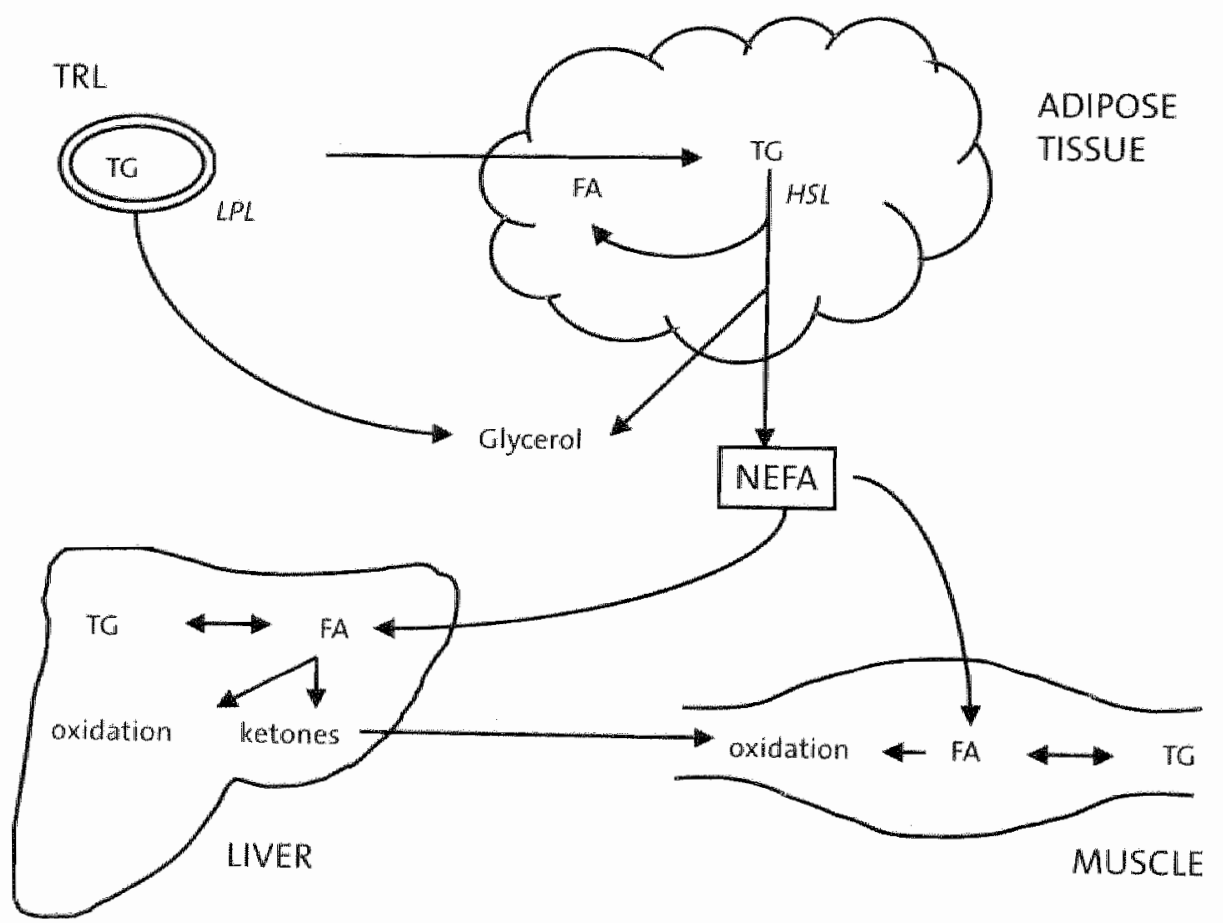

The turnover of adipocytes is regulated by HSL and $\mathrm{LPL}$, acting on intra-adipocyte and circulating lipoprotein triglyceride, respectively. FA relealsed from the adipocyte by HSL are transported into the circulation or are reesterified. FA are taken up by muscle and liver for either direct axidation, partial oxidation to ketones, or resterification to TC.

TRL: triglyceride-rich lipoproteins fchylomicrons, very low density lipoproteins (WLDL), TG: triglyceride, NEFA: non-esterified fatty acid, FA: fatty acid, HSL hormone-sensitiwe lipase, LPL: lipoprotein lipase. 
LPL, which is located on the capillary walls of the endothelium, hydrolyses the TG in circulating chylomicrons and very low density lipoproteins (VLDL), whereas the intracellularly located enzyme HSL plays an important role in the hydrolysis of adipocyte TG (32). The FA released from the adipocyte TG are transported through the circulation as non-esterified fatty acids (NEFA) bound to albumin. In contrast to glycerol, some FA never leave the fat cell and are reutilized in a process called re-esterification. Besides adipose tissue, liver and muscle tissue are also important sites for lipolysis (3).

After a meal, HSL is suppressed by insullin, and the release of NEFA and glycerol from adipose tissue decreases (33). However, the activity of adipose tissue LPL is stimulated by insulin. Studies of fatty acid and TG handling in human subcutaneous adipose tissue in vivo after meals with different fat content, suggest a peak of LPL action three to five hours after a meal (34). Therefore, after the decrease in NEFA and glycerol concentrations from adipose tissue due to HSL suppression, there is a subsequent increase as LPL activity increases.

Besides its role in lipolysis, insulin is also the main regulator of glucose metabolism (35). It lowers blood glucose concentrations through suppression of glucose generation by the liver and stimulation of glucose uptake by peripheral tissues, particularly skeletal muscle (quantitatively the most important) and adipose tissue. The role of glucose in adipose tissue is twofold. First, glucose oxidation seems to be the major route of adenosine triphosphate (ATP) generation in adipose tissue. In addition, in the postprandial period glycolysis provides glycerol 3-phosphate, which is needed for esterification of the fatty acids delivered to adipocytes from LPL in the capillaries.

Thus, lipid and glucose regulation is complex, due to the diversity of hormones and non-steady state conditions governing this process. The complexity is even greater when dysregulation occurs, as seen in obesity.

\section{Body fatness and lipid and glucose metabolism}

The unfavorable effects of increased body fatness on lipid metabolism are well established (36). In general, overweight and obese patients have increased fasting plasma TC and total cholesterol (TC) concentrations together with reduced plasma high density lipoprotein cholesteral (HDL-C) levels. Frayn et al (37) have now suggested that many of the metabolic consequences of obesity are mediated by increased adipose tissue release of NEFA. In fact, the rate of hepatic VLDL secretion is strongly dependent upon the rate of supply of NEFA to the liver (34). Failure to suppress the NEFA supply may lead to sustained VLDL production and impaired clearance of TG. 
rich lipoproteins. A further consequence is an increased production of low density lipoprotein (LDL) particles, resulting in increased apoB concentrations in plasma. In addition, HDL particles become relatively enriched in TG (30). since hepatic lipase $(\mathrm{HL})$ activity has been reported to be increased in visceral obesity, TG-rich HDL particles are submitted to hydrolysis by this enzyme, generating reduced $H D L C$ levels (38). All these changes are associated with increased risk for CHD (34). Normally, plasma NEFA concentrations are suppressed after a meal (39). Therefore, the adverse effects of elevated NEFA concentrations, will be most apparent in the postprandial period.

Body fatness, and in particular, visceral obesity is also associated with the features of the insulin resistance syndrome, also called the metabolic syndrome or syndrome $X$. This syndrome was first described by Reaven in 1988 (40). He suggested that there are a series of related variables that are of importance in the pathogenesis of CHD, such as glucose intolerance, hyperinsulinemia, increased VLDL-TG, decreased HDL-C, hypertension, and most importantly resistance to insulin-stimulated glucose uptake. Insulin resistance can be defined as the failure of high insulin concentrations to stimulate whole-body glucose disposal under hyperinsulinaemic, euglycemic clamp conditions (41). Insulin resistance may ultimately lead to the development of type 2 diabetes, which is characterized by the co-existence, to a variable extent, of abnormal insulin secretion and insulin resistance $(42,43)$. As about $80 \%$ of the patients with type 2 diabetes are obese at the time of the diagnosis, obesity is a strong predictor for the risk to develop type 2 diabetes. However, obesity is just one of several potential causes of insulin insensitivity, because even morbid obese individuals not always develop type 2 diabetes (36).

Després and colleagues have extensively studied the relationship between obesity and insulin resistance $(36,44,45)$. Kinetic studies have shown that an excess in total body fat is associated with hypersecretion of insulin, leading to systemic hyperinsulinemia (figure 1.2). This may be due to an increased release of NEFA in overweight and obese subjects (44). On one hand, elevated NEFA concentrations will stimulate hepatic gluconeogenesis resulting in an increased endogenous glucose production. This in turn leads to systemic hyperinsulinaemia. On the other hand, an increased release of NEFA leads to a sparing of glucose oxidation. This will result in decreased glucose uptake in the skeletal muscle (42) and consequently to hypersecretion of insulin by the pancreatic cells. Recent work from Kelley et al (46) however, has found that skeletal muscle in insulin resistance is accompanied by increased rather than decreased muscle glucose oxidation under basal conditions. Decreased glucose oxidation has been observed under insulin-stimulated circumstances. Fat oxidation was reduced in skeletal muscle of obese individuals under basal 
conditions (47). Such a situation could contribute to the accumulation of TG in the myocyte.

The disturbances in lipid and glucose metabolism observed in obesity are highly associated. First, the resistance to the antilipolytic effect of insulin in the postprandial period contributes to exposure of the liver to high concentrations of NEFA through the portal circulation (44). These high portal NEFA levels favor hepatic TG synthesis and VLDL secretion (36). Second, LPL is an insulin sensitive enzyme with reduced $L P L$ activity in the insulin resistant state. The reduced skeletal muscle LPL activity may also be involved in the hypertriglyceridaemic state through a decreased catabolism of triglyceride. rich lipoproteins (TRL).

\section{Figure 1.2:}

Body fatness and insulin resistance

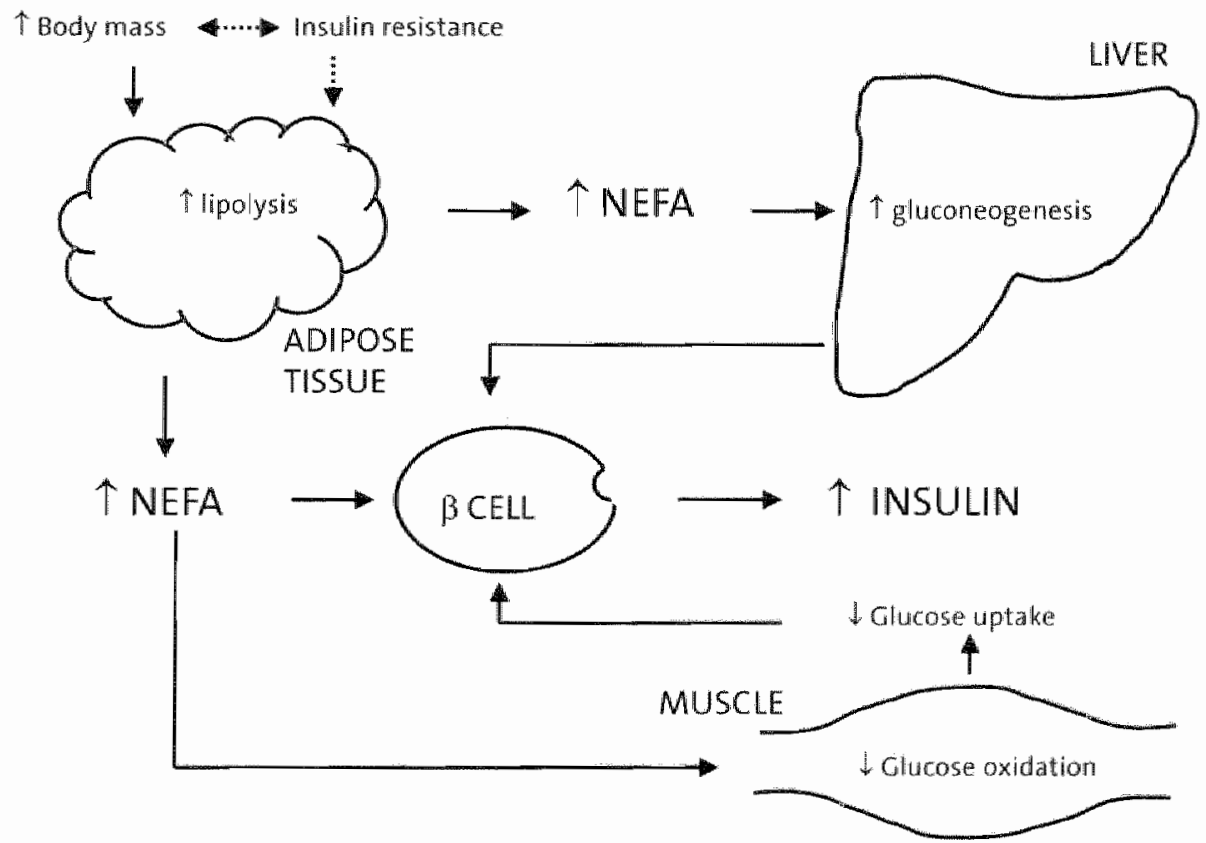

Body fatness and insulin pesistance lead to increased NEFA concentrations, resulting in a stimulation of hepatic glucomeogenesis and a sparing of glucose oxidation in skeletal muscle. This in turn leads to systemic hyperinsulinaemia.

NEEA: non-esterified fatty acid. 


\section{Products expressed by the adipose tissue}

As briefly mentioned in a previous section, adipose tissue secretes several products (table 1.1). This thesis focuses on insulin receptor substrate-1 (IRS-1), tumor necrosis factor- $\alpha$ (TNF- $\alpha$ ), interleukin-6 (L-6), and plasminogen activator inhibitor-1 (PAl-1).

\section{Insulin receptor substrate-1}

IRS-1 occupies a key position in the insulin signaling pathway, representing the first endogenous substrate of the insulin receptor tyrosine kinase (48) (figure 1.3). IRS-1 is present in insulin sensitive tissues, such as muscle, liver, and adipose tissue $(15,49)$. After insulin binding to the $\alpha$-subunit of the insulin receptor, the $\beta$-subunit of the receptor undergoes autophosphorylation, and in turn, phosphorylates other endogenous protein substrates, such as IRS-1, in the cascade of insulin action. Thus, an impaired IRS-1 function results in a defect in insulin signaling. Indeed, both type 2 diabetic patients (50) and obese subjects (15) have reduced phosphorylation of both the insulin receptor and IRS-1. In addition, a reduced IRS-1 expression in adipocytes of healthy subjects, particularly in those with a marked genetic predisposition for type 2 diabetes, has been observed (49). IRS-1 function is inhibited by TNF- $\alpha$ (51). As adipose tissue is a significant source of TNF- $\alpha$ production (52) TNF- $\alpha$ may be a link between obesity and impairments in insulin receptor and $\mathrm{R} S \mathrm{~S}-1$.

\section{TNF $\alpha$ and TNF-receptors}

Obese individuals express 2.5 fold more TNF- $\alpha$ MRNA in fat (in \%) as compared with lean controls (52). The pioneering studies of Hotamisligil et al (53.55) have highlighted the importance of TNF- $\alpha$ on insulin signaling. It is thought that TNF-a decreases IRS-1 function by reducing IRS-1 associated phosphatidylinositol (P) 3 kinase activity in adipocytes (56) and other major insulin-sensitive tissues (57). There is further evidence that prolonged exposure of 3T3-L1 adipocytes to TNF- $\alpha$ reduces glucose transporter 4 (GLUT4) mRNA and protein $(58,59)$. GLUT4 plays a major role in enhancing glucose transport in response to insulin in muscle and adipose tissue cells (60). This may ultimately lead to increased plasma glucose concentrations.

TNF- $\alpha$ also inhibits several enzymes involved in fat synthesis, such as fatty acid synthase (FAS), LPL, acetyl-COA carboxylase (ACC), fatty acid-binding protein (FABP), and glycerol phosphate dehydrogenase (GPDH) (61). This 
cytokine also stimulates TG degradation in the adipocyte by stimulating HSL. Partly as a result of these metabolic changes in adipose tissue and partly because it stimulates liver lipogenesis and hepatic VLDL production (61), TNF- $\alpha$ causes severe hypertriglyceridemia.

Adipose tissue also expresses two TNF-ch receptors (TNF-R60 and TNF-R80) (62). In contrast to TNF $\alpha$ itself, the soluble forms of these receptors are present in relatively high concentrations in the plasma (63). The functions of these circulating soluble TNF-receptors (STNF-R) are not clearly understood. STNF-R are derived from two different membrane bound TNF-receptors (mTNF-R60 and MTNF-R80) that become inactive upon shedding their TNFbinding domains as STNF-R $(64,65)$. sTNF-R may be involved in the inactivation of circulating TNF- $\alpha$ by binding TNF- $\alpha$ and competing with MTNF-R. On the other hand, it has also been suggested that sTNF-R serves as binding protein to carry TNF- $\alpha$ from the side of production or acts as a reservoir of bio-active TNF $\alpha$ (64). Hube et al (62) have found that plasma levels of both TNF- $\alpha$ receptors are significantly higher in obese subjects as compared with lean subjects. Hotamisligil et al (63), however, have observed only overexpression of TNF-R8O, but not of TNF-R60 in obese subjects in adipose tissue and the circulation. Strong correlations between plasma levels of TNF R80 with BMI, hyperinsulinemia and TNF $\alpha$ MRNA levels have been observed (62). These latter results suggest that in obesity TNF-R8O may play a more prominent role on modulating the actions of TNF-a than TNF-R60.

\section{Figure 1.3}

The insulin signaling pathway

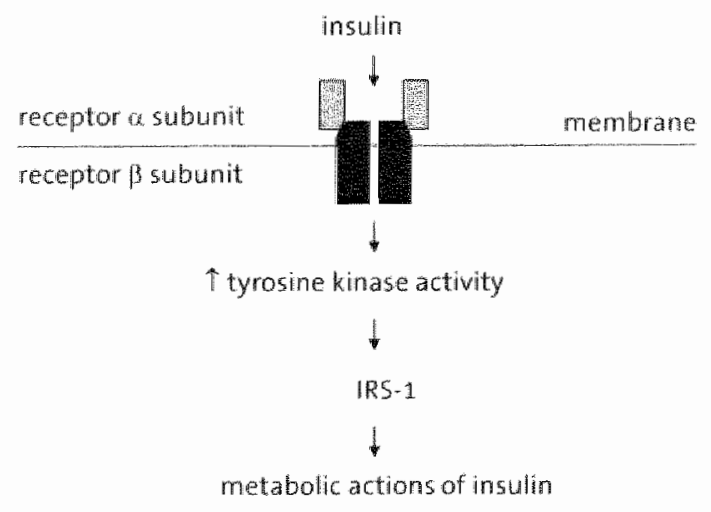

Binding of insulin to its receptor leads to autophosphorylation and increased tyrosine kinase activity in the $\beta$-subunits. The increased tyrosine kinase activity phosphorylates and activates IRS-1.

IR5-1; insulin receptor substrate-1. 


\section{Interleukin-6}

IL-6 is a cytokine, which is secreted by a number of different cells, including adipose tissue, macrophages, and lymphocytes. Its plasma concentration is positiwely related to the degree of obesity (13). This cytokine has significant effects on glucose and lipid metabolism (13). H stimulates basal glucose uptake, inhibits LPL activity and stimulates glucose and fatty acid oxidation (2). IL-6 is also associated with hepatic synthesis of C-reactive protein (CRP), a possible predictor for the occurrence of CHD (13). Both $1 L-6$ and CRP concentrations were independently related with cardiovascular risk factors (66). A recent report from the Rural Health Study has shown that also elevated concentrations of IL-6 predict total and cardiovascular mortality over a 5 year follow-up. This association was independent of prevalent vascular disease, smoking and traditional risk factors, and stronger than, and additive to that of CRP (67). Elevated levels of CRP and $\| L-6$ also predict the risk of type 2 diabetes (68). IL-6 may exert a more endocrine function than TNF- $\alpha$, because it is released from the fat depot and is thereby able to signal systemaitically (69).

\section{Plasminogen activator inhibitor-1}

PAl-1 inhibits plasminogen activation in blood (70), which is involved in the lysis of a thrombus. This may explain the frequently observed positive relationship between $\mathrm{PAI}-1$ concentrations with the risk for vascular disease (71). PAl-1 is partly synthesized by adipocytes (14) and a positive association between visceral fat mass and BMI with PAI-1 levels in humans has indeed been observed (72-74). Recently, however, it has been shown that PAl-1 gene expression was increased in subcutaneous adipose tissue of obese subjects at very low calorie diets, while plasma PAl-1 levels were decreased (75). Although the subjects were not in steady state, this study suggests that the relationship between PAI-1 gene expression in adipose tissue and plasma PAl-1 is more complex. Possibly, not adipose tissue per se, but insulin resistance may play a major role in the regulation of circulating PAI-1 in human obesity (76). In addition, TNF-a had a stimulatory effect on PAl-1 mRNA expression in human fat cells (14), which may also be a contributory mechanism to explain the increased PAI-1 concentrations in obese subjects (70).

\section{Genetic background and metabolic risk markers}

Responses of a phenotype (e.g. fat mass) to environmental changes (e.g. dietary intervention) can be modulated by genetic background. In this thesis, we focus on polymorphisms related to adipose tissue. Based on existing 
knowledge, three promising polymorphisms have been identified, located in the IRS-1-gene, TNF- $\alpha$ gene and the IL- 6 gene.

\section{IRS-1 polymorphism}

Two common polymorphisms in the IRS-1 gene (chromosome 2q36) are known, one at codon 513 and one at codon 972 (77). Especially the association between the Gly972Arg polymorphism and insulin sensitivity in humans has been studied extensively $(43,77-82)$, partly because of the relatively high prevalence of this polymorphism (approximately 10\%). In addition, Almind et al (83) have found that insulin signaling of myeloid progenitor cells transfected with the $972 \mathrm{Arg}$ variant of the human IRS-1 was impaired as compared to cells transfected with wildtype human IRS-1, which suggests that the Gly972Arg polymorphism is a functional polymorphism. In support, Clausen et al (43) have observed in obese subjects that carriers of the $972 \mathrm{Arg}$ variant had increased fasting glucose, TG, tissue plasminogen activator (tPA) concentrations, and decreased insulin sensitivity. This suggests that the $972 \mathrm{Arg}$ variant may interact with obesity in the pathogenesis of common insulin-resistant disorders.

\section{TNF- $\alpha$ polymorphism}

A common polymorphism in the TNF- $\alpha$ promoter, located on chromosome $6 \mathrm{p} 21$, has been identified at position $-308(84)$. When expressed in a human $B$ cell line, the heterozygous form of the polymorphism led to a higher transcription rate than the wild-type GG allele (85). Fernandez-Real et al (86) have observed increased insulin and leptin levels and a higher percentage of body fat in heterozygous (GA) and homozygous (AA) carriers compared with homozygous wild-type (GG) subjects of this polymorphism. In addition, the polymorphism is associated with other markers of obesity, such as BMI and body fat content $(87,88)$.

\section{IL-6 polymorphism}

A common polymorphism of the $\| \mathrm{L}-6$ gene on chromosome 7 p21 at codon 174 has been studied by Fernandez-Real et al (89) who observed increased TG, VLDL en NEFA levels in carriers of the $G$ allele compared with carriers of the $C$ allele. As IL-6 is overexpressed in obesity, it may be possible that the associations between the $G 174 \mathrm{C}$ pollymorphism and markers of glucose and fat metabolism is modified by BMI, but this has as yet not been studied in detail. 


\section{Dietary interventions and metabolic risk markers}

As the metabolic aberrations related to overweight and obesity have a huge impact on health, insight into effects of dietary components on metabolic risk markers in overweight and obese subjects is needed. Weight reduction has clear, positive effects on metabolic parameters in obese subjects (90). However, sustained weight loss is difficult to achieve. Therefore, other dietary interventions that possibly change metabolic parameters in a favorable way, deserve attention. In this thesis we have focused on fish oil supplementation, mainly because many large scale epidemiological studies have suggested a favorable effect of fish oil on the risk of CHD (91) and type 2 diabetes (92). In this section, we will now briefly describe some previous findings regarding these dietary interventions.

\section{Weight reduction}

Weight reduction improves insulin sensitivity $(90,93)$ and the risk of type 2 diabetes (94). It also beneficially affects other metabolic abnormalities. A meta-analysis of 70 studies indicated that weight reduction was associated with significant decreases in TC, LDL, VLDL, and TG concentrations (95). For every kilogram decrease in body weight, a $0.009 \mathrm{mmol} / \mathrm{L}$ increase in HDL-C and a $0.007 \mathrm{mmol} / \mathrm{L}$ increase in TG and LDL-C was achieved for subjects at a stabilized, reduced weight.

Besides effects on insulin sensitivity and blood lipids, inflammatory and fibrinolytic factors also improve after weight reduction. Kern et al (96) have found a decrease in TNF- $\alpha$ mRNA levels of $58 \%$ of the baseline levels and a decrease in TNF protein of $46 \%$ of the initiating levels after weight loss of on average $34.7 \mathrm{~kg}$ in eleven obese subjects. Also $1 \mathrm{~L}-6$ concentrations and PAl-1 concentrations significantly decreased after weight reduction $(97,98)$.

\section{Fish oil}

The n-3 family of fatty acids has attracted much scientific attention, since the studies of Bang and Dyerberg in Greenland Inuits pointed to these fatty acids as potential antiatherogenic nutrients (99). Knapp et al (100) reported that $n$ 3 fatty acids decrease platelet aggregation, resulting in a modest prolongation of bleeding times. Harris et al (101) conducted a meta-analysis on the effects of fish oill om serum lipid concentrations in humans. They showed that fish oil decreased TG concentrations, especially in hypertriglyceridemic patients. LDLC concentrations increased to a small extent. HDL-C concentrations were essentially unaffected by n-3 fatty acid treatment. Besides the effects of fish 
oil on lipoprotein metabolism, a relationship between fish oil and insulin sensitivity in animal and epidemiological studies has been observed (102, 103). However, these results could not be confirmed in human intervention trials (104, 105). Possibly, fish oil may especially exert tissue-specific insulin sensitivity or insulin-sensitivity in the postprandial state. Fish ofl supplementation may also affect inflammatory markers (106), although results are not consistent (107).

\section{General objective}

Although it is well known that the role of adipose tissue in glucose and lipid metabolism is important, more information on the role of genetic and dietary determinants involved in adipocyte function is needed. The objectives of the research described in this thesis were therefore twofold. The first objective was to examine if relationships between selected genetic polymorphisms on metabolic risk markers did depend on body fatness. For this, effects of polymorphisms in three genes (IRS-1, TNF- $\alpha$ and IL-6) that play a role in many metabolic routes and are transcribed in the adipocyte, are described. We further examined the relationship between a polymorphism in the IRS-1 gene and the prevallence of type 2 diabetes by means of a meta-analysis.

The second objective was to determine the effects of two dietary interventions (fish oil supplementation and weight loss) on lipid and glucose metabolism and on metabolic risk markers in obese men. In particular, attention was paid to the effects of these two interventions on subcutaneous adipose tissue metabolism and on inflammatory responses during the fasting and postprandial period.

\section{Outline of the thesis}

The interrelationships between the Gly972Arg polymorphism in the IRS-1 gene, body fatness, and metabolic risk markers is reported in chapter 2. For that study, we selected from a large population-based cohort 600 subjects according to BMI (BMI $26-40 \mathrm{~kg} / \mathrm{m}^{2}, n=304$ or BMI $18-24 \mathrm{~kg} / \mathrm{m}^{2}, n=296$ ) and the presence of the polymorphism (yes/no). Chapter 3 describes the results of a metawanalysis of the Gly972Arg polymorphism on the prevalence of type 2 diabetes. The associations between two other polymorphisms, the 6308.4 polymorphism in the TNF- $\alpha$ gene and the $G 174 \mathrm{C}$ polymorphism in the $1 \mathrm{~L}-6$ gene, body fatness, and metabolic risk markers in these 600 subjects are reponted in chapter 4 . 
Chapters 5 and 6 describe the effect of two dietary interventions, fish oil supplementation and weight loss, on metabolic risk markers, and on glucose and lipid metabolism. Eleven obese men participated in the fish oil intervention study, a double blind, randomized, cross-over study, existing of two periods of six weeks. After this study, eight subjects also participated in the weight loss study. At the end of each experimental period, measurements were performed during the fasting and postprandial state. Chapter 5 reports the results of these interventions on subcutaneous adipose tissue lipolysis as measured with the microdialysis technique. The effects of both interventions on inflammatory and fibrinolytic factors are described in chapter 6 . Specifically, we investigated the changes in TNF- $\alpha$, TNF-receptors, IL- 6 and PAl-1 concentrations after fish oil supplementation and weight loss.

Chapter 7 summarizes the findings of the different studies described in this thesis. The main results are discussed and put into a broader perspective. 


\section{References}

1. Samra J5. Sir David Cuthbertson Medal Lecture. Regulation of lipid metabolism in adipose tissue. Proc Nutr 5oc 2000;59:441-446.

2. Mohamed-Ali V. Pinkney MH, Coppack SW. Adipose tissue as an endocrine and paracrine organ. Int J Obes 1998;22:1145-1158.

3. Coppack $5 W$, lensen MD, Miles $J M$. In wivo regulation of lipolysis in humans. 1 Lipid Res 1994:35:177-193.

4. Coppack SW. Persson M, Judd RL, Miles JM. Glycerol and nonesterified fatty acid metabolism in human muscle and adipose tissue in vivo. Am J Physiol 1999;276:E233240 .

5. Frayn KN, Khan K, Coppack SW, Elia M. Amino acid metabolism in human subcutaneous adipose tissue in wivo. Clin Sci (Lond) 1991;80:471-474.

6. Kowalski TJ, Watford M. Production of glutamine and utilization of glutamate by rat subcutaneous adipose tissue in vivo. Am J Physiol 1994:266:E151-154.

7. DiGirolamo $M$, Newby $F D$, Lovejoy J. Lactate production in adipose tissue: a regulated function with extra-adipose implications. Faseb 1 1992;6:2405-2412.

8. Boulton KL, Hudson DU, Coppack SW, Frayn KN. Steroid hormone interconversions in human adipose tissue in wivo. Metabolism 1992;41:556-559.

9. Katz $J R$, Mohamed-Ali V. Wood PJ, Yudkin JS, Coppack SW. An in vivo study of the cortisol-cortisone shuttle in subcutaneous abdominal adipose tissue. Clin Endocrinol 1999:50:63-68.

10. Considine RV, Sinha MK, Heiman ML, et all, Serum immunoreactive-leptin concentrations in normal-weight and obese humans. N Engl I Med 1996;34:292-295.

11. Campbell DJ. Circulating and tissue angiotensin systems. J Clin Invest 1987;79:1-6.

12. Hotamisligil CS, Shargill NS, Spiegelman BM. Adipose tissue expression of tumor necrosis factor a:direct role in obesity-linked insulin resistance. Science 1993;259:87-91.

13. Yudkin JS, Kumari M. Humphries. SE, Mohamed-Ali V. Inflammatiom, obesity, stress and coronary heart disease: is interleukin-6, the link? Atherosclerosis 1999;148:209-214.

14. Cigolini $M$, Tonoli $M$, Borgato $L$, et al. Expression of plasminogen activator inhibitor-1 in human adipose tissue: a role for TNF-alpha? Atherosclerosis 1999;143:81-90.

15. Sesti $G$, Federic $M$. Hribal ML. Lauro D, Sbraccia P. Lauro R. Defects of the insulin receptor substrate (IRS) system in human metabolic disorders. Faseb J 2001:15:2099 2111.

16. Sniderman AD, Cianflone $K$. The adipsin-ASP pathway and regulation of adipocyte function. Ann Med 1994:26:388-393.

17. Tall AR. Plasma cholesteryl ester transfer protein. J Lipid Res 1993;34:1255-1274.

18. Coppack SW, Yost TJ, Fisher RM, Eckel RH, Miles JM. Periprandial systemic and regional lipase activity in normal humans. Am J Physiol 1996;270:57:18-722.

19. Strubbe JH. Obesity. In: Westerterp-Plantenga MS, Fredrix EWHM, Steffens AB, eds. Food intake and energy expenditure. Boca Raton: CRC press, 1994:183-194.

20. WHO. Obesity: preventing and managing the global epidemic. Geneva, 1998.

21. Hill JO, Melanison EL, Wyatt HT. Dietary fat intake and regulation of energy balance: implications for obesity. J Nutr 2000;130:2845-2885.

22. Flegal $\mathrm{KM}$, Carroll MD, Ogden $\mathrm{CL}$, johnson $\mathrm{Cl}$. Prevalence and trends in obesity among US adults, 1999 2000. JAMA 2002;288:1723-1727.

23. Flegal KM. The obesity epidemic in children and adults: current evidence and research issues. Med Sci Sports Exerc 1999;31:5509-514. 
24. Vischer TL, Kromhout $\mathrm{D}$, Seidell JC. Long-term and recent time trends in the prevalence of obesity among Dutch men and women. Int 1 Obes Relat Metab Disord 2002:26:12181224.

25. Herskind AM, MGGie M, Sorensen TI. Harvald B. Sex and age specific assessment of genetic and environmental influences on body mass index in twins. Int I Obes Relat Metab Disord 1996;20:106-113.

26. Stunkard Al. Genetic contributions to thuman obesity. Res Publ Assoc Res Nerv Ment Dis $1991 ; 69: 205 \sim 218$.

27. Hitman GA. Molecular genetics of obesuty. In: Kopelman PG, Stock Mu, eds. Clinical Obesity. Oxford: Blackwell Scienice, 1998:73-85.

28. Schmidt I. Metabolic diseases: the environment determines the odds, ewen for genes. News Physiol Sci $2002 ; 17 * 115-121$.

29. Bouchard $\mathbb{C}$. Genetics and the metabolic syndrome. Int I Obes Relat Metab Disord 1995:19 Suppl 1:552-59.

30. Tchernof $A$, Després JP. Obesity and Ijpoprotein mettabolism. In: Kopelman PG, Stack MJ, eds. Clinical Obesity. Oxford: Blackwell Science, 1998:176-204.

31. Vague 1. La différenciation sexuelle, facteur déterminant des formes de l'obésité. Pressie Medicale 1947:30:339-340.

32. Aimer P, Eckel RH. Adipose tissue as a storage organ. In: Bray $G_{y}$ Bunchard $C_{x}$ James MPT, eds. Handbook of obesity. New York: Dekker, 1998:379-395.

33. Summers LK, Arner P. lic V. Clark ML, Humphreys SM, Fraym KN. Adipose tissue metabolism in the postprandiall period: microdialysis and arteriovenous techniques compared. Am J Physiol 1998;274:E651-655.

34. Frayn $\mathrm{KN}$, Williams $C M$. Armer $P$. Are increased plasma non-esterified fatty acid concentrations a wisk marker for coronary heart disease and other chronic diseases? clin Sc: $1996: 90: 243-253$

35. Frayn KA, 5 ummers LK. Substrate fluxes in skeletal muscle and white adipose tissue and their importance in the development of obesity. In: Kopelman PG, stock M, eds. Clinical Obesity. Oxford: Blackwell Science, 1998:129-157.

36. Després J.P. Dyslipidaemia and obesity. Bailliere* Clin Endocrim Metab 1994;8:629-660.

37. Frayn KN. Role of non-esterified fatty acids in the metabolic changes in obesity. Int 1 Obes Rel Metab Dis 1996:20(suppl4):7-10.

38. Despres J-P. Marette A. Relation of components of insulim resistance syndrome to coronar disease risk. Curr opin lipidol 1994:5:274-289.

39. Frayn KN, Summers LK. Fielding BA. Ragulation of the plasma non-esterified fatty acid concentration in the postprandial state Proc Nutr Soc 1997:56:713-721.

40. Reaven GM. Role of insulin resistance in human disease. Diabetes $1988,37: 1595-1607$.

41. Wilding J. Williams C. Diabetes and obesity. In: Kopelman PG, Stock Mu, eds. Clinical Obesity. Oxford: Blackwell Science, 1998:308-349.

42. Bonadonna $\mathrm{RC}$, Bonora E. Clucose and free fatty acid metabolism in human obesity: Relationships to insulin resistance. Diabletes Reviews 1997;5:21-51.4

43. Clausen JO, Hansen T, Bjprbaek $C_{\text {, tal }}$ Insulin resistance: interactions between obesity and a common variant of insulin receptor substrate-1. Lancet 1995:346:397-402.

44. Despres $\mathrm{J}$. Abdominal obesity as important component of insulinmesistance syrorome. Nutrition $1993 ; 9: 452-459$.

45. Despres J-P. The insulin resistance dyslipidemia syndrome: the most prevalent cause of coronary artery disease? Can Med Assoc J 1993:148:1339-1340.

46. Kelley DE, Mandarino L. Fuel selection in human skeletal muscle in insulin resistance: a reexamination. Diabetes 2000;49:677-683. 
47. Km IN, Hickner RC, Cortright RL, Dohm GL, Houmard JA. Lipid oxidation is reduced in obese human skeletal muscle. Am I Physiol Endocrinol Metali 2000:279:1E1039-1044.

48. White MF, Kahn CR. The insulin signalung system. J Biol Chem 1994:269:14.4.

49. Smith U. Impaired ('diabetic) insulin sigmaling and action occur in fat cells long before glucase intolerance-is insulin resistance initiated in the adipose tissue? Int J Obes Relat Metab Disord 2002;26:897-904.

50. Saad M, Araki E, Mira peix Mo Rothenberg PL, White MF, Kahn CR. Regulation of insulim receptor substrate- 1 in liver and muscle of animal models of insulin resistance. I Clin Invest 1992;90:1839-1849.

51. Hotamisligil CS. Spiegelman BM. Tumot necrosis factor-a: a key component of the obesity-diabetes, link. Diabetes 1994:43:1271-1278.

52. Hotamisligil GS, Arner P, Caro JF, Atkinson RL. Increased adipose tissue expression of tumor necrosis factor-a in human obesity and insulin resistance. I Clin invest 1995:95:2409-2415.

53. Hotamisligil G5, Murray DL, Choy $\mathrm{LN}$. Tumor necrosis factor $\alpha$ inhibits signaling from the insulin receptor. Proc Natt ACad 5ci USA 1994:91:4854-4858.

54. Hotamisligil GS, Budavari A, Murray D, Spiegelman BM. Reduced tyrosine kinase activity of the insulin receptor in obesity-diabetes. J Clin Invest 1994:94:1543-1549.

55. Hatamisligil G5, Peraldi P, Budavari A, Ellis R, White MF. IRS-1-mediated inhibition of insulin receptor tyrosine kinase activity in TNF- $\alpha$ and obesity-induced insulin resistance. Science 1996:271:665-668.

56. Liu SL, Spelleken $M_{2}$ Röhrig K, Hauner H, Eckel J. Tumor necrosis factor d acutely inhibits insulin signaling in human adipocytes. Diabetes 1998;47:515-522.

57. Hotamisligil GS. The role of TNFalpha and TNF receptors in obesity and insulin resistance. J Intern Med 1999;245:621-625.

58. Stephens $J M$, Lee J, Pilch PF. Tumor necrosis factor- $\alpha$-induced insulin resistance in $3 T 3-$ L1 adipocytes is accompanied by a loss of insulin receptor substrate-1 and GLUTA4 expression without a loss of insulin receptor-mediated signal trarisduction. J Biol Chem $1997 ; 272: 971-976$.

59. Ruan H, Hacohen N, Golub TR, Wan Parijs L, Lodish HF. Tumor necrosis factor-alpha suppresses adipocyte-specific genes and activates expression of preadipocyte genes in 3T3-L1 adipocytes: nuclear factor-kappaB activation by TNF-alpha is obligatory. Diabetes 2002:51:1319-1336.

60. Kahn BB. Pedersen O. Suppression of GIUT4 expression in skeletal muscle of rats that are obese from high fat feeding but not from high carbohydrate feeding or genetic obesity. Endocrinology 1993:132:13-22.

61. Bulló-Bonet M, GarciamLorda P, Löpez-Soriano F. Argilés $\mathbb{M}$ M, Salas-Salvadó J. Tumour necrosis factor, a key role in obesity? FEBS letters 1999:451:215-219.

62. Hube F. Hauner $H$. The role of TNF- $\alpha$ in human adipose tissue: prevention of weight gain at the expense of insulin resistance? Horm Metab Res 1999;31:626-631.

63. Hotamisligil GS, Arner $P$, Atkinson RL, Spiegelman BM. Differential regulation of the $p 80$ tumor necrosis factor receptor in thuman obesity and insulin resistance. Diabetes $1997: 46: 451-455$.

64. Van Greevembroek MM, wan der Kallen $C J$, Geurts $J M$, Janssen RG, Buurman WA, de Bruin TW. Soluble receptors for tumor necrosis factor-all pha (TNF-R P55 and TNF-R P75) in familial combined hyperlipidemia. Atherosclerosis 2000;153:1.8.

65. Liebmann PM, Reibnegger $G$, Lehofer $M$, et al. Circadian rhythm of the solublle p75 tumor necrosis factor (STNF-R75) receptor in humans-a possible explanation for the circadian kinetics of TNR-alpha effects. Int Immunol 1998;10:1393-1396. 


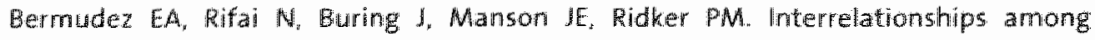
circulating interleukin-6. C-ireactive protein, and traditional cardiovascular risk factors in women. Arterioscler Thromb Vasc Biol 2002:22:1668-1673.

67. Harris TB. Fermcei L, Tracy RP, et al. Associations of elevated interleukin-6 and $C$ reactive protein levels with mortality in the elderly. Am J Med 1999;106:506-512.

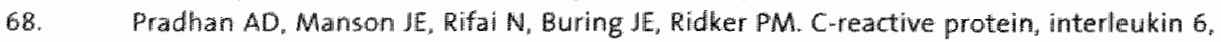
and risk of developing rype 2 diabetes rinellitus. JAMA 2001:286:327-334.

69. Mohamed-Ali $V$, Goodrick $S$, Rawesh $A$, al. Subcutaneous adipose tissue releases interleukin-6, but not tumor necrosis: factor.alpha, in wivo. I Clin Endocrinol Metab $1997 ; 82: 4196-4200$.

70. Loskutoff DJ, Samad F. The adipocyte and hemostatic ballance in obesity. Arterioscler Thromb vasc Biol $1998 ; 18: 1-6$.

71. Hamstem A. Hemostatic function and coronary artery disease. Engt I Med $1995 ; 332: 677-678$.

72. Cigolini M. Targher $G$, Bergamo Andreis IA, Tonoli M. Agostino C, De Sandre G. Wisceral fat accumulation and its relation to plasma hemostatic factors in healhy men. Arterioscler Thromb Vasc Biol 1996;16:368-374.

73. Shimomura I, Funahashi T, Takahashi M, et al. Enhanced expression of PAl-1 in wisceral fat possibile contributor to vascular disease in obesity. Nat Med 1996;2:800-803.

74. Var Harmelen V, Wahrenberg H, Eriksson P. Arner P. Role of gender and genetic variance in plasminogen activator inhibitor-1 secretion from human adipose tissue. Thromb Haiemost 2000;83:304-308.

75. Bastard IP, Vidal H, Jardel $C_{\text {, }}$ et al Subcutaneous adipose tissue expression of plasminogen activator inhibtor-1 gene during very low calorie diet in obese subjects. Int J Obes Relat Metab Disord 2000;24:70-74.

76. Bastard JP, Pieroni L, Hainque B. Relationship between plasma plasminogen activator inhibitor 1 and insulin resistance. Diabetes Metab Res Rev 2000,16:192-201.

77. Almind $\mathrm{K}$. Aminaacid polymorphisms of insulin receptor substraite-1 in non-insulindependent diabetes mell tus Lancet $1993,342: 828-832$

78. Vamada $K$, Vuan $X$, Is.hyama S, et all. Codon 972 polymorphism of the unsulin receptor substrate-1 gene in impaired glucose tolerance and late-onset NIDDM. Diabetes Care $1998 ; 21753-756$.

79. Laakso M. Malkki M. Kekälänen P, Kuusisto J, Deeb 55 . Insulin receptor substrate-1 variants in non insulin-dependent diabethes. J Clin Invest 1994:94:1141-1146.

80. Ossei-Gerning N Mansfield MW, stickland MH. Grant PJ. Insuin receptor substrate-1 gene polymorphism and cardiovascular risk in non-insulin dependent diabetes mellitus. and patients undergoing coronary angiography. Clin Lab Haem $1997 ; 19: 123-128$.

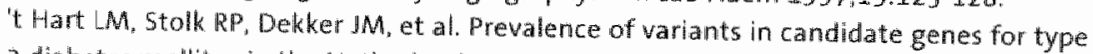
2 diabetes mellitus in the Netherlands: The Rotterdam study and the Hoorn study. J Clin Endocrinol Metab 1999:84:1002-1006.

82. Krempler F. Hell E. Winkler C. Breban D, Patsch W. Plasma leptin levels - interaction of obesity with a commom variant of insulin receptor substrate. 1 . Arterioscler Thromb Vasc Biol 1998;18:-1686-1690.

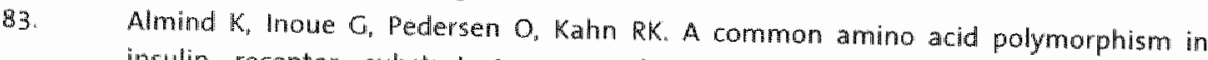
insulin receptor substrate-1 causes imparred insulin signaling. I Clin Inwest 1996:97:2569-2575.

84. Wison AG, di Giovine FS, Blakemore Al, Duff $C W$. Single base polymorphism in the human tumour necrosis factor alpha (TNF alpha) gene detectable by Ncol restriction of PCR product. Hum Mol Gienet, $1992 ; 1: 353$. 
85. Wilson $A G$, Symons $1 \mathrm{~A}$, McDowell $T L$ di Giovine FS, Duff GW. Effects of a tumour mecrosis factor (TNF-a) promoter base transition on transcriptional activily. $\mathrm{Br} J$ Rheumatol $1994 ; 33$ (suppl 1 ):39.

86. Fernandez-Real MM, Gutierrez C.Ricart W, et al. The TNFalpha gene Nco I polymorphism influences the relationship among insuim resistance, percent body fat, and increased serum leptin levels Diabetes 1997;46:1468-1472

87. Brand E, Schorr U, Kunz I, et al. Tumor necrosis factor-allpha-308 GrA polymorphism in obese Caucasians. Int I abes Relat Metab Disord 2001,25-581-585.

88. Hoffstedt J, Eriksson P, Hellstrom L, Rosisner 5 , Rydien M, Armer P. Excessive fat accumulation is associated with the TNF alpha-308 G/A promoter polymorphism in women but not in men. Diabetologiai $2000 ; 43: 117-120$.

89. Fernandez-Real IM, Broch $M_{\text {. }}$ Vendrell J, Richart $C$, Ricart W. Interteukin-6 gene polymorphism and lipid abnormalities in healthy subjects. I Cin Endocrinol Metab $2000,85: 1334-1339$

90. Riccardi $G_{n}$ Rivellese AA. Dietary treatment of the metabolic syndrome--the optimal diet. Br I Nutr 2000;83 Suppl 1:5143-148.

91. Kris-Etherton PM, Harris WS, Appel U. Fish consumption, fish oll, omega-3 fatty acids, and cardiovascular disease. Circulation 2002;106:2747-2757.

92. Gibson RA. The effect of diets containing fish and fish olls on disease risk factors in humans. Aust N ZI Med 1988;18:713-722.

93. Weinstock RS, Dai $H$, Wadden TA. Diet and exercise in the treatment of obesity: effects of 3 interventions on insulin resistance. Arch Intern Med 1998;158:2477-2483.

94. Tuomilehto I, Lindstrom J, Eriksson $1 G_{y}$ et al. Prevention of type 2 diabetes mellitus by changes in lifestyle among subjects with impaired glucose toherance. N Engl I Med 2001:344:1343-1350.

95. Dattilo $A M$, Kris-Etherton PM. Effects of weight reduction on blood liphids and lipoproteins: a meta-analysis. Am J Clim Nutr 1992;56:320-328.

96. Kern P, Saghizadeh M, Ong JM, Bosch RJ, Deem R, Simsolo RB. The expression of tumor necrosis factor in human adipore tissue J Chin Invest 1995:95:2111-2119.

97. Ziccardi $P$, Nappo $F$, Giugliano $G$, et al. Reduction of inflammatory cytokine concentrations and improvement of endothelial fumctions in obese women after weight loss over one year. Circulation 2002;105:804-809.

98. Folsom AR, Qamhieh HT, Wing RR, et al. Impact of weight loss on piaminogen activator inhibitor (PAl-1), factor vil, and other hemostatic factors un moderately ovenweight adults. Arterioscler Thromb 1993:13:162-169.

99. Bang HO. Dyerberg J. Plama lipids and lipoproteins in Greenlandic west coast Eskimos. Acta Med Scand 1972;19:2:85-94.

100. Knapp HR. Dietary faty acids in human thrombosis and hemostasis. Am I Clin Nutr $1997 ; 65: 16875-16985$.

101. Harris WS n-3 fatty acids and serum lipoproteins: human studies. Am J clin Mutr $1997 ; 65: 16455-16545$

102. Storlien LH, Kraegen EW, Chisholm DI, Ford GL, Bruce DG, Pascoe Ws. Fish oil prevents insulin resistarce induced by high-fat feeding in rats. Science 198:7:237:885-888.

103. Feskens $\mathrm{E}$, Bowles $\mathrm{CH}$, Kromhou $\mathrm{D}$. Inverse association between fish intake ard risk of glucose intolerance in normoglycemic elderly men and women. Diabetes Care $1991 ; 14: 935 \cdot 941$

104. Fasching P, Ratheiser K, Schneeweiss B, Rohac M, Nowotry P, Waidhausl W. No effect of short-term dietary supplementation of saturated and poly-and monounsaturated fatty acids on insulin secretion and sensitivity in healthy men. Ann Nutr Metab 1996;40:116122. 
105. Vessby $B$, Unsitupa $M$, Hermansen $K$, al substituting dietary saturated for monounsaturated fat impairs insulin sensitivity in thealthy men and women: The KANWU Study. Diabetologia 2001;44:312-319.

106. Endres 5, Ghorbani R, Kelley VE, et al. The effect of dietary supplementation with n-3 polyunsaturated fatty acids on the synthesis of interleukin-1 and tumor necrosis factor by monionuclear cells. N Engl A Med 1989;320:265-271.

107. Blok WL, Deslypere J.P. Demaker PNM, et al. Pro- and anti-inflammatory cytokines in healthy volunteers fed warious doses of fish oil for 1 year. Eur I Clin Invest $1997: 27: 1003-1008$. 


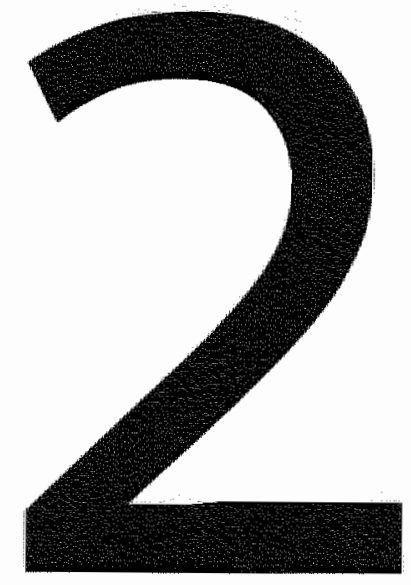

\section{Metabolic risk markers in an overweight and normal weight population with oversampling of carriers of the IRS-1 972Arg variant}

Annemarie Jellema ${ }^{1,2}$, Ronald P. Mensink ${ }^{2}$, Daan Kromhout ${ }^{1}$, Wim H.M. Saris ${ }^{2}$, Edith J.M. Feskens ${ }^{2}$

*. Centre for Nutrition and Health, National Institute for Public Health and the Environment, Bilthoven, The Netherlands

2. Department of Human Biology, Maastricht University, Maastricht, The Netherlands 


\section{Abstract}

Background: The relationship between the Gly972Arg polymorphism in the insulin receptor substrate-1 (IRS-1) gene and metabolic risk markers is not clear, possibly due to small sample sizes. Modification by body mass index (BMI) has also been suggested. Our aim was therefore to determine the association of this 972Arg variant with insulin, glucose and lipid levels in overweight and non-overweight subjects with oversampling of subjects with the 972 Arg variant.

Methods: We first genotyped 3,684 subjects selected from a large populationbased cohort $(n=23,000)$ according to $B M I\left(B M I 26-40 \mathrm{~kg} / \mathrm{m}^{2}\right.$ or BMI $18-24$ $\left.\mathrm{kg} / \mathrm{m}^{2}\right)$. Next, we examined 600 of these subjects for fasting metabolic risk markers according to BMI group and genotype.

Results: Subjects with the $972 \mathrm{Arg}$ variant had significantly higher insulin concentrations ( $4.08 \mathrm{pmol} / \mathrm{L}, \mathrm{p}=0.024)$ and lower triglyceride (TG) levels (-0.13 $\mathrm{mmol} / \mathrm{L}, \mathrm{p}=0.001$ ) compared with non-carriers when adjusted for age, sex, waist to hip ratio, BMI, alcohol consumption, physical activity and cigarette smaking. These associations were more pronounced in the high BMI group, although the interactions were not statistically significant.

Conclusions: Our large population-based sample shows that the IRS-1 Gly972Arg polymorphism relates to higher fasting insulin levels and, unexpectedly, lower TG levels. Modification by overweight may be smaller than suggested previously. 


\section{Introduction}

IRS-1 occupies a key position in the insulin signaling pathway (1). After binding of insulin to the $\alpha$-subunit, the $\beta$-subunit of the insulin receptor undergoes autophosphorylation, and in turn, phosphorylates other endogenous protein substrates in the cascade of insulin action. As IRS-1 is the first substrate in this cascade, an impaired IRS-1 function may result in a defect in insulin signaling.

Several polymorphisms in the IRS-1 gene, located on chromosome 2936, have been found (2). The association between the so-called Gly972Arg polymorphism and insulin sensitivity in humans has been studied most extensively, probably because the prevalence of this genotype is relatively high (approximately 10\%) (3-8). Results of this impact on metabolic risk factors such as insulin resistance are not always consistent. Almind et al (3) found a higher proportion of carriers among type 2 diabetic patients compared to controls, but diabetic carriers had lower fasting insulin concentrations as compared with non-carriers. Others did not observe differences in fasting insulin concentrations or insulin sensitivity between type 2 diabetic patients with and without the $972 \mathrm{Arg}$ variant $(7,8)$. On the other hand, the proportion of carriers was higher in type 2 diabetic patients with either insulin resistance or dyslipidemia (9). The frequency of the $972 \mathrm{Arg}$ variant was also significantly higher among Italian patients with coronary heart disease (CHD) than among controls (5). In this study, no associations between insulin or glucose concentrations with genotype were observed, but, independent of CHD, total cholesterol (TC) concentrations were higher in carriers than in non-carriers. In contrast, a British study including patients with diabetes or CHD reported lower TC and TG concentrations in carriers compared with non-carriers (8).

The relationship between the Gly972Arg polymorphism of the IRS-1 gene and metabolic risk parameters may depend on body weight. This is suggested by the results of Clausen et al (6), who observed an association between the

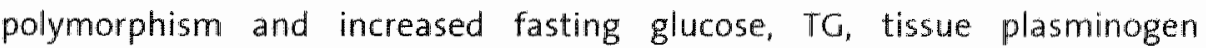
activator concentrations, and decreased insullin sensitivity in obese but not in non-obese subjects. Also Baroni et al (4) observed an association between the IRS-1 variant and metabolic cardiovascular risk parameters in obese, but not in non-obese healthy subjects. However, the number of carriers of the IRS-1 variant in previous studies was generally small, which probably explains a large part of the inconsistent findings.

The aim of the present study is therefore to quantify the interrelationships between the Gly972Arg IRS-1 polymorphism and obesity on insulin, glucose 
and lipid levels in a large population-based study with oversampling of carriers of the polymorphism.

\section{Subjects and methods}

\section{Subjects}

Subjects were selected from participants of the Cardiovascular Disease Risk Factor Monitoring Project and the Monitoring. Project on risk factors for Chronic Disease (MORGEN-project) in the Maastricht area, in the south of the Netherlands. A detailed description of these studies has been published elsewhere $(10,11)$. The first examination, which included height and weight measurements and collecting of non-fasting blood samples, was carried out between 1987 and 1997 . Buffy coats were isolated and stored at $-20^{\circ} \mathrm{C}$. A re. approach including a questionnaire on body weight took place in 1998.

For the present study, we selected two groups of Caucasian subjects from whom buffy coats were available. The first group had a BMI between 19 and $23 \mathrm{~kg} / \mathrm{m}^{2}$ at the first physical examination and between 18 and $24 \mathrm{~kg} / \mathrm{m}^{2}$ at the postall re-approach. The second group had a BMIl between 27 and 39 $\mathrm{kg} / \mathrm{m}^{2}$ and between 26 en $40 \mathrm{~kg} / \mathrm{m}^{2}$ at the examination and postal reapproach respectively. None of the subjects had diagnosed diabetes mellitus. Buffy coats of 3,684 subjects, which had been stored for 2 to 12 years, could be used to determine the IRS-1 Gly972Arg polymorphism. From this group all carriers $(n=519)$ and a random sample of wildtype subjects $(n=497)$ were invited for a second physical examination. Sixty percent of the invitees participated. After the re-approach, ten subjects had become diabetic and were excluded. Thus, data of 600 subjects could be used for the present analysis. Power analysis showed that this study size has sufficient power $(80 \%$ at a puvalue of $5 \%$ ) to detect a difference in fasting insulin of $10 \mathrm{pmol} / \mathrm{L}$ (standard deviation (SD) 30 pmol/L) between carriers and non-carriers among one of the weight groups, a difference for example observed by Baroni et al (4) among lean subjects. Subjects filled in an informed consent form before the measurements started. The protocol was approved by the Medical Ethical Committee of TNO Prevention and Health, Leiden.

\section{Clinical measurements}

After an overnight fast, subjects were weighed without shoes to the nearest $0.1 \mathrm{~kg}$. Waist and hip circumferences were measured to the nearest $0.1 \mathrm{~cm}$ and height was measured without shoes to the nearest $0.1 \mathrm{~cm}$. Blood was 
drawn into a $10 \mathrm{ml}$ vacuum tube containing $K_{3} E D T A$ and a $4.5 \mathrm{~m} /$ vacuum tube containing 9 sodium citrate for measurements to be reported elsewhere.

The subjects filled in a general health questionnaire, which included questions about cigarette smoking, alcohol consumption and physical activity. Subjects were classified as cigarette smokers or non-smokers. Alcohol consumption was categorized as follows: no alcohol, between 0 and 1 glass of alcohol a day, between 1 and 3 glasses of alcohol a day, and more than three glasses of alcohol a day. Bouts of exercise, biking or gardening etc. were included to assess physical activity if they lasted 30 minutes per day or more. Subjects who reported such activities on three or more days a week were considered to be physically active. Subjects active on $0-2$ days a week were classified as nonactive.

\section{Laboratory measurements}

DNA was extracted from buffy coats by proteinase $\mathbb{k}$ digestion and phenol extraction (12). The Gly972Arg polymorphism was determined using the conventional polymerase chain reaction (PCR). BstNI restriction enzyme analysis and agarose gel electrophoresis as described by Almind et al (3). EDTA-plasma was used to measure TC, TG, and high density lipoprotein cholesterol (HDL-C) concentrations after a dextran sulfate- $\mathrm{Mg}^{2 *}$ precipitation by enzymatic methods (Boehringer Mannheim, Germany). If TG concentrations were below $4.5 \mathrm{mmol} / \mathrm{L}$ low density lipoprotein cholesterol (LDL-C) was calculated by using the Friedewald equation (13). Plasma glucose concentrations were measured with a commercially available kit (Roche Diagnostica, Basel, Switzerland and WAKO, Neuss, Germany). Insulin concentrations were determined using a sensitive ELISA kit with crossreactivity with C-peptide and proinsulin less than $0.01 \%$ (Mercodia, Uppsala, Sweden). Proinsulin was also measured with an ELISA kit (Mercodia, Uppsala, Sweden). Insulin resistance was calculated with a homeostasis model assessment for insulin resistance (HOMA $\mathrm{A}_{12}$ ) as described previously (14).

\section{Statistical analysis}

A Kolmogorov-Smirnov test was performed to test normality of the data. TG, insulin, proinsulin and glucose concentrations and HOMA distributed, but were after a log transformation. Partiall correlations between variables were calculated adjusted for age and sex. Differences in subject characteristics between the Gly and Arg variant were examined by analysis of variance with adjustments for age and sex. To examine the interaction between BMI group (high or low) with genotype on the metabolic parameters, 


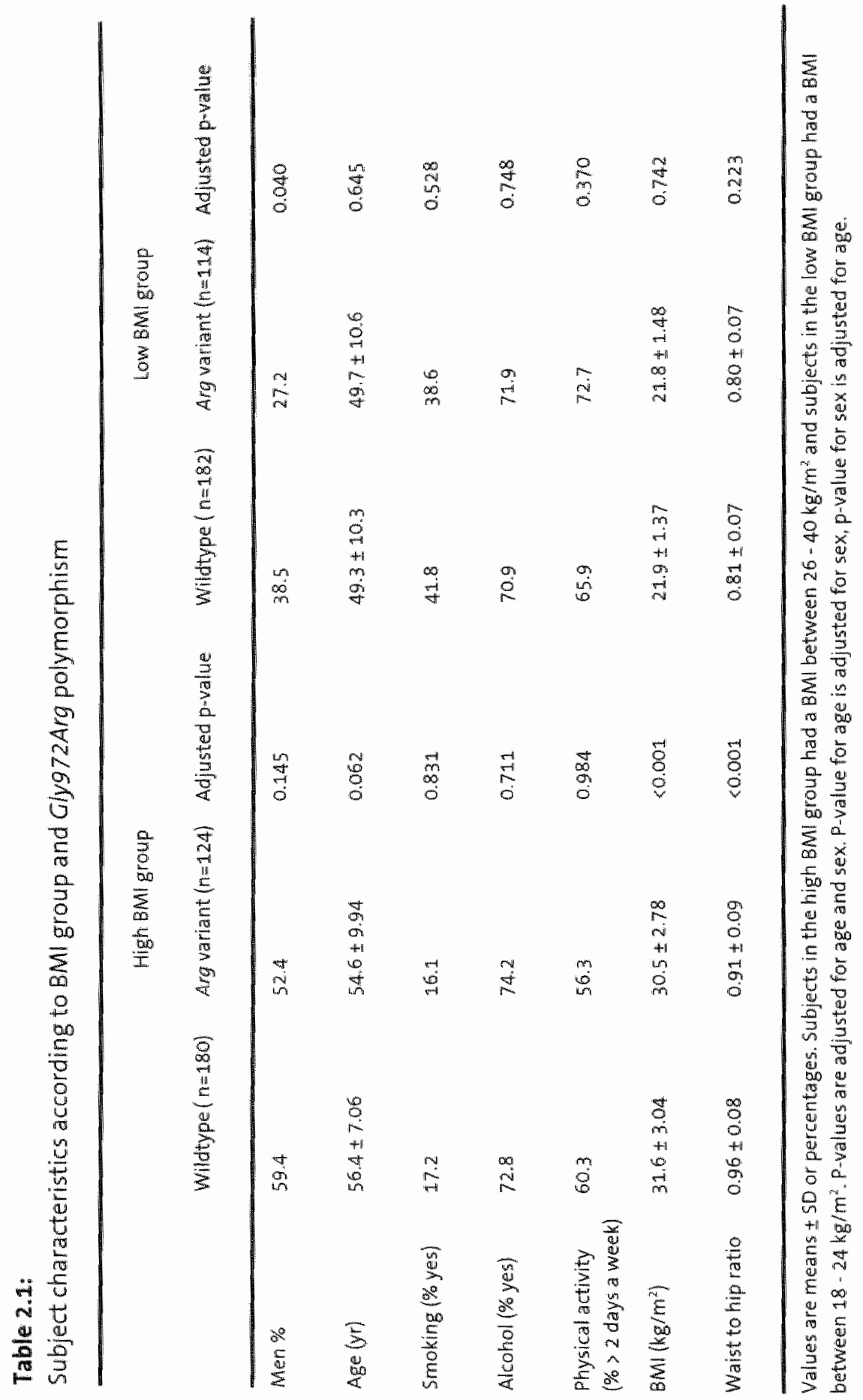


additional adjustments were made for waist to hip ratio, BMI, alcohol consumption, physical activity, and cigarette smoking. The interaction term was omitted from the statistical model if it did not reach statistical significance. In this way, the effects of the Gly972Arg polymorphism could be estimated. Data are expressed as mean \pm 50 or medians with inter-quartile ranges for skewed variables. A two-tailed value of $p<0.05$ was considered to be statistically significant. All analyses were performed using SPSS, PC release 10.0 .

\section{Results}

Among the population-based sample of 3,684 subjects the prevalence of the heterozygous and homozygous forms of the Gly972Arg polymorphism were $14.1 \%$ and $0.5 \%$. The allele frequencies were not different between the overweight and non-overweight group (0.075 ws. 0.076). The distribution of the genotypes was in Hardy-Weinberg equilibrium ( $p=0.750)$, both in the low and in the high BMI group. Participants of the re-examination for metabolic risk markers (273 men, 327 women) were between 26 and 71 years old. Mean BMI was $21.9 \mathrm{~kg} / \mathrm{m}^{2}$ (SD $\left.1.4 \mathrm{~kg} / \mathrm{m}^{2}\right)$ in the low BMI group and $31.2 \mathrm{~kg} / \mathrm{m}^{2}$ (SD $3.0 \mathrm{~kg} / \mathrm{m}^{2}$ ) in the high BMI group. Due to the deliberate oversampling of the carriers, this final study population included 362 non-carriers, 228 heterozygous carriers and 10 homozygous carriers of the Gly972Arg polymorphism.

\section{Table 2.2:}

Crude medians and adjusted differences in insulin, proinsulin, glucose and HOMA $A_{\mathbb{R}}$ of the total group according to Gly972Arg polymorphism

\begin{tabular}{|c|c|c|c|}
\hline Metabolic risk markers & Wildtype $(n-362)$ & Arg wariant $(n=238)$ & Adjusted p-value \\
\hline Insullin (pmol/L) & $42.5(27.8-60.8)$ & $44.8(31.7-65.3)$ & \\
\hline Adjusted difference $(95 \% \mathrm{Cl})$ & \multicolumn{2}{|c|}{$4.08(0.55 .7 .59)$} & 0.024 \\
\hline Proinsulin (pmol/L) & $6.49(4.09-12.0)$ & $5.80(3.95-10.8)$ & \\
\hline Adjusted difference $(95 \% \mathrm{Cl})$ & \multicolumn{2}{|c|}{$-0.14(-0.83,0.58)$} & 0.718 \\
\hline Glucose (mmol/L) & $5.17(4.84-5.63)$ & $5.15 .(4.77-5.60)$ & \\
\hline Adjusted difference $(95 \% \mathrm{CI})$ & \multicolumn{2}{|c|}{$-0.02(-0.11,0.08)$} & 0.748 \\
\hline HOMA & $1.57(1.05-2.46)$ & $1.70(1.22-2.61)$ & \\
\hline Adjusted difference $(95 \% \mathrm{Cl})$ & \multicolumn{2}{|c|}{$0.17(0,02,0.31)$} & 0.029 \\
\hline
\end{tabular}

Values are medians with inter-quartile rarges. Subjects in the high BMI group had an BM between $26-40 \mathrm{~kg} / \mathrm{m}^{2}$ and subjects in the low BMil group had a BMl between $18 \cdot 24 \mathrm{~kg} / \mathrm{m}^{2}$. P-values and differences are adjusted for age, sex, BMI, waist to hip ratio, smoking, physical activity and alcohol comsumption by amalysis of covariance (ANOVA), $95 \% \mathrm{Cl}: 95 \%$ confidence interval. 


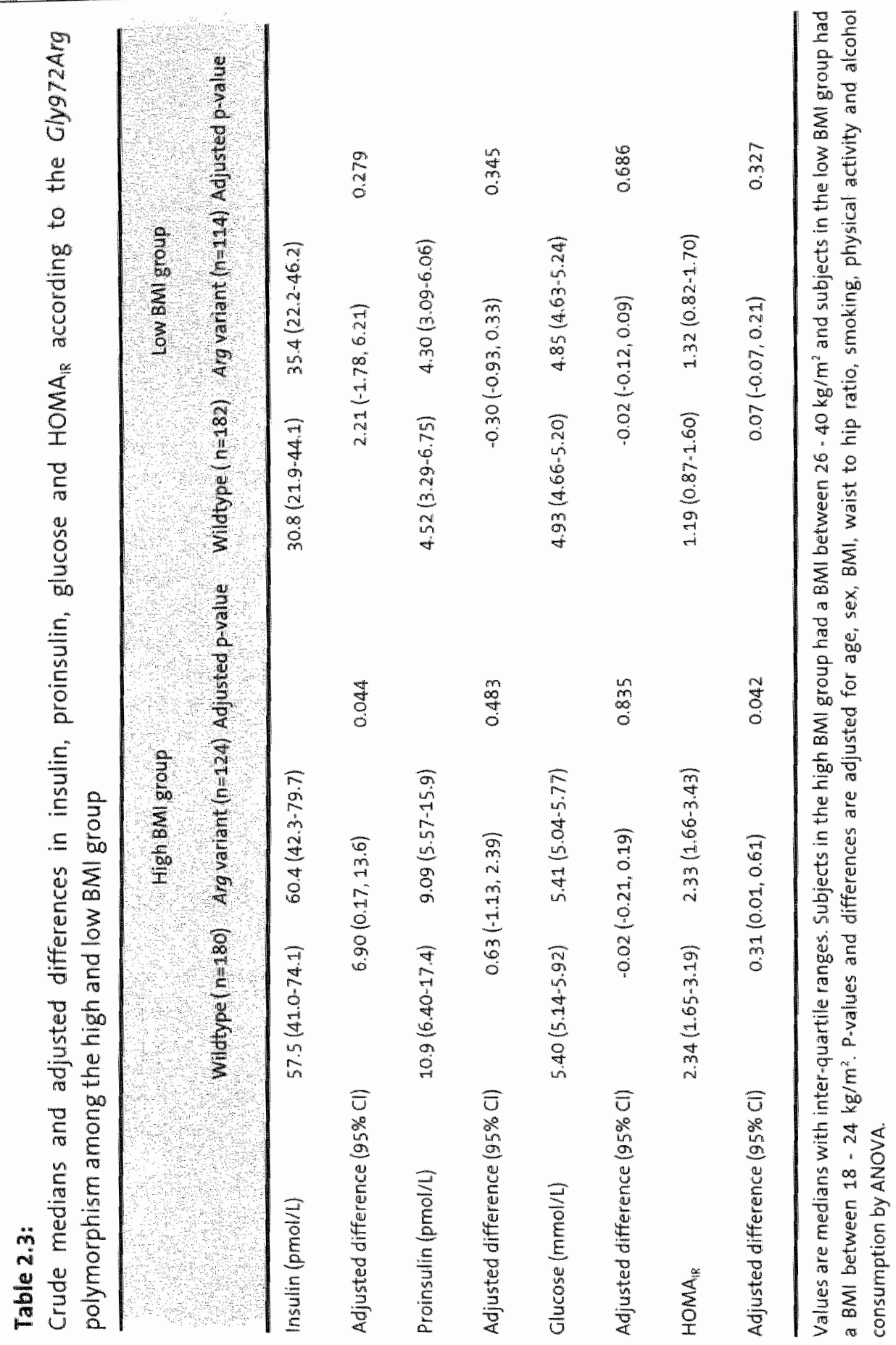


The overweight group was older and included more men compared with the low BMI group (table 2.1). Comparisons were therefore made after adjustment for age and sex. After this adjustment, carriers in the high BMI group had a significantly lower BMI compared with non-carriers. In the low BMI group, however, there was no difference in BMI between carriers and non-carriers. A similar difference between carriers and non-carriers according to BMI was observed for waist to hip ratio ( $p$ for interaction<0.001). For all other parameters, no significant interaction between the IRS-1 Gly972Arg polymorphism and BMI was observed ( $p>0.150)$.

After adjustments for age, sex, BMI, waist to hip ratio, physical activity, alcohol consumption, and cigarette smoking insulin concentrations were higher in carriers of the Arg variant compared with the non-carriers (table 2.2). The difference between carriers and non-carriers in the high BMll group, however, was much more pronounced than that in the low BMI group (6.90 pmol/L or $12 \%$ versus 2.21 pmol/L or $7 \%$ table 2.3$)$. Insulin resistance as estimated with the HOMA $\mathrm{A}_{\mathbb{R}}$ model was also significantly different between carriers and non-carriers ( $p=0.029$; table 2.2). Glucose and proinsulin concentrations did not differ between carriers and non-carriers of the Gly972Arg polymorphism. TG concentrations were significantly lower in the Arg variant compared with the Gly variant $(-0.13 \mathrm{mmol} / \mathrm{L}$ or $13 \% ; p=0.001$, table 2.4). Again, differences were more pronounced in the high BMI group (table 2.5). TC, LDL-C, and HDL-C levels were not different between both groups.

\section{Table 2.4:}

Crude means or medians and adjusted differences in serum lipids of the total group according to Gly972 Arg polymorphism

\begin{tabular}{|c|c|c|c|}
\hline Metabolic risk markers & Wildtype $(n=362)$ & Arg variant $(n=238)$ & Adjusted $p$-value \\
\hline TC (mmalls) & $5.36 \pm 1.02$ & $5.35 \pm 1.00$ & \\
\hline Adjusted difference $(95 \% \mathrm{cl})$ & \multicolumn{2}{|c|}{$0.04(-0.13,0.20)$} & 0.660 \\
\hline LDL-C (mmol/L) & $3.48 \pm 0.98$ & $3.56 \pm 0.93$ & \\
\hline Adjusted difference $(95 \% \mathrm{cl})$ & \multicolumn{2}{|c|}{$0.13(-0.03,0.29)$} & 0.119 \\
\hline HDLC (mmol/de) & $1.27 \pm 0.36$ & $1.26 \pm 0.37$ & \\
\hline Adjusted difference $(95 \% \mathrm{Cl})$ & \multicolumn{2}{|c|}{$0.05(-0.09,0.01)$} & 0.066 \\
\hline To $(\mathrm{mmol} / \mathrm{L})$ & $1.25(0.75-1.71)$ & $0.98(0.63-1.52)$ & \\
\hline Adjusted difference & \multicolumn{2}{|c|}{$-0.13(-0.21,-0.05)$} & 0,001 \\
\hline
\end{tabular}

Values are means with SD or medians with inter-quartile ranges. 5 ubjects in the high BMI group had a BMl between $26-40 \mathrm{~kg} / \mathrm{m}^{2}$ and subjects in the low BMil group had a BMI between 18 - 24 $\mathrm{kg} / \mathrm{mm}^{2}$. P-values and differences are adjusted for age, sex, BMI. waist to hip ratio, smoking. physical activity and alcohol consumption by ANONA. 


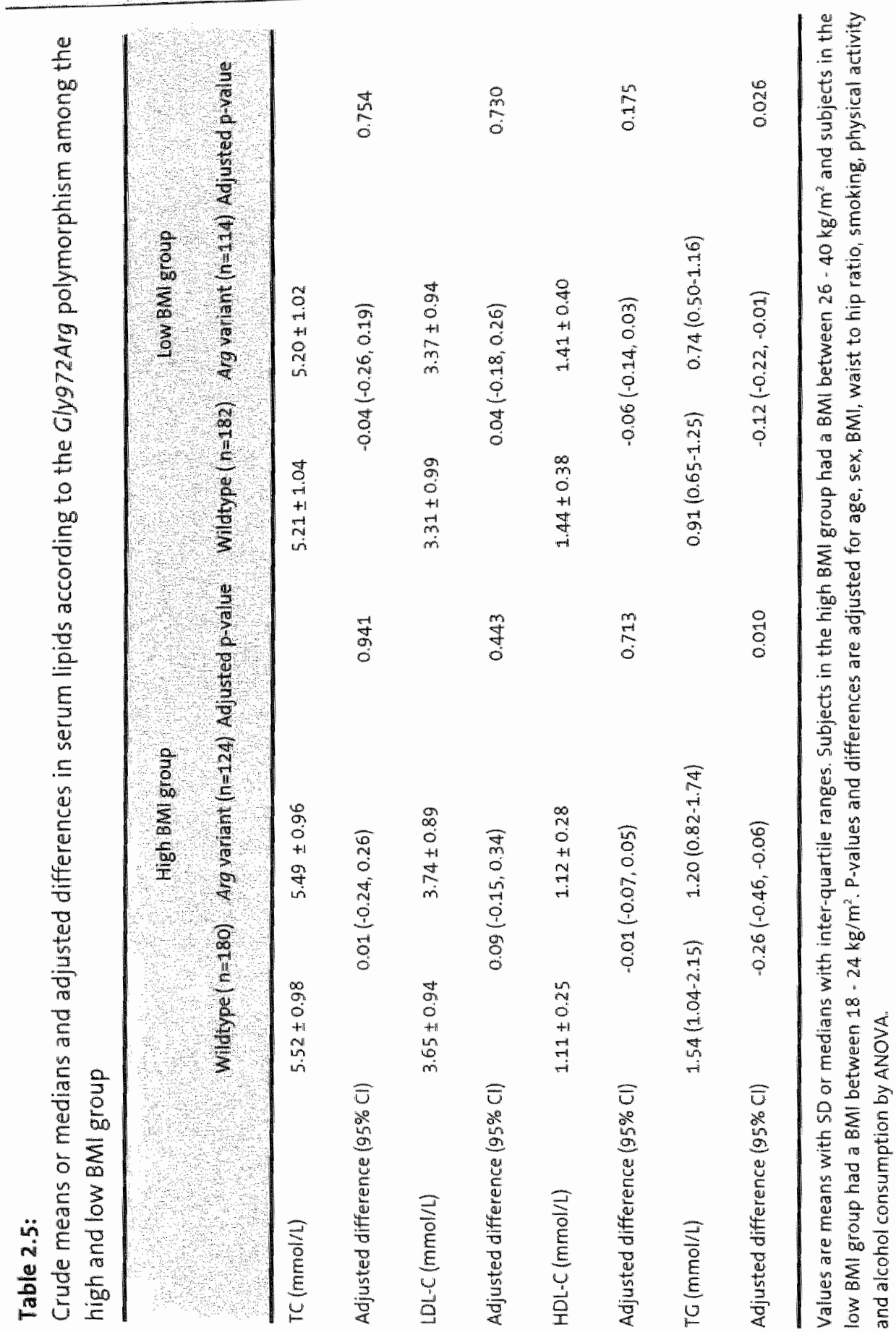




\section{Table 2.6:}

Partial correlation coefficients between insulin and HOMA with other metabolic parameters in the total study population

\begin{tabular}{|c|c|c|c|c|}
\hline \multirow{2}{*}{$\begin{array}{lll}+2 \\
\end{array}$} & \multicolumn{2}{|c|}{ Insulin } & \multicolumn{2}{|c|}{ HOMA } \\
\hline & Partialr & p-value & Pantialr & p-value \\
\hline Glucose & 0.36 & $<0.001$ & 0.52 & 60.001 \\
\hline Proinsulin & 0.66 & $<0.001$ & 0.71 & $<0.001$ \\
\hline$T G$ & 0.31. & $<0.001$ & 0.34 & $<0,001$ \\
\hline$T C$ & 0.02 & 0.548 & 0.03 & 0.468 \\
\hline LDL.EC & 0.08 & 0.042 & 0.09 & 0.034 \\
\hline HDL-C & -0.34 & $<0,001$ & -0.35 & $<0.001$ \\
\hline
\end{tabular}

Values are adjusted for age and sex.

Correlation coefficients of insulin and $\mathrm{HOMA}_{1}$ with other metabolic parameters are listed in table 2.6. A significant inverse correlation was seen between concentrations of TG and HDL-C $(r=-0.40 ; p<0.001)$.

\section{Discussion}

Previous studies on the impact of the codon 972Arg variant of the IRS-1 gene on metabolic risk markers included a limited number of carriers, which may partly explain inconsistencies in the results. Using oversampling of the carriers within a population-based cohort we showed that the Arg variant is associated with higher insulin concentrations and insulin resistance and lower TG concentrations.

An effect of the Glyg72Arg polymorphism of the IRS-1 gene on metabolic risk markers seems plausible, because of the central role of IRS-1 in the insulin signaling cascade. In support, Almind et al (15) found that insulin signaling of myeloid progenitor cells transfected with the $972 \mathrm{Arg}$ variant of the human IRS-1 was impaired as compared to cells transfected with wildtype human IRS-1. Human studies, however, are less conclusive $(3,4,6,8,16)$, which may be due to the limited number of carriers included. Further, previous studies have suggested that effects of this polymorphism may depend on $\operatorname{BM}(4,6)$ with obese carriers having up to 81.7 pmol/L higher fasting insulin levels than obese non-carriers (4).

Using oversampling of the carriers within a population-based cohort we showed that differences in fasting insulin and $H O M A_{I R}$ between carriers and non-carriers were more pronounced and statistically significant in the high BMI group, but not in the low BMI group. However, the differences were smaller than previously suggested. In addition, despite our large number of carriers, the interaction term testing for modification by overweight was not 
statistically significant $(p=0.170)$, indicating that the combined impact is not very strong.

Our results suggest that the IRS-1 Gly972Arg polymorphism is associated with insulin resistance, albeit to modest extent, whereas lower TG levels were seen. Insulin resistance is generally associated with increased TG concentrations (17), and our finding of lower TG concentrations in carriers of the Arg variant is therefore surprising and may be a chance finding. A similar finding has been reported before on type 2 diabetic patients and subjects with CHD (8). This suggests that the observation in our population may not be a chance finding only, and that exclusion of diabetic subjects from our study may not solely explain our results. We can only speculate about a further explanation. The insulin signaling pathway is involved in the insulin-dependent inhibition of hepatic VLDL-TG production (18), but may in the liver involve IRS-2 rather than IRS-1 (2, 19). Therefore, in IRS-1 972Arg carriers, high insulin levels combined with relative hepatic insulin sensitivity could have resulted in reduced fasting TG concentrations. This, however, remains to be confirmed by other studies. Apart from affecting insulin sensitivity, also B-cell function may be impaired in the IRS-1 G/y972Arg polymorphism. Recently, human pancreatic islets from $972 \mathrm{Arg}$ carriers were found to have reduced insulin content, altered insulin release, and a greater number of immature secretory granules (20). However, results of clinical studies so far are mixed $(21,22)$. We measured proinsulin as an indicator of a defect in insulin secretion (23). Although proinsulin levels were strongly associated with insulin levels and $\mathrm{HOMA}_{\mathrm{iR}}$ in our population, they were not different between carriers and non-carriers of the Arg variant. Although insulin and $H O M A_{\mathbb{R}}$ were inversely associated with $\mathrm{HDL}-\mathrm{C}$ in our population and reduced $H D L-C$ levels are a feature of insulin resistance (17), we observed no clear difference in HDL-C between carriers and non-carriers. Insulin resistance is in general not uniformly associated with TC levels (24). Indeed, HOMA $A_{\text {IR }}$ or insulin was not associated with TC levels in our population. In addition, TC concentrations were not different between carriers and noncarriers of the $972 \mathrm{Arg}$ variant. This is in agreement with several other studies (4, 6), although also higher (5) or lower (8) cholesterol levels have been reported in studies with smaller number of carriers. LDL particle size may change because of insulin resistance (25), but has not yet been studied in relation to the $972 \mathrm{Arg}$ variant, nor has apolipoprotein $B$.

$B M I$ was $1.2 \mathrm{~kg} / \mathrm{m}^{2}$ lower in our carriers than in non-carriers within the overweight group, and also their waist to hip ratio was reduced. These differences were not observed in the low BMI group. A lower BMI and waist to hip ratio were also seen in healthy normal glucose tolerant $972 \mathrm{Arg}$ carriers from Germany (26). Others observed a positive association between the IRS-1 $972 \mathrm{Arg}$ variant and body weight (27). Similarly, in type 2 diabetic patients an increased BMI in carriers was seen (16). However, their control subjects over 
40 years of age with the 972 Arg variant had a lower BMI compared with noncarriers.

The lower BMI in our overweight carriers might have been the result from the exclusion of diabetic subjects, as overweight carriers are more prone to develop type 2 diabetes. On the other hand, IRS-1 protein expression is markedly increased during maturation of human pre-adipocytes and IRS-1 is also relevant in insulin growth factor-1 (IGF-1) signaling (2). Our findings suggest therefore that studies on the impact of the $972 \mathrm{Arg}$ variant on these processes may be useful as well.

Finally, the prevalence of the Gly972Arg polymorphism among the population-based sample of our cohort was $14.6 \%$. It should be noted that regional variance in the Netherlands has been reported (11 to $18 \%$ ), but this was based on small sample sizes only and may be a chance finding (28). Our proportion of carriers fell well within the range of the two previous observations and agrees with results of two other population-based studies in the Netherlands (15.3\% and 14.1\%) (RM van Dam, personal communication).

This large population-based study of healthy individuals shows that presence of the IRS-1 Gly972Arg polymorphism is associated with increased insulin concentrations and insulin resistance and decreased TGi concentrations. These associations are more pronounced among overweight subjects, but the cambined effect may be smaller than suggested previously.

\section{Acknowledgements}

The study was supported by a grant from the Netherlands Organization for Scientific Research (NWO), grant number 980-10-006, Nutrition and Chronic Diseases. The Cardiovascular Disease Risk Factor Monitoring Project and the Monitoring Project on Risk Factors for Chronic Disease were supported by the Dutch Ministry of Welfare, Public Health and Culture. We thank Prof. Dr $\mathbb{R}$. Frants and Dr P. Hanifi Moghaddam from the department of Human Genetics, University of Leiden and Dr B. Hoebee and Dr E. van Schothorst from the Laboratory of Toxicology, Pathology and Genetics, National Institute for Public Health and the Environment, Bilthoven, for the genotyping. We are indebted to J. Stegen and $M$. Kunen from the Maastricht University, Department of Human Biology, Maastricht, for their laboratory assistance. We gratefully acknowledge T. Heemskerk and S. Ebbing for their contribution in the screening. We thank Prof. Dr C. Kluft from TNNO Gaubius, Leiden, for analyzing proinsulin. 


\section{References}

2.

White MF, Kahn CR. The insulin signaling system. I Biol Chem 1994;269:1-4.

Sesti $G$, Federici M, Hribal ML, Lauro D. Sbraccia $P$, Lauro R. Defects of the insulin receptor substrate (IRS) system in human metabolic disonders. Faseb I 2001;15:2099211 1

Almind $K$. Aminoacid polymorphisms of insulin receptor substrate-1 in non-insulindependent diabetes mellitus lancet $1993,342: 828-832$.

Baroni MO. Arca M, Sentinelli $F$, et al. The 0972 variant of the irsulin receptor substrate-1 (|ns-1) gene, body fat distribution and insilin-resistance. Diabetologia $2001 ; 4: 4: 367-372$

Baroni MG, Dindrea MP. Montali $A$, al. A common mutation of the insulin receptor substrate-1. gene is a risk factor for coronary artery disease. Arterioscler Thromb Vasc Bial $1999 ; 19: 2975-2980$.

Clausen JO, Hansen T. Bjorbaek C, at al. lnsulin resistance: interactions between obesity and a common variant of insulin receptor substrate-1. Lancet 1995,346:397\%402.

Laakso M, Malkki M, Kekalainer P, Kusisto J, Deeb SS. Insulin receptor substrate-1 variants in nom-insulin dependent diabetes. J Clin Invest 1994;94:1141-1146.

Ossei Gerning N, Mansfield MW, Stickland MH, Grant Pl. Insulin receptor substrate-1 gene polymorphism and cardiovascular risk in non-insulin dependent diabetes mellitus and patients undergoing coronary angiography, Clin Lab Haem 1997;19:123-128.

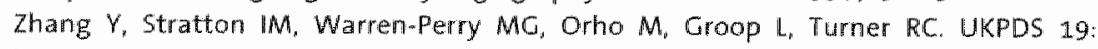
heterogeneity in NDDM: separate contributions of IRS-1 and beta3-adrenergicreceptor mutations to insulin resistance and obesity respectively with no evidence for glycoger synthase gene mutations. Diabetologia 1996;39:1505-1511.

Verschuren WMM, vam Leer EM, Bloksitra A. et al. Cardiovascular disease risk factors in The Netheriands. Neth J Cardiol 1993;4:205-210.

van Dam RM, Boer JM. Feskens EI, Seldell IC. Parental history of diabetes modifies the association between abdominal adiposity and hyperglycemia. Diabetes Care 2001:24:1454-1459.

Miller SA, Dykes DD, Polesiky HF. A simple salting out procedure for extracting DNA from human nucleated cells. Nucleic Acids Res 1988;16:1215.

Friedewald WT, Lewy Rl, Fredrickson DS Estimation of the concentration of low-density lipoprotein cholesterol in plasma, without use of the preparative ultracentrifuge. Cun Chem $1972 ; 18: 499-502$.

Matthews DR, Hosker JP, Rudemski AS, Naylor BA. Treacher DF, Tumer RC. Homeostasis model assessment: insulin resistance and beta-cell function from fasting plasma glucose and insulin concentrations in man. Diabetologia 1985;28:412-419.

Amind $k$. Inove $G$, Pedersen $O$, Kahn RK. A common amino acid polymorphism in insulin receptor substrate-1 causes impaired insulin signaling. $\mathrm{J}$ clin Imwest $1996,97: 2569-2575$

Sigal R., Doria A. Warram JH, Krolewski AS. Codon 972 polymorphism in the insulin receptor substrate-1 gene, obesity, and risk of noninsulin dependent diabetes mellitus. J Clin Endocrinol Metab 1996;81:1657-1659. Howard BV. Insulin resistance and lipid metabolism. Am J Cardiol 1999:84:28j-32J. Phung TL, Roncone $A$, Jensen KL, Sparks CE, Sparks JD. Phosphomositide 3-kinase activity is necessary for insulin-dependent inhibition of apolpoprotein $B$ secretion by rat hepatocytes and localizes to the endoplasmic reticullum. I Biol chem 1997;272:30693-
30702 . 
19. Previs SF, Withers DJ. Ren MM, White MF, Shulman Gl Contraisting effects of las-1 versus IRS-2 gene disruption on carbohydrate and lipid metabolism in wo. I Biol Chem $2000 ; 275: 38990-38994$.

20. Sparks JD, Sparks CE. Insulin regulation of triacylgycerol-rich lipoprotein synthesis and secretion. Biochim Biophys Acta 1994;1215:9-32.

21. Stumvoll $M_{3}$ Fritsche $A$, Volk $A$, et al. The Gly972Ang polymorphism in the insulin receptor substrate-1 gene contributes to the variation in insulin secretion in normal glucose-tolerant humans. Diabetes 2001;50:882-885.

22. 't Hart LM, Nijpels G, Dekker JM, Maassen JA, Heine RI, wan Haeften TW. Variations in insulin secretion in carriers of gene variants in IRS-1 and -2. Dabetes 2002;51:884-887.

23. Ruige JB. Dekker JM, Nijpels $G$, et al. Hyperproinsulinaemia in impaired glucosk tolerance is associated with a delayed insulin response to glucose. Diabetologia $1999: 42: 177-180$

24. Reaven GM. Non-insulin-dependent diabetes mellitus, abnormal lipoprotein metabolism, and atherosclerosis. Metabolism 1987:36:1-8.

25. Reaven GM. Chen Y-DI, Jeppesen I, Maheux $P$, Krauss RM. Insulin resistance and hyperinsulinemia in individuals with smal, dense, low density lipoprotein particles.J Clin Invest 1993:92"141-146.

26. Stumvoll $M$, stefan $N$, Fritsche $A$, et al. Interaction effect between common polymorphisms in PPARgamma(2) (Pro12Ala) and insulin receptor substrate 1 (Gly972 Arg) on insulin sensitivity. J Mol Med 2002;80:33-38.

27. Le HH, Coresh J, Shuldiner AR, Boerwinkle E, Brancatti FL. Varants of the insulin receptor substrate-1 and fatty acid binding protein 2 genes and the risk of type 2 diabetes, obesity, and hyperinsulinemia in African-Americans: the atherosclerosis risk in communities study. Diabetes 1999:48:1868-1872.

28. "t Hart $L M$, Stolk RP, Dekker JM, et al. Prevalence of variants in candidate genes for type 2 diabetes mellitus in the Netherlands: The Rotterdam study and the Hoorn study. I Clin Endocrinol Metab 1999;84:1002-\#1006. 


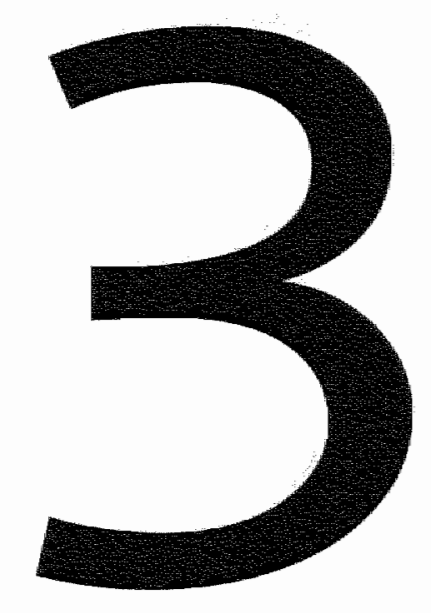

\section{Gly972Arg variant in the insulin receptor substrate-1 gene and association with type 2 diabetes: a meta-analysis of 27 studies}

Annemarie Jellema ${ }^{\mathbb{1}, 2}$, Maurice P.A. Zeegers ${ }^{3}$, Edith J.M. Feskens ${ }^{1}$, Pieter C. Dagnelie ${ }^{3}$, Ronald P. Mensink ${ }^{2}$

1. Centre for Nutrition and Health, National Institute for Public Health and the Environment, Bilthoven, The Netherlands

2. Department of Human Biology, Maastricht University, Maastricht, The Netherlands

3. Department of Epidemiology, Maastricht University, Maastricht, The Netherlands

Diabetologia 2003, 46:990-995 


\section{Abstract}

Background: Several case-control studies have examined the association between the Glyg72Arg variant in the IRS-1 gene and type 2 diabetes, but most had limited power and results could therefore be conflicting.

Methods: We systematically reviewed the literature by means of a metaanalysis and investigated sources of heterogeneity in results of different studies.

Results: The summary risk ratio, based on 3,408 cases and 5,419 controls from 27 studies, was 1.25 (95\% Cl 1.05-1.48). The results, however, differed according to type of study, method of verifying non-diabetic status of the control subjects, and age of the case subjects. Population-based studies reported lower odds ratios (OR) than hospital-based studies (OR $0.98,95 \% \mathrm{Cl}$ $0.74-1.30$ versus OR $1.43,95 \% \mathrm{Cl} 1.17-1.74)$. Also, the diagnostic test to exclude diabetes among controls interacted with the association between the IRS-1 Gly972Arg variant and type 2 diabetes $(p=0.025)$. Finally, the OR reduced with increasing age $(p=0.033)$.

Conclusions: Overall, carriers of the $972 \mathrm{Arg}$ variant of the IRS-1 gene are at a $25 \%$ increased risk of having type 2 diabetes compared with non-carriers. The OR are generally higher in hospital-based studies, including relatively young, symptomatic, cases. 


\section{Introduction}

Insulin receptor substrate-1 (IRS-1) is the first substrate of the insulin receptor in the insulin signaling pathway (1). Due to this central role, the IRS-1 function could be related to the development of type 2 diabetes. Polymorphisms in the IRS-1 gene were identified for the first time in 1993 (2). Since then, many casecontrol studies have examined the association between the Gly972 Arg variant and type 2 diabetes (2-26). Results, however, are not consistent. It has been noticed that the heterozygous variant of the Gly972Arg polymorphism occurred more frequently in type 2 diabetes subjects compared to controls $(19 \%$ vs 7\%) (2). Based on seven studies published up to $1996(2-5,8,12)$, a combined $O R$ of 1.49 has been reported (12). However, since then a number of other studies have been published in which no association was observed (1517, 19-23). Besides study power and other methodological issues, interaction with important diabetic risk factors such as body weight could have resulted in heterogeneous findings. Indeed, an association between the Arg variant and insulin resistance in obese but not in lean subjects has been observed (27). It has been suggested that excess body weight positively interacts with the Arg variant thereby increasing the type 2 diabetes risk (12).

The airm of our study was therefore to review the literature systematically by means of a meta-analysis, and to provide a quantitative summary estimate on the association between the Gly972Arg variant in the IRS-1 gene and the prevalence of type 2 diabetes. In addition, sources of heterogeneity between studies were examined.

\section{Subjects and methods}

\section{Search strategy}

Studies were identified through a computerized Medline, Current Contents and Science Citation Index search on studies published until January 2002 using the free text words: diabetes, insulin receptor substrate, IRS-1, genotype, variant, Cly972Arg, and polymorphism. References in relevant publications were also examined. There were no language restrictions. For inclusion in this analysis, the publications had to give information about the prevalence of the Gly972Arg polymorphism in type 2 diabetes patients and healthy non-familial control subjects. Another prerequisite was that sufficient data were presented to calculate OR. All investigations analyzed in this metaanalysis have been carried out in accordance with the Declaration of Helsinki. 


\section{Data collection}

For each study, information was collected concerning the characteristics of the subjects (age, sex, BMI, ethnicity, age of diagnosis), technique of the polymorphism (single strand conformation polymorphism analysis (SSCP) or direct enzyme digestion), type of study (hospital-based or population-based), and the diagnostic test used to exclude diabetes presence in control subjects (glucose tolerance test (GT), fasting blood glucose measurement or no laboratory measurement). These study characteristics were used to evaluate sources of variation in effect estimates. All articies were independently scored by three reviewers (AJ, MZ, EF) similar to an earlier approach (28). Disagreements were solved in consensus meetings. Assuming a dominant model of inheritance, homozygous mutants were combined with the heterozygous group. Unadjusted OR were calculated using $2 \times 2$ contingency tables for each study, based on the Gly972Arg variant (wildtype versus heterozygous and homozygous mutant) and prevalence of type 2 diabetes (present versus not present).

Authors of all publications were approached for additional information about the BMI of the subjects, high BMI (BMI $>27 \mathrm{~kg} / \mathrm{m}^{2}$ ) or low BMI (BMI $\leq 27$ $\mathrm{kg} / \mathrm{m}^{2}$ ). This additional information was provided by nine authors on ten study populations $(8,13,15-20,23)$.

\section{Study characteristics}

We identified 44 articles published until January 2002 on the Gly972Arg polymorphism in type 2 diabetic patients and control subjects. We excluded five studies because they examined the expression of the mutation instead of the prevalence (29-33). We excluded seven studies because case subjects were relatives of type 2 diabetic patients (34-37) or were obese subjects $(27,38,39)$ instead of type 2 diabetic patients. An appropriate control group was missing in five studies $(7,40-43)$, three studies did not provide clear data about prevalence rates (44-46) and two studies were excluded because OR could not be calculated $(24,25)$. Of the 22 included publications (figure 3.1), five provided separate associations in different populations $(8,15,17,19,23)$. These associations were considered as separate studies.

Of the studies five were population based studies $(5,8,19,21)$ and 22 studies were hospital-based studies $(2-4,6,9-18,20,22,23,26)$. Seventeen studies included Caucasian subjects $(2-5,8,11,12,14,15,18-20,22,23,26)$, eight studies included Asian subjects $(6,8-10,13,16,17)$, and three studies black or South American subjects $(15,21,23)$ (see figure 3.1). Diagnostic tests to exclude diabetes presence in the control subjects were a single fasting blood glucose test in ten studies $(2,3,8,14,18-22)$ and a GT in nine studies $(5,6,8$ - 
$10,16,17,23)$. In nine studies no diagnostic test has been used or reported (4, $11-13,15,23,26)$. SSCP analysis has been used in three studies to determine the polymorphism $(6,15)$, fifteen studies used direct enzyme digestion $(8,10$, $12,14,16-22,26)$, and seven studies used both $(2,4,5,9,11,13,23)$. The method of analysis was not reported in three studies $(3,23)$.

\section{Statistical analysis}

To check for publication bias, a funnel plot was constructed. We examined funnel plot asymmetry visually and measured the degree of asymmetry using Egger's unweighted regression asymmetry test (47). Studies were tested for Hardy-Weinberg equilibrium in the control group using chi-square tests (48). Summary OR and corresponding $95 \%$ confidence intervals ( $95 \% \mathrm{Cl}$ ) were estimated by random effects meta-regression analysis using the STATA 7.0 statistical software package (49). To explore reasons for observed heterogeneity, we carried out sensitivity analyses on study characteristics and tested their influences on the association between the Gly972 Arg variant and prevalence of type 2 diabetes. A p-value of 0.05 was considered statistically significant.

\section{Figure 3.1:}

Study characteristics and OR of published articles concerning the effect of the Gly972Arg variant on the prevalence of type 2 diabetes

\begin{tabular}{|c|c|c|c|c|c|c|}
\hline Reff & Autther & Year & Ethmicity & Tesst & $\begin{array}{l}\text { Pop } \\
\text { based }\end{array}$ & $\begin{array}{l}\text { Cases } \\
\text { cas }\end{array}$ \\
\hline 2 & Amind & $199 x$ & Caluc & fasting & no & 86 \\
\hline 3 & Hager & 1993 & Caule & forsting & no & 233 \\
\hline 4 & mas & 1994 & Canc & nothest & rto & 31 \\
\hline 5 & Latak 50 & 1994 & Case & Cामीं & yes & 112 \\
\hline 6 & Shimokatwa & 1994 & Ansian? & GI & $n$ & 197 \\
\hline 8 & foitman & 1995 & Aasiatin & fasting & noo & 126 \\
\hline 8 & Foluting & 1.995 & Cande & GT & yes & 40 \\
\hline 9: & Whori & 1995 & Ausiany & GTI & no & 226 \\
\hline 10 & Ehuabes & 1996 & Ansiatiti & GTT & n:o & 89 \\
\hline 11 & 乨: ammanella & 1096 & Catuc & . & $\operatorname{th}$ & 6 \\
\hline 12 & 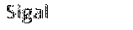 & 1996 & Caln: & notest & 100 & 192 \\
\hline 13 & Ling & 1996 & Astan & notest & no & 100 \\
\hline $1 y_{4}^{2}$ & 2hăg & 2996 & Caut & fasting & no & 227 \\
\hline 1.5 & Pis & 1997 & Cautac & notest & no & 1,0 \\
\hline 115 & $\operatorname{Pan} 2$ & 1997 & Black & no fust & noto & 20 \\
\hline 15 & deprotrete & 1998 & Astan & $G T$ & no & 49 \\
\hline 17 & ramado & 1998 & Asian & GIT & no & 86 \\
\hline 17 & "ramadza & 1998 & Assia:n & GIT & no & 224 \\
\hline 28 & Baroni & 1999 & Catit & fasting & no & 400 \\
\hline 19 & "thath & 1999 & Castox & fosting & yes: & 190 \\
\hline 19 & " & 1999 & Catax & fosting & yes & 199 \\
\hline .70 & Hto & 1939 & Catan & fasting & no & 130 \\
\hline 71 & lei & 1999 & black & fiusting & yes & 321 \\
\hline 22 & Benedke & 2000 & Catur & finsting & no & 37 \\
\hline 23 & ceti & 2000 & S. Amper. & $\mathrm{GTT}$ & no & 31 \\
\hline 23 & Centi & 2000 & Callo & . & no & 60 \\
\hline 26 & Rosskopf & 2000 & Catuc & no test & no & 320 \\
\hline
\end{tabular}

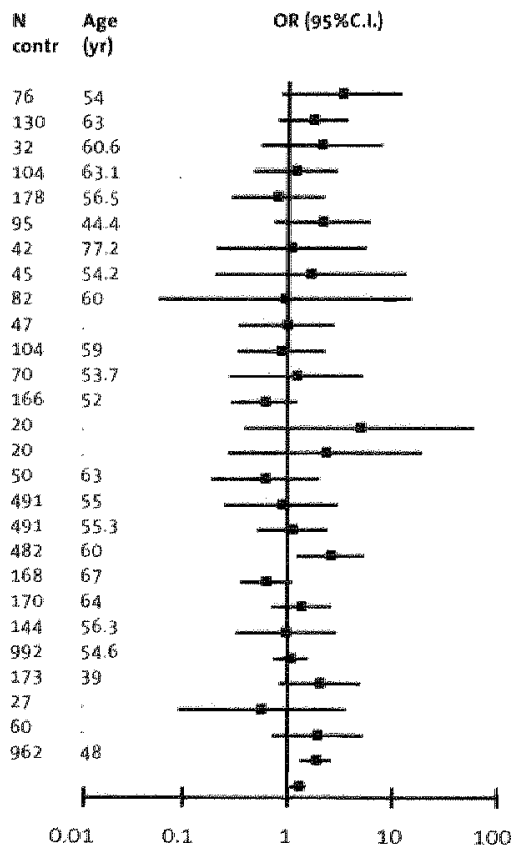




\section{Results}

Results from 27 studies with 3,408 diabetic patients and 5,419 non-related control subjects were included in this meta-analysis (figure 3.1). We could not identify heterogeneity visually (figure 3.2 ) or in terms of statistical significance $(p=0.159)$, indicating no publication bias.

The allele frequencies of the control group of one study (5) were not in HardyWeinberg equilibrium. Calculations were performed with and without this study. As results were similar, this study was not excluded.

OR of type 2 diabetes for carriers compared to non-carriers of the Gly972Arg variant ranged from 0.55 to 4.75 (figure 3.1). The summary OR was 1.25 ( $95 \%$ Cl 1.05-1.48). The average proportion of carriers was $8.6 \%$ in healthy control subjects and $11.4 \%$ in diabetic patients. The overall population attributable risk was $2.1 \%$.

\section{Figure 3.2:}

Funnel plot for subjects with the Arg variant versus subjects without this variant, unadjusted

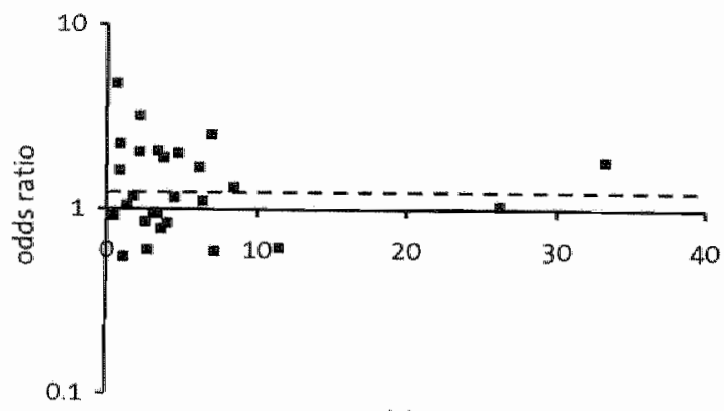

precilsion

Interrupted and uninterrupted reference lines indicate no effect and total summary OR, respectively.

We further examined if the association of the Gly972Arg variant with type 2 diabetes did depend on ethnicity, type of study, or diagnostic test used to exclude diabetes presence, type of measurement of the polymorphism, prevalence of the polymorphism, and age of the cases. Heterogeneity was observed for type of study, diagnostic test used to exclude diabetes in the control group and age of the case subjects (figure 3.3).

The summary OR was $0.98(95 \% \mathrm{Cl} 0.74-1.30)$ for population-based studies, including 860 cases and 1,476 controls, compared with a summary OR of 1.43 
(95\% Cl 1.17-1.74) for hospital-based studies including 2,548 cases and 3,943 control subjects $(p=0.031)$. Studies using a GTT to exclude diabetes presence showed a lower OR compared with studies using a single fasting blood glucose test or no test at all $(p=0.025)$. The summary $O R$ decreased with age of cases $(p=0.033)$. Based on the regression equation the $O R$ reduced from 1.87 (95\% Cl 1.24-2.82) for cases aged $35-45$ years to 0.85 (95\% Cl $0.59-1.24)$ for cases that were 65-75 years old. The age of cases was lower in hospital-based studies compared with population-based studies (54.9 \pm 6.4 versus $65.2 \pm 8.2$ years; $p=0.045$ ). There was no difference in the age of cases between studies that used a GTT, fasting glucose determination or no test $(60.5 \pm 7.6,55.4 \pm 8.8$, $55.3 \pm 5.7$ years respectively, $p=0.363$ ). All population-based studies used a GTT or fasting blood glucose determination to exclude diabetes among the control subjects. No test was done in six hospital-based studies. As the three modifiers (type of study, type of test to exclude diabetes, and age of cases) were highly interrelated it was not possible to assess the independent impact in the meta-regression analysis.

Although the OR for studies with Caucasian subjects was slightly higher than that for studies with Asian subjects (figure 3.3) this difference was not statistically significant $(p=0.258)$. The prevalence of the polymorphism and the analytical method to detect the polymorphism did not change the summary $O R$.

\section{Figure 3.3:}

Crude summary OR for the Gly972Arg variant and prevalence of type 2 diabetes by ethnicity, type of study, test in controls and age of cases

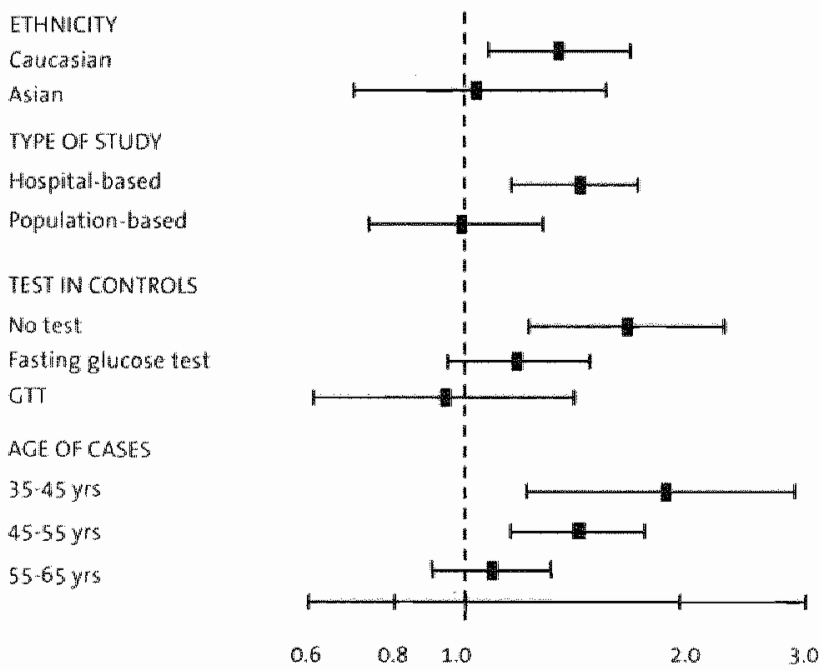


Additional information on $\mathrm{BM}$ was retrieved from ten studies $18,13,15-20$, 23). The summary $O R$ for these studies was $1.14(95 \% \mathrm{Cl} 0.78-1.65)$. In studies with subjects with an average BM! greater than $27 \mathrm{~kg} / \mathrm{m}^{2}$ (395 type 2 diabetic subjects and 367 control subjects) or an average BMI less than or equal to 27 $\mathrm{kg} / \mathrm{m}^{2}$ (788 diabetic patients and 1,523 controls), no effect of the Arg variant on the prevalence of type 2 diabetes was found (OR $0.76,95 \% \mathrm{Cl} 0.46-1.25$ and OR $1.2395 \%$ (l 0.75-2.01).

\section{Discussion}

Transfection studies with insulin receptor cells indicated that the Gly972Arg polymorphism of the IRS-1 gene impaired insulin-stimulated signaling (32). A relationship between this polymorphism with the risk for type 2 diabetes is therefore biologically plausible. Indeed, in our meta-analysis of 27 studies, including 3.408 diabetic patients and 5,419 control subjects, the summarized findings suggest an association between the presence of the Gly972Arg variant and type 2 diabetes. In addition, several sources of heterogeneity between different studies were identified.

The summary OR for population-based studies was lower than for hospitalbased studies. This difference could be due to differences in phenotype. Cases detected in population-based studies include subjects with mild forms of diabetes, such as subjects newly diagnosed with diabetes after a single GTT. Hospital-based studies generally include patients with more overt and symptomatic diabetes. These could be genetically different from those with newly diagnosed diabetes as individuals with milder glucose intolerance may not develop clinical symptoms or only at a high age (50). Diabetes diagnosed at lower age is thought to have a greater genetic predisposition (51). We indeed observed an increasing OR with a lower age of the cases. The age of cases was also lower in hospital-based studies compared with populationbased studies. This suggests that related differences in phenotype of the diabetic patients could account for the observed heterogeneity between population-based and hospital-based studies.

The difference in OR found in population-based studies and hospital-based studies could also be due to the type of test that has been used. All included population-based studies used a fasting glucose concentration or a GTT to classify subjects as control subjects. Hospital-based studies did not consistently use one test: in fact different types of tests (GTT, fasting or no test) were used evenly. Our results indicated that a more extensive test to detect diabetes in controls such as a GTT resulted in a lower OR. This may be due to the detection of a larger number of individuals with mild diabetes. 
In general, a population-based design may be preferable in studies of nonrelated subjects as it is more likely that the control subjects are recruited from the same source population, avoiding selection bias (52). This could be methodologically more sound compared to hospital-based studies with often only a limited description of the control subjects and the selection process, leading to differential and non-differential misclassification of the control subjects. Both population- and hospital-based association studies have been criticized, because population admixture could be a source of confounding (53). Family-based studies have been advocated as the preferred design for detecting genetic associations, because they check for population stratification. However, others have shown that there is only a relatively small effect from population stratification in a well-designed population association study (54).

Only one family-based study on the Gly972Arg polymorphism and type 2 diabetes has been reported to date (55). No association was found, although there was a trend in the same direction (OR $1.1595 \% \mathrm{Cl} \quad 0.71-2.03$ ) as compared with our study. It is not clear from this study whether the results were different according to phenotype, because it included type 2 diabetes patients as well as subjects with impaired glucose tolerance or a prediabetic state.

A major difficulty in identifying genes responsible for type 2 diabetes is the definition of the phenotype (56). This is also illustrated by the small population attributable risk of $2.1 \%$ in our study, due to the relatively low prevalence of the IRS-1 Arg972 variant. Since most individuals do not develop diabetes until later in life, a more appropriate phenotype might be insulin resistance or impaired insulin secretion. These metabolic abnormalities are identifiable even in the early stages of the natural history of type 2 diabetes when glucose tolerance is normal. The Gly972Arg polymorphism has been associated with increased insulin resistance in obese subjects $(27,57,58)$. Human pancreatic islets from Arg972 carriers had reduced insulin content, altered insulin release, and a greater number of immature secretory granules (59). As our results suggest that the IRS-1 Gly972Arg genotype is associated with a diabetes phenotype occurring at an earlier age, the importance of gene-gene interactions is also a matter that needs further elucidation (60).

In conclusion, this meta-analysis, including all available evidence to date, indicates that carriers of the $972 \mathrm{Arg}$ variant of the IRS-1 gene are at a $25 \%$ increased risk of having type 2 diabetes compared with non-carriers, contributing to about $2 \%$ of the prevalence. The OR are higher for hospitalbased studies, including relatively young, symptomatic, cases. The contribution to specific subtypes of type 2 diabetes could therefore be higher. 


\section{Acknowledgements}

The study was supported by a grant from the Netherlands Organization for Scientific Research (NWO), grant number 980-10-006, Nutrition and Chronic Diseases. We would like to thank all authors from whom we received additional information concerning BMI of the subjects. We thank Dr H.C. Boshuizen from the National Institute of Public Health and the Environment, Centre for Information Technology and Methodology, for statistical advice. 


\section{References}

1.

2.

3.

4.

5.

6.

8.

9.

10.

11.

12.

13.

14.

15.

16.

Gupta BBP. Mechanism of insulin action. Current Science $1997 ; 73: 993-1003$.

Almind K. Aminoacid polymorphisms of insulin receptor substrate i in non-insulimdependent diabetes mellitus. Lancet 1993;342:828-832.

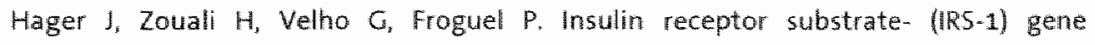
polymorphisms in French NIDOM families. lamcet 1993;3:42:1430.

Imai $\gamma$, Fusco A, Suzuki $Y$, et all. Variant sequences of insulin receptor substrate-1 in patients with noninsulindependent dlabetes mellitus. J Clin Endocrinol Metab 1994:79:1655-1658.

La.kso M, Malkki $M_{0}$ Kekäläinen $P$. Kuusisto J, Deeb 55 . Insulin receptor substrate-1 variants in non-insulin-dependent diabetes. I Clin Invest 1994:94:1141-1146.

Shimokawa $K$, Kadowaki $H$, Sakura $H$, et al. Molecular scanning of the glycogen sylnthase and insulin receptor substrate- 1 genes in Japanese subjects with non-insulin: dependent diabetes mellitus. Biochem Biophys Res Commun 1994:202:463-469.

Grant Pli, Stickland MH, Mansfield MW. Insulin receptor substrate-1 gene and cardiovascular risk factors in NDDM. Lancet 1995;346:841-842.

Hitman GA, Hawrami $K$, McCarthy MI, et al. insulin receptoi substrate-1 gene mutations in NIDDM; implications for the study of polygenic disease. Diabetologia $1995: 38: 481-486$.

Mori $H$, Hashiramoto M, Kishimoto M. Kasuga M. Amino acid polymorphisms of the insulin receptor substrate-1 in Japanese noninsulin-dependent diabetes mellitus. 1 Clin Endocrinol Metab 1995:80:2822-2826.

Chuang LM, Lall CS, Yeh II, WU HP, Tai TY, Lin BJ. No association between the Gly971Arg variant of the insulin receptor substrate 1 gene and NDDDM in the Taiwanese population. Diabetes Care 1996;19:446-449.

Mammarella S, Esposito DL, Creati B, et al Mutationall analysis of the insulin receptor substrate-1in non-insulin dependent diabetes. Diabetologia 1996,39:A75.

Sigal RJ, Doria A Warram JH, Krolewski A5. Codon 972 polymorphism in the insulin receptor substrate-1. gene, obesty, and risk of nonimsulindependent diabetes mellitus. J Clin Endocrinol Metab 1996;81:1657-1659.

3. Ura 5 , Araki E, Kishikawa $H$, al Molecular scanning of the insulin receptor substrate-1. (IRS-1) gene in Japanese patients with NIDDM: identification of five movell polymorphisms. Diabetologia 199:6:39:600-608.

Zhang $Y$, Stratton IM, Warrenwery MG, Orho M, Groop L. Turner RC. UKPDS 19. heterogeneity in NDDM: separate contributions of 1 RS-1 and betas-adrenergic. receptor mutations to insulin resistance and obesity respectively with no evidence for glycogen synthase gene mutations. Diabetologilia 1996:39:1505-1511.

5. Panz VR, Raal Fl, O'Rahilly $S$, Kedda MA, Joffe Bil. Insulin receptor substrate-1 gene variants in lipoatrophic diabetes mellitus and non-insuln-dependent diabetes mellitus: a study of South African black and white subjects. Hum cenet 1997 101:118-119.

Lepretre $F$, Vionnet N. Budhan 5 , et al. Genetic studies of polymorphisms in ten noninsulin-dependent diabetes mellitus candidate genes in Tamil indians from Pondichery. Diabetes Metab 1998,24244-250.

Yamada $K$, Yuan $X_{\text {. }}$ Ishiyama 5 , et al. Codon 972 polymorphism of the insulin receptor substrate-1.gene in impaired glucose tolerance and late-onset NDDM. Diabetes Care $1998: 21: 753 \times 756$. 


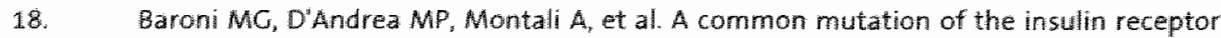
substrate-1 gene is a risk factor for coronary artery disease. Arterioscler Thromb Vasc Bül 1999;19:2975:2980.

19. 't Hart LM, Stolk RP, Dekker JM, et al. Prevalence of variants in candidate genes for type 2 diabetes mellitus in the thetherlands: The Rotterdam study and the Hoorn study. I clin Endocinol Metab 1999:84:1002-1006.

20. to $K$, Katsini $A$, Furuta $M$, et al. Insulin sensitivity is not affected by mutation of codori 972 of the human IRS-1 gene. Horm Res $1999,52: 230-234$.

21. Lei HH, Coresh I, Shuldineir $\mathrm{AR}_{\mathrm{N}}$ Boerwinkle $\mathrm{E}_{\mathrm{s}}$ Brancati $\mathrm{FL}$. Variants of the insulin receptor substrate-1 and fatty acid binding protein 2 genes and the risk of type 2 diabetes, obesity, and hyperinsulinemia in African-Americans: the atherosclerosis risk in communities study. Diabetes 1999:48:1868-1872.

22. Benecke H. Topak H, won zur Muhlen A, schuppert F. A study on the genetics of obesity: influence of polymorphisms of the beta-3-adrenergic receptor and insullin receptor

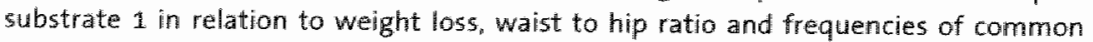
cardiovascular risk factors. Exp Clin Endocinol Diabetes 2000;108:86 92.

23. Celi FS, Negri $C$. Tanner $K$ et al. Molecular scanning for mutations in the insulin receptor substrate-1 (IRS-11) gene in Mexican Americans with type 2 diabetes mellitus. Diabetes Metab Res Rev 2000;16:3770-377.

24. Celi FS, Silver K. Walston I, Knowler WC, Bogardus C, Shuldiner AR. Lack of $4 R$ S-1 codon 513 and 972 polymorphism ir Pima Indians. J Clin Endocinol Metab 1995:80:2827-9.

25. Zeng WM, Peng J, Wan $X X$. Chen SH, song HP. The mutation of insulin receptor substrate-1 gene in chinese patients with non insulin-dependent diabetes mellitus. Chin Med J 2000;113:80-83.

26. Rosskopf D, Frey U, Eckhaldt $S$, et al. Interaction of the G protein beta 3 subunit T825 allele and the IR5-1 Arg972 variant in type 2 diabetes. Eur I Med Res 2000;5:484-490.

27. Clausen 10 , Hansen T, Bjorbaek $C$, et al. Insulim resistance: interactions between obesity and a common variant of insulin receptor substrate-1. Lancet 1995:346:397-402.

28. Zeegers MP, Tan $\mathrm{FF}_{3}$ Goldbohm RA, van den Brandt PA. Are coffee and tea comsumption associated with urinary tract cancer risk? A systematic review and meta-analysis. Int Epidiemiol $2001 ; 30: 353-362$.

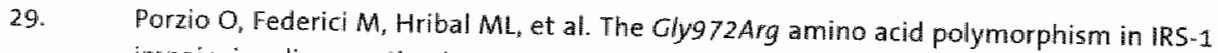
impairs insulin secretion in pancreatic $\beta$ cells. I Clin Invest 1999:104:357-364.

30. Yoshimura $R_{,}$Araki $\mathbb{E}$, Ura $S$, et al. Impact of natural $R R^{5}-1$ mutations on insulin signals: mutations of IRS- 1 in the PTB domain and near SH2 protein binding sites result in impained function at different steps of $I R S-1$ signaling. Diabetes 1997;46:929-936

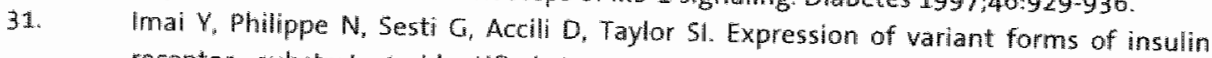
receptor substrate-1 identified in patients with maninsulin-dependent diabetes mellitus. I Clin Endocrinol Metab 1997,82:4201-4207.

32. Almind $k$, Inove $G$, Pedersen $O$, Kahn $R K$. $A$ common amino acid polymorphism in insulin receptor substrate-1 causes impaired insulin signaling. I Cin linvest 1996:97:2569-2575.

33. Whitehead $\gg \mathrm{P}$, Humphreys $P$, Krook $\mathrm{A}$, at. Molecular scanning of the insulin receptor substrate $1 \mathrm{gene}$ in subjects with severe insulin resistance. Diabetes $1998 ; 47$.

34. Koch $M$, Rett $K_{*}$ Volk A, at al. Amino acid polymorphism Gly 972 Arg in IRS-1 is not associated to lower clamp-derived insulin sensitivity in young healthy first degree relatives of patients with type 2 diabetes. Exp Clin Endocrinol Diabetes 1999:107:31.8.
322 . 
35. Armstrong M, Haldane F, Avery PJ, et al. Relationship between insulin sensitivity and insulin receptor substrate- 1 mutations in non-diabetic relatives of NDOM families. Diabet Med 1996:13:341-345.

36. Carvalho $E$, Jansson PA, Axelsen $M$, et al. Low cellular IRS 1 gene and protein expresion predict insulin resistance and NIDDM. Faseb / 1999:13:2173-2178.

37. Rett $K$, Koch $M$, Volk A, Maerker $\mathbb{E}$, Jacab 5, Haering H.U. codon 972 polymorphism of the IRS-1 gene is prevalent in offspring of subjects with type 2 diabetes without determining clamp-derived insulin action. Diabetes 1998;47:393a.

38. Clement K, Dina C. Basdevant A, et al. A sib pair analysis study of 15 candidate genes in French families with morbid obesity: indication for linkage with islet 1 locus on chromosome 5q. Diabetes 1999;48:398-402

39. Krempler F, Hell E, Winkler C, Breban D, Patsch W. Plasma leptin levels - interaction of obesity with a common variant of insulin receptor substrate-1. Arterioscler Thromb Vasc Biol 1998:18:1686-1690.

40. Ossei Gerning $\mathbb{N}$, Mansfield MW, Stickland MH, Grant PJ. Insulin receptor substrate-1 gene polymorphism and cardiovascular risk in non-imsulin dependent diabetes mellitus and patients undergoing coronary angiography. Clin Lab Haem 1997;19:123-128.

41. Armstrong M, Haldane F, Taylor RW, Alberti KGMM, Turnbull DM, Walker M. Human insulin receptor substrate-1: variant sequences in familial non-inisulin dependent diabetes mellitus. Diabet Med 1996;13:133-138.

42. Tagawa $T$, Yoshioka $R$, Kodama $M$, Sakamoto $K$, Watarai $T$, Yamasaki $Y$. The characteristics of NIDDM patients with the codon-972 variant of IRS-1 gene. Diabetes 1998;47:393a.

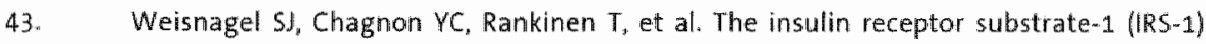
Gly972Arg polymorphism is associated with obesity in the Quebec Familiy study (QFS). Diabetes 2000;49:822.

44. Stern MP, Mitchell $B D, B$ langero J, et al. Evidence for a major gene for type Il diabetes and linkage analyses with selected candidate genes in Mexican-Americans. Diabetes $1996: 45: 563-568$.

45. Delafontaine P. IRS-1 variant: A new risk factor for coronary artery disealse? Arterioscler Thromb Vasc Biol 2000;20:283-284

46. Hansen $T$, Hansen $L_{r}$ Remeland $R$, et al. Hyperglycemia and obesity independently interact with the Cly972Arg variant of the insulin receptor substrate-1 to increase imsulin resistance. Proc Gen Diab 1997:35:1309.

47. Egger M, Davey Smith $G$, Schneider M, Minder $C$. Bias in meta-analysis detected by a simple, graphical test. Bmj 1997;315:629-63:4.

48. Schaid DJ, Jacobsen SI. Buared tests of association: comparing of allele frequericies when departing from Hardy -Weinberg proportions. Am J Epidemiol 1999:149:706-711.

49. Statacorp. Stata Statistical Software Release 6.0 ed. College station, Texas: Stata corporation, 1999.

50. Burke JP, Haffner SM, Gaskill SP, Williams, KL, Stern MP. Reversion from type 2 diabetes to nondiabetic status. Influence of the 1997 American Diabetes Association criteria. Diabetes Care 1998;21:1266-1270.

51. Owen $K$. Ayres 5 , Corbett 5, Hattersley A. Increased risk of diabetes in first-degree relatives of young-onset type 2 diabetic patients compared with relatives of those diagnosed later. Diabetes Care 2002;25:636-637

52. Langholz $B$, Rothman $\mathbb{N}$, Wacholder 5 . Thomas DC. Cohort studies for characterizing measured genes. I Natl Cancer Inst Monogr 1999:26:39-42.

53. Altshuler D, Kruglyalk $L_{\text {, }}$ Lander E. Genetic polymorphisms and disease. N Engl I Med 1998:338:1626. 
54. Wacholder $S$, Rothman $N$. Caporaso $N$. Population stratification in epidemiologic studies of common genetic variants and cancer: quantification of biass I Natl Cancer inst 2000;92:1151-1158.

55. Altshuler D, Hirschhorn IN, Klannemark $M_{*}$ et al. The common PPARgamma Pro12Ala polymorphism is associated with decreased risk of type 2 diabetes. Nat Genet 2000;26:76-80.

56. Defronzo RA. Pathogenes is of type 2 diabetes: Metabolic and molecular implications for identifying diabetes genes. Diabetes Reviews 1997;5:177-269.

57. Jellema A, Feskens EM, Mensink RP, Saris WHM, Kromhout D. Cardiovascular risk markers in an overweight and normal weight population with oversampling of carriers of the IRS-1 972Arg variant (Abstract). Atherosclerosis 2002;3 (suppl 2)"133.

58. Baroni $M G$, Arca $M$, Sentinelli $F$, et al. The $G 972 R$ variant of the insulin receptor substrate-1 (IRS-1) gene, body fat distribution and insullin-resistance. Diabetologia 2001;44:367-372.

59. Marchettï $P$, Lupi $R$, Federici $M$, et al. Insulin secretory function is impaired in isolated human islets carrying the Gly(972) - >Arg IRS-1 polymorphism. Diabetes 2002;51:14191424.

60. Saltiel AR, Kahn CR. Insulin signalling and the regulation of glucose and lipid metabolism. Nature 2001;41.4:799-806. 


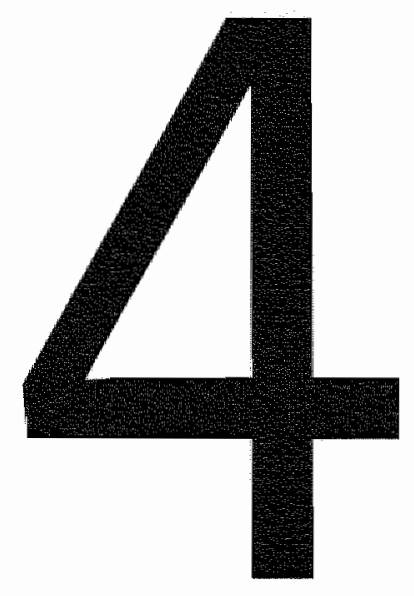

Impact of polymorphisms in the IL-6 and TNF- $\alpha$ genes on metabolic risk markers and the interaction with overweight

Annemarie Jellema ${ }^{1,2}$, Ronald P. Mensink ${ }^{2}$, Daan Kromhout ${ }^{1}$, Wim H.M. Saris ${ }^{2}$, Edith J.M. Feskens ${ }^{1}$

1. Centre for Nutrition and Health, National Institute for Public Health and the Environment, Bilthoven, The Netherlands

2. Department of Human Biology, Maastricht University, Maastricht, The Netherlands 


\section{Abstract}

Background: Several studies have reported unfavorable effects of the $C G$ variant of the $G 174 \mathrm{C}$ polymorphism in the interleukin-6 (IL-6) gene and of the AA variant of the $6308 \mathrm{~A}$ polymorphism in the tumor necrosis factor-a (TNF- $\alpha$ ) gene on metabolic risk markers. As expression of these two cytokines is increased in overweight subjects, we decided to determine the relationship between these two functional polymorphisms with anthropometric parameters, plasma insulin and lipid concentrations, and C-reactive protein (CRP).

Methods: We examined 600 men and women, sampled from a populationbased cohort according to body mass index (BMI), with a mean age of $52.6 \pm$ 9.9 years.

Results: In the high BMI group (mean BMl $31.2 \mathrm{~kg} / \mathrm{m}^{2}$ ), the waist to hip ratio was significantly lower in $C C$ subjects than in $G C$ and $G G$ subjects $(0.91$ versus 0.94 and $0.95 ; p=0.033$ ) of the $1 L .6$ polymorphism. This relationship was not found in the low BMI group (mean BMI $21.9 \mathrm{~kg} / \mathrm{m}^{2}$ ). In subjects with a high $B M I$, carriers of the AA variant had higher triglyceride (TG) and lower high density lipoprotein cholesterol (HDL-C) levels compared with carriers of the GA or GO variant of the TNF-a polymorphism (2.46 mmol/L versus 1.41 and $1.26 \mathrm{mmol} / \mathrm{L} ; p=0.001$ for $\mathrm{TG}$ and $1.01 \mathrm{mmol} / \mathrm{L}$ versus 1.17 and $1.09 \mathrm{mmol} / \mathrm{L}$; $p=0.016$ for HDL-C). This relationship was again not found in subjects with a low BMI. For both polymorphisms no other significant associations were observed. Subjects with the IL-6 GG variant and the TNF- $\alpha$. AA variant had significantly higher TG levels compared with all other combinations.

Conclusions: In subjects with high BMI the G174C IL-6 polymorphism was related to a higher waist to hip ratio and the G308A TNF- $\alpha$ polymorphism to higher TG and lower HDL-C concentrations. These genetic variants may interact with respect to fasting TG levels. 


\section{Introduction}

Adipose tissue is not just a passive organ for storage of energy. It also secretes many bioactive compounds such as TNF- $\alpha$ and 1L-6, which both play an important role in glucose and fat metabolism $(1,2)$. In vitro studies, for example, thave shown that these two cytokines inhibit lipoprotein lipase (LPL) activity and stimulate adipose tissue lipolysis $(3-5)$. IL-6 was also found to stimulate glucose and lipid oxidation (6). TNF- $\alpha$ is involved in $T G$ degradation in the adipocyte through activating hormone sensitive lipase ( $H S L$ ) (7). It also increases insulin resistance through effects on phosphorylation of insulin receptors and insulin receptor substrate-1 (IRS-1) (8). These effects lead to increased fuel mobilization from the adipose tissue (9). Indeed, in overweight subjects there is an overexpression of TNF- $\alpha$ and IL-6 acting like adipostatic molecules possibly involved in body weight control.

Polymorphisms that are associated with glucose and fat metabolism in the genes encoding for IL-6 and TNF- $\alpha$ have been identified. For IL-6, a G174C polymorphism in the promoter region has been reported by Fishman et al (10). It was found that carriers of the $G$ allele had higher IL-6 levels (10), insulin resistance (11) and llipid abnormalities (12) compared with carriers of the CC allele. For TNF- $\alpha$, a polymorphism at position -308 in the promoter region is known (13). Women with the AA genotype were markedlly more obese than women with the $A G$ or $G G$ genotype (14). In addition, an increased insulin resistance in carriers of the $A$ allele of the polymorphism compared with GG carriers was found (15).

Although TNF- $\alpha$ and $I L-6$ are expressed by adipose tissue, it is not known if the observed associations between the polymorphisms for IL-6 and TNF- $\alpha$ with markers of glucose and fat metabolism are affected by body weight. Therefore, the aim of the present study was to determine the relationships

between these two functional polymorphisms with anthropometric parameters, plasma insulin and lipild concentrations, and CRP in the general population and separately in subjects with a high or low BMI. In addition, the presence of gene-gene interactions was investigated.

\section{Subjects and methods}

\section{Subjects}

Subjects were selected from participants of the Cardiovascular Disease Risk Factor Monitoring Project and the Monitoring Project on Risk Factors for 
Chronic Disease (MORGEN-project) in the Maastricht area, which is located in the south of the Netherlands. These projects were carried out between 1987 and 1997 (16). All participants were re-approached in 1998 with a selfadministered questionnaire with questions an general health. A group of Caucasian subjects who had at the first examination and the postal reapproach a BMI between $18-24 \mathrm{~kg} / \mathrm{m}^{2}$ or between $26-40 \mathrm{~kg} / \mathrm{m}^{2}$ was selected based on the variants in the Gly972Arg polymorphism of the IRS-1 gene (17). Sixty percent of the subjects had the wildtype variant, forty percent were heterozygous or homozygous for this polymorphism. The low BMI group included 478 subjects and the high BMI group 538 subjects. None of the subjects had diagnosed diabetes. All these subjects were invited for a new physical examination. Sixty percent of the invitees participated. However, ten subjects had developed diabetes after the re-approach and were excluded. Data of 600 participants could be used for the present analysis of the TNF-Ca polymorphism. For the IL-6 polymorphism data from 596 subjects were used, as for four subjects not enough DNA was available. Participants filled in an informed consent form before the measurements started. The protocol was approved by the Medical Ethical Committee of TNO Prevention and Health, Leiden.

\section{Clinical measurements}

After an overnight fast, subjects were first weighed without shoes to the nearest $0.1 \mathrm{~kg}$. Waist and hip circumferences were then measured to the nearest $0.1 \mathrm{~cm}$ and height was measured without shoes to the nearest $0.1 \mathrm{~cm}$. Blood was drawn into a $10 \mathrm{ml}$ vacuum tube containing $K_{3}$ EDTA (Belliver industrial estate, Plymouth, UK). The subjects were sent a general health questionnaire, which was handed in at the physical examination. This questionnaire included questions about cigarette smoking, alcohol consumption and physical activity. Subjects were classified as cigarette smokers or non-simokers. Alcohol consumption was categorized as follows: no alcohol, between 0 and 1 glass of alcohol a day, between 1 and 3 glasses of alcohol a day, and more than three glasses of alcohol a day. Bouts of exercise, like biking or gardening were included to assess physical activity if they lasted 30 minutes per day or more. Subjects who reported such activities on three or more days a week were considered to be physically active. All other subjects were classified as non-active. 


\section{Laboratory measurements}

DNA was extracted from buffy coats by proteinase $K$ digestion and phenol extraction (18). The G174C polymorphism in the $\mathrm{LL}-6$ gene was determined using the conventional polymerase chain reaction (PCR), Lwe-l restriction enzyme analysis and agarose gel electrophoresis as described by Fishman et al (10).

The G308A polymorphism in the TNF- $\alpha$ gene was determined using the conventional PCR, NCo-I restriction enzyme analysis and agarose gel electrophoresis as described by Fernandez-Real et al (15). EDTA plasma was used to measure total cholesterol (TC), TG, and HDL-C concentrations after a dextran sulfate- $\mathrm{Mg}^{2 *}$ precipitation by enzymatic methods (Boehringer Mannheim, Germany). If TG concentrations were below $4.5 \mathrm{mmol} / \mathrm{L}$, low density lipoprotein cholesterol (LDL-C) was calculated by using the friedewald equation (19). Plasma glucose concentrations were measured with a commercially available kit (Roche Diagnostica, Basel, Switzerland and WAKO, Neuss, Germany). High sensitive CRP concentrations were measured with an ELISA kit (Mercodia, Uppsala, Sweden and DAKO, Glosstrup, Denmark). Insulin concentrations were determined with a sensitive ELISA kit with crossreactivity with C-peptide and proinsulin less than $0.01 \%$ (Mercodia, Uppsala, Sweden). Proinsulin was also measured with an ELISA kit (Mercodia, Uppsala, Sweden). Insulin resistance was calculated with a homeostasis model assessment for insulin resistance $\left(\mathrm{HOMA}_{\mathbb{R}}\right)(20)$.

\section{Statistical analysis}

A Kolmogorov-Smirnov test was performed to test normality of the data. Concentrations of CRP, glucose, proinsulin, TG, and insulin, and HOMA were not normally distributed, but were after a log transformation. Both polymorphisms were in Hardy-Weinberg equilibrium and were not related to the IRS-1. polymorphism. Differences between the polymorphism groups in subject characteristics were examined with analysis of variance (ANOVA) or the chi-square test. The relationships of the polymorphisms with metabolic risk markers were studied with ANOVA adjusted for age and sex. Data are expressed as mean \pm standard deviations (SD) or geometric means (antilogged SD). A two-tailed value of $p<0.05$ was considered to be statistically significant. All analyses were performed using SPSS; PC release 10.0. 


\section{Results}

The study population included 273 men and 327 women from 26 to 71 years (mean age $52.6 \mathrm{yrs}$ ). The mean BMI was $31.2 \mathrm{~kg} / \mathrm{m}^{2} \pm 2.99 \mathrm{~kg} / \mathrm{m}^{2}$ in the high BMI group $(n=304)$ and $21.9 \mathrm{~kg} / \mathrm{m}^{2} \pm 1.41 \mathrm{~kg} / \mathrm{m}^{2}$ in the low BMI group $(n=296)$.

\section{IL-6 polymorphism}

The prevalence of the IL-6 $174 C C$ genotype was $12.4 \%$, the GC genotype was present in $49.2 \%$, and $38.4 \%$ of the subjects had the $G G$ genotype. The prevalences did not differ between the low and high BMI group or between the IRS-1 polymorphism. Therefore, the primary analyses included the total study population. Age, sex, alcohol consumption, smoking, and physical activity were comparable between the variants of the $1 \mathrm{~L}-6$ polymorphism (table 4.1). The IL-6 polymorphism was significantly associated with waist to hip ratio (table 4.2). Subjects with the $C C$ genotype had a waist to hip ratio of 0.85 compared to 0.88 in subjects with the $G C$ and $G G$ genotype $(p=0.049)$. After stratification for sex there was a significant effect of the polymorphism in men ( $p=0.051)$, but not in women $(p=0.540)$. The difference in waist to hip ratio between the genotype groups was only evident in the high $\mathrm{BMl}$ group as is seen in figure $4.1(p=0.018)$. The difference between the $C C$ and $G G$ variant in the high BMI group was 0.035 compared with a difference between both variants of 0.008 in subjects in the low BMI group. There were no significant associations between the IL-6 polymorphism with other metabolic variables neither in the total group nor in the high and low BMl group separately.

Table 4.1:

Subject characteristics according to the $G 174 C$ polymorphism in the $1 L-6$ gene

\begin{tabular}{lllll}
\hline & $G C(n=229)$ & $G C(n=293)$ & $c c(n=74)$ & $p-v a l u e$ \\
\hline Age $(y r)$ & $52.4 \pm 9.70$ & $53.0 \pm 10.0$ & $52.2 \pm 10.3$ & 0.711 \\
Men \% & 44.1 & 47.8 & 43.2 & 0.630 \\
Alcohol (\% yes) & 72.7 & 77.5 & 77.5 & 0.437 \\
Smoking (\% yes) & 28.6 & 28.6 & 32.4 & 0.792 \\
Physical activity (\% high) & 62.3 & 64.0 & 65.3 & 0.878 \\
\hline
\end{tabular}

Values are means $\pm S 0$ or percentages. ANOVA was used for statistical analyses. 


\section{Table 4.2:}

Differences in metabolic risk markers according to the G174C polymorphism in the $1 \mathrm{~L}-6$ gene

\begin{tabular}{|c|c|c|c|c|}
\hline 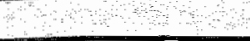 & $\operatorname{col}(n=229)$ & $\operatorname{coc}(n=293)$ & $\operatorname{cc}(n=74)$ & p value \\
\hline BMI $\left(\mathrm{kg} / \mathrm{m}^{2}\right)$ & $26.6 \pm 5.00$ & $26.8 \pm 5.00$ & $26.1 \pm 5.00$ & 0.540 \\
\hline Waist to hip ratio & $0.88 \pm 0.08$ & $0.88 \pm 0.09$ & $0.85 \pm 0.08$ & 0.049 \\
\hline Insulin (pmol/L) & $45.0(1.76)$ & $41.8(1.75)$ & $39.8(1.77)$ & 0.188 \\
\hline Proinsulin (pmol/t) & $6.81(2.12)$ & $7.03(2.12)$ & $6.45(2.10)$ & 0.660 \\
\hline Glucose (mmal/h) & $5.27(1.13)$ & $5.26(1.13)$ & $5.12(1.13)$ & 0.212 \\
\hline HOMA & $1.75(1.87)$ & $1.63(1.87)$ & $1.51(1.87)$ & 0.159 \\
\hline $\mathrm{TC}(\mathrm{mmol} / \mathrm{L})$ & $5.31 \pm 0.95$ & $541 \pm 0.96$ & $5.32 \pm 0.95$ & 0.422 \\
\hline HDL-C (mmol/L) & $1.28 \pm 0.33$ & $1.24 \pm 0.32$ & $1.31 \pm 0.32$ & 0.234 \\
\hline TG (mmol/ll) & $1.08(1.79)$ & $1.11(1.79)$ & $1.07(1.78)$ & 0.776 \\
\hline CRP (mg/L) & $2.10(2.21)$ & $2.12(2.21)$ & $2.07(2.21)$ & 0.976 \\
\hline
\end{tabular}

Values are age and sex adjusted means \pm SD or geometric means (anti-logged SD). ANOVA WaS used for statistical analyses adjusted for age and sex.

\section{Figure 4.1:}

Waist to hip ratio according to the different variants of the $1 \mathrm{~L}-6$ polymorphism in the high and low BMI group

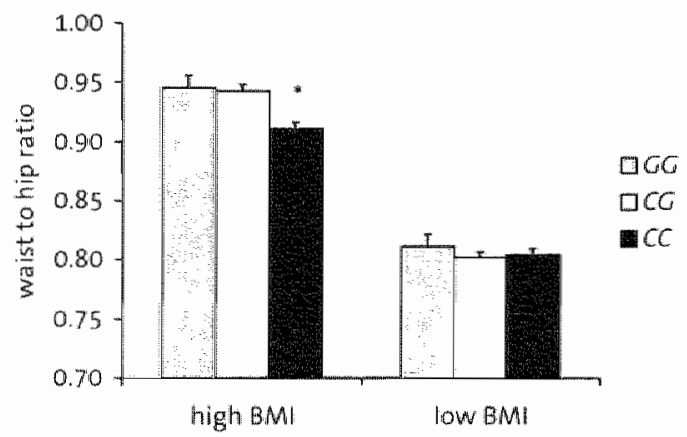

Values are means \pm standard errors (SE). ANOVA was used for statistical analyses adjusted for age and sex. "P<0.05. Subjects in the high BMI group had a BMI between $26-40 \mathrm{~kg} / \mathrm{m}^{2}$ and subjects in the low BMI group had a BMI between $18-24 \mathrm{~kg} / \mathrm{m}^{2}$.

\section{TNF- $\alpha$ polymorphism}

The TNF-a $3086 G$ genotype was present in $68.7 \%$ of the subjects, $28.0 \%$ were heterozygous and homozygosity for the rare allele of the TINF-a polymorphism (AA genotype) was found in $3.3 \%$ of the participants. The prevalences did not differ according to the IRS-1 polymorphism or between the high and low BMI group ( $3.6 \%$ AA in high BMI group versus $3.0 \%$ in low BMI group), and the 
groups were combined for the primary analyses. No significant differences in age, sex, alcohol consumption, smoking, and physical activity were seen between the different variants of the TNF-a polymorphism, although alcohol consumption seems to differ between subjects with the AA genotype versus the $G A$ and $G G$ genotype (table 4.3). However, results were not different after adjusting for alcohol consumption. TG concentrations were significantly different between the genotype groups $(p=0.008)$ as seen in table 4.4 . Subjects with the AA genotype had significantly higher TG levels compared with subjects with the GG or GA genotype $(1.48 \mathrm{mmol} / \mathrm{L}$ versus 1.11 and 1.00 mmoll/L). These differences were more pronounced in the high $B M I$ group than in the low BMI group (figure 4.2A). TG concentrations of subjects in the AA group were $1.18 \mathrm{mmol} / \mathrm{L}(p=0.001)$ and $1.05 \mathrm{mmol} / \mathrm{L}(p=0.003)$ higher than those in the $G A$ and $G G$ group respectively. In contrast, differences between the genotype groups in the low BMI group were not statistically different $(p=0.465)$. HDL-C concentrations did not significantly differ between the variants of the TNF- $\alpha$ polymorphism. However, after stratification for BMI, HDL -C concentrations were significantly lower in the $A A$ variant compared with the GA variant $(P=0.025)$ in the high $B M$ group, but not in the low $B M I$ group (figure 4.2B). No other significant associations between metabolic risik markers and the variants of the TNF- $\alpha$ polymorphism were found in the total group or in the high and low BMI group separately (table 4.4).

\section{Gene-gene interaction}

No association was found between the TNF- $\alpha$ and IL-6 polymorphism $(p=0.150)$. However, a gene-gene interaction was present with respect to TG concentrations ( $p$ for interaction $=0.026$ ). Subjects with the $G G$ variant of the IL-6 polymorphism and the AA variant of the TNF-a polymorphism $(n=8)$ had significantly higher TG concentrations compared with all other combinations of variants adjusted for age and sex $(3.04 \mathrm{mmol} / \mathrm{L}$ versus e.g. $1.04 \mathrm{mmol} / \mathrm{L}$ in

\section{Table 4.3:}

Subject characteristics according to the G308A polymorphism in the TNF- $\alpha$ gene

\begin{tabular}{lllll}
\hline & $G G(\mathrm{n}=412)$ & $G A(\mathrm{n}=168)$ & AA $(\mathrm{n}=20)$ & $\mathrm{p}$-value \\
\hline Age $(y \mathrm{r})$ & $52.2 \pm 10.2$ & $53.8 \pm 9.53$ & $50.8 \pm 7.92$ & 0.167 \\
Men \% & 44.4 & 47.6 & 50.0 & 0.718 \\
Alcohol (\% yes) & 74.7 & 75.5 & 95.0 & 0.120 \\
Smoking (\% yes) & 28.5 & 29.7 & 36.8 & 0.719 \\
Physical activity (\% high) & 62.8 & 64.9 & 70.0 & 0.746 \\
\hline
\end{tabular}

Values are means \pm SD or percentages. ANOVA was used for statistical analyses. 
IL-6 CC / TNF $\alpha$ GG carriers). The interaction between both polymorphisms with respect to HDL-C concentrations nearly reached statistical significance (p for interaction $=0.079)$. HDL-C concentrations were lower in subjects with the $G G$ variant of the $\mathbb{L}-6$ polymorphism and the $A A$ variant of the TNF $\alpha$ polymorphism compared with all other combinations (1.03 mmol/L versus e.g. $1.33 \mathrm{mmol} / \mathrm{L}$ in IL-6 CC / TNF- $\alpha$ GG carriers). Results were not different after adjusting for BMl.

\section{Table 4.4:}

Differences in metabolic risk markers according to the $6308 \mathrm{~A}$ polymorphism in the TNF-o gene

\begin{tabular}{|c|c|c|c|c|}
\hline 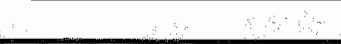 & $G G(n=412)$ & GA $(n=168)$ & $A M(D=20)$ & p-value \\
\hline BM $\left(\mathrm{kg} / \mathrm{m}^{2}\right)$ & $26.6 \pm 4.99$ & $26.4 \pm 5.00$ & $26.8 \pm 5.00$ & 0.905 \\
\hline Waist to hip ratio & $0.87 \pm 0.08$ & $0.87 \pm 0.08$ & $0.87 \pm 0.08$ & 0.957 \\
\hline Insulin (pmol/L) & $43.2(1.76)$ & $41.1(1.76)$ & $44.3(1.76)$ & 0.602 \\
\hline Proinsulin (pmol/L) & $6.97(2.11)$ & $6.47(2.11)$ & $7.61(2.10)$ & 0.450 \\
\hline Glucose (mmol/L) & $5.24(1.13)$ & $5.24(1.12)$ & $5.19(1.13)$ & 0.919 \\
\hline HOMAR & $1.68(1.86)$ & $1.59(1.06)$ & $1.66(1.87)$ & 0.640 \\
\hline TC (mmol/L) & $5.35 \pm 0.95$ & $5.39 \pm 0.95$ & $5.27+0.95$ & 0.796 \\
\hline HDLC (mmol/L) & $1.26 \pm 0.32$ & $1.30 \pm 0.32$ & $1.15 \pm 0.32$ & 0.133 \\
\hline $\mathrm{TG}(\mathrm{mmol} / \mathrm{L})$ & $111(1.76)$ & $1.00(1.78)$ & $1.48(1.78)$ & 0.008 \\
\hline $\operatorname{CRP}(\mathrm{m} g / \mathrm{L})$ & $2.11(2.19)$ & $2.11(2,21)$ & $2.02(2.22)$ & 0.970 \\
\hline
\end{tabular}

Values are age and sex adjusted means 1 SD or geometric means (anti-logged SO). ANOWA was used for statistical analyses adjusted for age and sex.

\section{Figure 4.2:}

TG (fig 4.2A) and HDL-C (fig 4.2B) concentrations according to the different variants of the TNF $\alpha$ polymorphism in the high and low BMI group

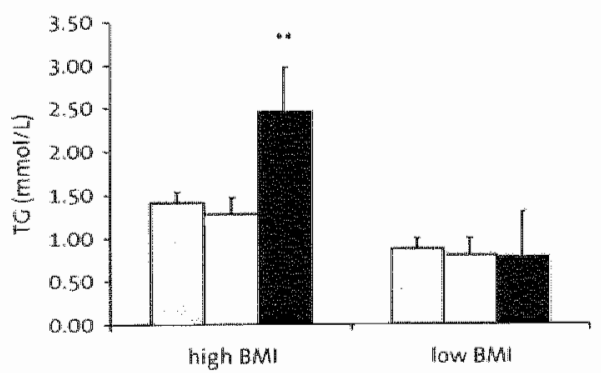

B

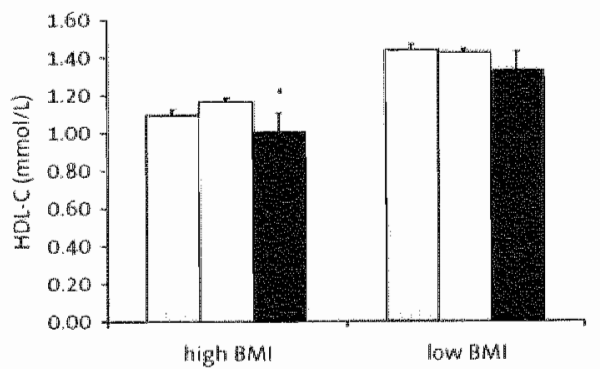

Values are geometrical means \pm antilogged SE (figure 4.2a) or means \pm SE (figure 4.2b). ANOVA was used for statistical analyses adjusted for age and sex. "P<0.05, "P<0.01. Subjects in the high BMI group had a BMI between $26-40 \mathrm{~kg} / \mathrm{m}^{2}$ and subjects in the low BMI group had a BMI between $18-24 \mathrm{~kg} / \mathrm{m}^{2}$. 


\section{Discussion}

We studied the impact of the IL-6 G174C and TNF-a G308A polymorphism in a subsample from a large population based cohort from the Netherlands (16). The subjects were selected randomly, stratified according to BMI (high or low) and presence of the IRS-1 Gly972Arg polymorphism. As the presence of the IL-6 or TNF-a polymorphism under study was not related to the IRS-1 polymorphism or the BMI classification, the samples were combined for the initial analyses.

Our results show that the CC variant of the $1 L-6$ polymorphism was associated with a reduced waist to hip ratio in the subjects with overweight, but not in subjects with a low BMI. Concerning the TNF-a polymorphism, subjects with the AA variant had higher TO levels compared to subjects with the GA or GG variant. This association was also more evident in the high BMll group. HDL-C concentrations did not significantly differ between the variants of the TNF- $\alpha$ polymorphism. However, after stratification for BMI, HDL-C levels were significantly lower in the $A A$ variant compared with the $G A$ and $G G$ variant in the high BMI group. Finally, a gene-gene interaction between both polymorphisms with respect to TG was found, indicating that the impact of the TNF-a AA genotype was especially clear among IL-6 CC carriers.

\section{L-6 polymorphism}

The prevalence of the CC variant in our population amounted to $12.4 \%$ and was slightly lower as compared with that of English subjects (18.3\%) (10). Fernandez-Real $(11,12)$ even reported a prevalence of $34.4 \%$ in a small sample from Spain. Possibly, some regional variation exists in Europe, in addition to the ethric variation observed by Fishman et al (10), but we need more data to confirm this.

The IL-6 polymorphism may be a functional polymorphism. When comparing constructs in a vector transfected into HeLa cells, Fishman et al (10) reported a 0.6 fold lower expression of the $-174 \mathrm{C}$ construct compared with the $-174 \mathrm{G}$ construct. In support, increased IL-6 concentrations in subjects with the $G$ variant of the polymorphism have been observed $(10,21)$. This suggests that subjects with the $G$ allele may have a more unfavorable risk profile for cardiovascular disease, as increased 1 L-6 concentrations are related to insulin resistance and lipid abnormalities (22).

Indeed, significant relationships between the $G$ allele and increased concentrations of fasting insulin, TG, free fatty acids and VLDL-TG have been observed in a small study population $(11,12)$. HDL.C levels tended to be lower (12). In contrast, we observed in a larger study population only a significant 
association between the IL- 6 CC variant and a reduced waist to hip ratio in overweight subjects, although there was a tendency for lower fasting insulin levels and $\mathrm{HOMA}_{\mathrm{IR}}$ index. The relationship between the $\mathbb{L}-6$ polymorphism and waist to hip ratio has not been reported before. However, Yudkin et al (23) observed a significant correlation between IL-6 levels and waist to hip ratio, which is in concordance with our study. Our finding is also corroborated by the recent observation that the IL- 6 GG variant is found more often among hyperadrogenic women, and that healthy women carrying the $G G$ variant had higher IL-6 levels as well as a tendency for higher testosterone concentrations, which is associated with a higher waist to hip ratio (21).

It should be noted that Humphries et al (24) observed a significant relationship between the $C C$ variant and an increased rather than decreased prevalence of coronary heart disease (CHD). Brull et al (25) also showed that the IL-6 response to stimuli such as coronary by-pass surgery is increased in subjects with the $C C$ variant. However, others reported reduced asymptomatic atherosclerosis (26) and CHD risk (27) in CC homozygotes. In addition, our metabolic data do not point at an increased risk for CHD.

\section{TNF- $\alpha$ polymorphism}

The prevalence in our population of the GG genotype of the TNF- $\alpha$ polymorphism was $68.7 \%, 3.3 \%$ had the $A A$ variant and $28.0 \%$ was heterozygous. These values are in good agreement with those of other investigators studying Caucasian populations (14, 28-30).

Using transfection studies, Wilson et al (31) showed that the presence of the $A$ allele increased TNF- $\alpha$ production in a human cell line as compared with the $G$ allele. In view of the role of TNF- $\alpha$ on obesity and insulin resistance relationships between the TNF- $\alpha$ polymorphism and metabolic parameters were hypothesized. Indeed, an association between the $A$ allele and insulin resistance was observed in Spanish overweight subjects (15).

in our study, there was an association between the rare $A A$ variant of the TNF $\alpha$ polymorphism with increased TG concentrations. Others $(14,1.5,32,33)$ have not found such an association. However, in two of these studies $(15,32)$ heterozygous and homozygous carriers of the $A$ allele were combined. This may have diluted this relationship, as we found no difference in TO concentrations between subjects with the more common GA genotype and the $G G$ genotype. Further, most of the studies have not stratified subjects for $B M I$. This may have obscured possible relationships, as in our study the relation with $T G$ concentrations with the $A A$ genotype was especially evident in the high BMI group. This suggests that in particular the combination of increased body weight with the presence of the AA genotype, two factors that increase TNF- $\alpha$ production, is related with increased TO concentrations. A 
relationship between TNF- $\alpha$ and lipid metabolism has been observed earlier, as treatment with recombinant TNF- $\alpha$ increased energy expenditure, plasma cortisol and TG levels, and increased glycerol and non-esterified fatty acid (NEFA) turnover, suggesting increased whole body lipolysis and fat utilization (34).

We did not find an association between the C308A genotype and other metabolic markers such as insulin and glucose concentrations. Other studies thowever, reported increased fasting insulin concentrations, but comparable glucose concentrations in carriers of the $A$ allele of this TNF- $\alpha$ polymorphism (15, 33, 35). TNF- $\alpha$ has important effects on insulin signaling (36). TNF- $\alpha$ infusion causes insulin resistance and elevation of plasma NEFA and TG, and induces gene expression favoring adipose tissue NEFA release (37). Thus, an association between the TNF- $\alpha$ polymorphism and insulin concentrations seems to be likely. However, also others failed to find an association $(14,32)$, and studies including more exact measurements of insulin or including more subjects homozygous for the A allele, should shed more light on this issue.

\section{Gene-gene interaction}

The relationship between the AA variant of the TNF- $\alpha$ polymorphism on TG levels was most pronounced in subjects with the GG variant of the IL- 6 polymorphism. This observation may be plausible based on the results of transfection studies $(10,31)$, as these subjects may have the highest TNF- $\alpha$ and IL-6 expression. Indeed, IL- 6 is known to be induced by TNF- $\alpha$ (38). On the other hand, it is now more often realized that early publications tend to report stronger genetic associations than later publications, and that through e.g. publication bias the predisposition conferred by a genetic polymorphism may be overestimated (39). Our finding of interaction between the genotypes with respect to fasting TG is therefore a finding that needs verification.

\section{Conclusion}

Our study illustrates the impact of the IL-6 174 and TNF- $\alpha 308$ genotypes in the general Dutch population. In our population with high BMI, the IL-6 polymorphism was related to higher waist to hip ratio and the TNF- $\alpha$ polymorphism to higher TG and lower HDL-C concentrations. Such relationships were not observed in our low BMI group. This suggests that effects of these polymorphisms depend on BMI. The genetic variants may interact with respect to fasting TG levells. 


\section{Acknowledgements}

The study was supported by a grant from the Netherlands Organization for Scientific Research (NWO), grant number 980-10-006, Nutrition and Chronic Diseases. We thank Dr B. Hoebee and Dr E. van Schothorst from the Laboratory of Effects Research, National Institute for Public Health and the Environment, Bilthoven, the Netherlands, for the genotyping of TNF- $\alpha$. We are indebted to J. Stegen and $M$. Kunen for their laboratory assistance. We gratefully acknowledge T. Heemskerk and S. Ebbing for their contribution in the screening. We thank Prof. Dr C. Kluft from TNO Gaubius, Leiden for analyzing proinsulin and CRP. 


\section{References}

ait.

2.

3.

4.

8.

9.

Fried SK, Bunkin DA, Greenberg AS. Omental and subcutaneous adipose tissues of obese subjects release interleukin 6 : depot difference and regulation by glucocorticoid. $J \mathrm{Clin}$ Endocrinol Metab 1998;83:847-850.

Hotamisligil CS, Arner P, Caro JF, Atkinson RL, Spiegelman BM. increased adipose tissue expression of tumor necrosis factor-alpha in human obesity and insulin resistance. I clin Invest 1995:95:2409-2415.

Hauner $H_{4}$. Petruschke T, Russ M, Rohrig $K$, Eckel I. Effects of tumour necrosis factor alpha (TNF alphia) on glucose transport and lipid metabolism of newly-differentiated human fat celis in cell culture. Diabetologia 1995;38:764-771.

Van 5nick J. Interleukin-6: an overview. Annu Rew Immunol 1990;8:253-278.

Hardardottir I, Crunfeld C, Feingold KR. Effects of endotoxin and cytokines on lipid metabolism. Curr Opin Lipidol 1994;5:207-215.

Stouthard IM, Romijn JA, Wan der Poll T, et al. Endocrinologic and metabolic effects of interleukin-6 in humans. Am J Physiol 1995;268:E813-E819.

Pekala PH, Kawakami $M$, Angus CW, Lane MD, Cerami A. Selective inhibition of synthesis of enzymes for de novo fatty acid biosynthesis by an endotoxin-induced mediator from exudate cells. Proc Natl Acad Sci U 5 A 1983;80:2743-2747.

. Hotamisligil GS, Peraldi P, Budavari A, Ellis R, White MF. IR5-1-mediated inhibition of insulin receptor tyrosine kinase activity in TNF-a and obesity-induced insulin resistance. Science 1996:271:665-66:8.

Mohamed-Ali V, Pinkney JH. Coppack SW. Adipose tiss.ule as an endocrine and paracrine organ. Int J Obes 1998;2:1145-1158.

10. Fishman $D$, Faulds $G$, Jeffery $R_{n}$ et al. The effect of novel polymorphisms in the interleukin-6 (IL-6) gene on IL-6 transcription and plasma IL-6 levels, and an association with systemic-onset juvenile chronic arthritis. J Clin Invest 1998;102:1369-1376.

1. Fernandez-Real $J M$, Broch $M$, Vendrell J, et al. Interleukin-6 gene polymorphism and insulin sensitivity. Diabetes 2000;49:517-520.

2. Fernandez-Real $J M$, Broch $M$, Vendrell J, Richart $C$, Ricart W. Interleukin-6 gene polymorphism and lipid abnormalities in healthy subjects. I Clin Endocrinol Metab 2000;85:1334*1339.

3. Wilson AG, di Glovine FS, Blakemore Al, Duff GW. Single base polymorphism in the human tumour necrosis farctor alpha (TNF alpha) gene detectable by Ncol restriction of PCR product. Hum Mol Genet 1992;1:353.

4. Hoffstedt J, Eriksson P, Hellstrom L, Rossner S, Ryden M, Arner P. Excessive fat arccumulation is associated with the TNF alpha-308 G/A promoter polymorphism in women but not in men. Diabetologia 2000;43:117-120.

5. Fernandez-Real $M_{i}$ Gutierrez $C_{\text {, }}$ Ricart $W_{\text {, }}$ et al. The TNF-all pha gene Nco I polymorphism influences the rellationship among insulin resistance, percent body fat, and increased serum leptin levels. Diabetes 1997:46:1468-1472.

6. van Dam RM, Boer JM, Feskens EJ, Seidell JC. Parental history of diabetes modifies the association betweer abdominal adiposity and hyperglycemia. Diabetes care 2001;24:1454-1459.

7. Jellema A, Feskens EMM, Mensink RP, Saris WHM, Kromhout D. Cardiovascular risk markers in an overweight and normal weight population with oversampling of carriers of the IRS-1 972.Arg variant (Abstract). Atherosclerosis 2002,3 (suppl 2):133. 
18. Miller $S A$, Dykes DD, Polesky HF. A simple sialting out procedure for extracting DMA from human nucleated cells. Nucleic Acids Res 1988:16:1215.

19. Firiedewald WT, Levy R. Fredrickson DS. Estimation of the concentration of low density lipopratein cholesterol in plasma, without use of the preparative ultracentrifuge. Clin Chem $1972 ; 18: 499-5102$

20. Matthews DR, Hosker JP, Rudenski AS, Naylor BA, Treacher DF, Turmer RC. Homeostasis model assessment: insulin resistance and betawell function from fasting plasma glucose and insulin concentrations in man. Diabetologia 1985:28:412-419.

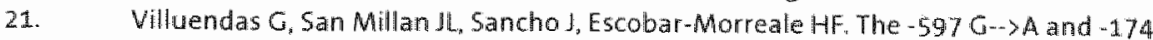
$G-->C$ polymorphisms in the promoter of the $1 \mathrm{~L}-6$ gene are associated with Ihyperandrogenism. J Clin Endocrinol Metab 2002;87:1134-1141.

22. Vudkin 15, Kumari M, Humphries. SE, Mohamed-Ali V. Inflammation, obesity, stress and coronary heart disease: is inteleukin-6 the link? Atherosclerosis 1999:148:209-214.

23. Yuikin JS, stehouwer CDA, Emeis J), Coppack SW. C-reactive protein in healthy subjects: Associations with obesity, insulin resistance, and endothelial dysfunction. Arterioscler Thromb Vasc Biol 1999:19:972-978.

24. Humphries SE, Luong LA, Ogg MS, Hawe E, Miller GJ, The interteukin-6 -174 G/C promoter polymorphism is associated with risk of coronary heart disease and systolic blood pressure in healthy men. Eur Heart 1 2001:22:2243-2252.

25. Brull DJ, Montgomery HE, Sanders 1 , et al. Interleukin-6 gene $-174 \mathrm{~g}-3 \mathrm{C}$ and $-572 \mathrm{~g}>\mathrm{C}$ promoter polymorphisms are strong predictors of plasma interleukin-6 levels after coronary artery bypass surgery. Arterioscler Thromb Vasc Biol 2001:21:1458-1463.

26. Rauramaa $R$, Vaisanen $5 B$, Luong $L A$, et al. Stromelysin-1 and interleukin-6 gene promoter polymorphisms are determinants of asymptomatic carotid artery atherosclerosis. Anterioscler Thromb Vasc Biol 2000;20:2657-2662.

27. Basso F, Lowe GD, Rumley A, McMahon AD, Humphries SE. Interleukin-6 -174G->C polymorphism and risk of coronary heart disease in West of Scotland coronary prevention study (WOSCOPS). Arterioscler Thromb Vasc Biol 2002;22:599-604.

28. Walston $\downarrow$, Seibert M, Yen C-J, Cheskin U. Anderser RE. Tumor necirosis factor-alpha-238 and -308 polymorphisms do niot associate with traits rellated to obesity and insulin resistance. Diabetes $1999 ; 48: 2096-2098$.

29. Romeo 5 , sentinelli $\mathbb{F}$, Capici $F_{\text {, }}$ et al. The $G$-308A variant of the Tumor Necrosis Falctoralpha (TNF-alpha) gene is not associated with obesity, insulin resistance and body fat distribution. BMC Med Genet $2001 ; 2: 10$.

30. Brand E, schorr U, Kunz I, et all. Tumor necrosis factot-alpha-308 G/A polymorphism in obese Caucasians. Int I Obes Relat Metab Disord 2001:25:581-585.

31. Wilson AG, Symons JA, MCDOwell TL, MCDevitt HO, Duff GW. Effects of a polymorphism in the human tumor necrosis factor allpha promoter on transcriptional activation. Proc Natl Acad SCIUSA 1997:94:3195-3199.

32. Lee SC, Pu YB, Thomas GH, et al. Tumor necrosis factor alpha gene Gm308A polymorphism in the muetabolic syndrome. Metabolism 2000,49:1021-1024.

33. Dalziel B, Gosby AK, Richman RM, Bryson JM, Caterson ID. Association of the TNF alpha $308 \mathrm{G} / \mathrm{A}$ promoter polymorphism with insulin resistance in obesity. Obes Res $2002 ; 10: 401 ; 407$.

34. Starnes HF, Jr. Warren RS, Jeevanandam $M$, et al. Tumor necrosis factor and the acute metabolic response to tissue injury in man. J Clin lrivest 1988:82:1321 1325 .

35. Nicaud V, Raoux 5, Poirier 0 , Cambien F, ORelly DS, Tiret L. The TNFalpha/G 308A polymorph:sm influences insulin sensitiwity in offs pring of patients with coronary heart disease. The European Atheroselerosis Research Study I1. Atherosclerosis 2002:161:317. 325. 
36. Hotamisligil GS. The role of MNF-a and TNF receptors in obesity and insulin resistance. I intern Med 1999;245:621-625.

37. Ruan $H$, Miles PD, Ladd CM, et al. Profiling gene transcription in vivo reveals adipose tissue as an immediate target of tumor necrosis factor-alpha: implications for insulin resistance. Diabetes 2002:51:3176-3188.

38. Pang G, Couch L, Batey R, Clancy R, Cripps A. GM-CSF, IL-1 alpha, L- 1 beta, IL-6, IL-8, IL10, KCAM-1 and VCAM-1 gene expression and cytokine production in human duodenal fibroblasts stimulated with lipopolysaccharide, L-1 alpha and TNF-alpha. Clin Exp Immunol 1994:96:437-443.

39. Lannidis IP, Ntzani EE, Trikalinos TA, Contopoulos.loannidis DG. Replication validity of genetic association studies. Nat Genet 2001;29:306-309. 


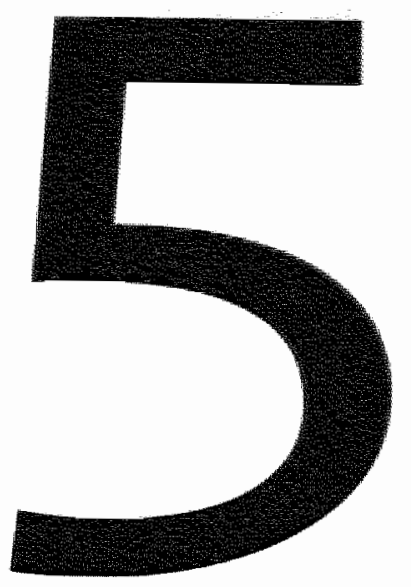

\section{Effects of fish oil and weight reduction on subcutaneous adipose tissue lipolysis in the fasting and postprandial state}

Annemarie Jellema ${ }^{1,2}$, Ellen E. Blaak ${ }^{1}$, Ronald P. Mensink ${ }^{1}$, Peter Arner $^{3}$, Gerrit J. Kemerink ${ }^{4}$, Edith J.M. Feskens ${ }^{2}$, Wim H.M. Saris ${ }^{1}$

1. Department of Human Biology, University of Maastricht, Maastricht, The Netherlands

2. Centre for Nutrition and Health, National Institute for Public Health and the Environment, Bilthoven, The Netherlands

3. Department of Medicine, Karolinska Institute, Huddinge University Hospital, Huddinge, Sweden

4 Department of Nuclear Medicine, University Hospital Maastricht, Maastricht, The Netherlands 


\section{Abstract}

Background: The beneficial effects of weight reduction and fish oil on metabolic changes during the fasting and postprandial phase may be related to a decrease in adlipose tissue lipolysis, possibly due to a better insulin sensitivity.

Methods: To examine this, eleven obese men with a body mass index (BM) between 30 and $35 \mathrm{~kg} / \mathrm{m}^{2}$ received for two periods of six weeks in random order control capsules or fish oil capsules providing daily $0.60 \mathrm{~g}$ eicosapentaenoic acid (EPA) and $0.51 \mathrm{~g}$ docosahexaenoic acid (DHA). Eight of them also participated in a weight reduction study. After a weight reduction period of six weeks and a stabilization period of two weeks, subjects lost on average $9.36 \mathrm{~kg}$ of body weight. At the end of each period, a postprandial test took place, during which subcutaneous abdominal adipose tissue lipolysis was measured with the microdialysis technique.

Results: Compared with control values, the overall glycerol release across the adipose tissue was significantly increased after fish oil supplementation $(p=0.005)$ especially during the late postprandial period, suggesting an increased subcutaneous abdominal adipose tissue lipolysis. Weight reduction decreased circulating glycerol and non-esterified fatty acids (NEFA) concentrations $(p<0.001)$ compared to control values, indicating a decreased whole body lipolysis during basal and postprandial conditions. Subcutaneous adipose tissue lipolysis tended to be lower initially, but was significantly increased during the late postprandial period ( $p$ for interaction=0.044) after weight reduction.

Conclusions: A decreased subcutaneous abdominal adipose tissue lipolysis during the postprandial phase cannot explain the effects of fish oil and weight loss on lipid and glucose metabolism. In fact, subcutaneous abdominall adipose tissue lipolysis was increased in the late postprandial period, although insulin sensitivity seemed to be improved. 


\section{Introduction}

It is well recognized that obese subjects have increased fasting and prolonged postprandial elevations of circulating NEFA (1). This may lead to adverse metabolic events, such as sustained very low density lipoprotein (VLDL) production, impaired clearance of triglyceride-rich lipoproteins (TRL), low high density lipoprotein cholesterol (HDL-C) concentrations, hyperglycemia and hyperinsulinaemia, all factors associated with an increased risk for the development of type 2 diabetes mellitus and coronary heart disease (CHD) (2, 3). The changes in NEFA metabolism have been ascribed to an increased release of NEFA from the enlarged adipose tissue mass due to increased basal lipolysis and a reduced responsiveness of hormone-sensitive lipase (HSL) to insulin (4-6).

Besides weight reduction $(7,8)$, changes in dietary fatty acid composition may reverse some of the metabolic disturbances seen in obesity. In particular, fish oil may be beneficial as several epidemiological studies have found an inverse relationship between fish oil consumption and the incidence of type 2 diabetes (9) and CHD (10-12). The beneficial effects of fish oil may be related to its content of long chain n-3 polyunsaturated fatty acids (n-3 LCPUFA) (13). N-3 LCPUFAs may beneficially affect lipid and glucose metabolism (14) by lowering fasting and postprandial plasma triglyceride (TG) concentrations (15-18) and improving insulin sensitivity (19). One of the possible mechanisms underlying the beneficial effects of weight reduction and fish oil may be related to a suppression of adipose tissue lipolysis. Using the microdialysis technique, studies in fasting subjects have indeed demonstrated that obesity is associated with increased NEFA concentrations and a normal subcutaneous adipose tissue lipolysis per unit fat mass (20), but effects during the postprandial period or of fish oil intervention are not known. The aim of this study was therefore to compare the effects of fish oil and weight reduction on subcutaneous adipose tissue lipolysis in the fasting and postprandial period.

\section{Subjects and methods}

\section{Subjects}

Eleven obese men with a $\mathrm{BMI}$ between 30 and $35 \mathrm{~kg} / \mathrm{m}^{*}$ and a mean age ( \pm standard deviation (SD)) of $59 \pm 9$ years participated in the fish oil intervention study, while eight of them also agreed to participate in the weight reduction study. Before the start of the study, the men were invited for 
two screening visits. At that time, mean total cholesterol (TC), HDL-C and TG concentrations were respectively $5.72 \pm 0.93 \mathrm{mmol} / \mathrm{L}, 1.00 \pm 0.19 \mathrm{mmol} / \mathrm{L}$, and $1.53 \pm 0.60 \mathrm{mmol} / \mathrm{L}$. All subjects had plasma cholesterol levels below the cut off levels according to the Dutch Cholesterol Consensus (21). Three of the subjects had characteristics of disturbed glucose metabolism (fasting glucose concentrations between $6.1 \mathrm{mmol} / \mathrm{L}$ and $9.3 \mathrm{mmol} / \mathrm{L}$ ). None of the subjects used blood glucose lowering medication or any other medication known to influence the measurements and all were weight stable during the three months preceding the study. Their systolic and diastolic blood pressure were respectively below $160 \mathrm{mmHg}$ and $95 \mathrm{mmHg}$. Further, the participants did not change their physical activities and smoking habits during the study. The subjects were given a detailed description of the study before they gave their informed consent. The study has been carried out in accordance with the Declaration of Helsinki and was approved by the Ethics Committee of the University of Maastricht.

\section{Study protocol}

\section{Fish oil study}

The fish oil study was a double-blind cross-over study consisting of two periods of six weeks, interrupted by a wash-out period of at least two weeks. During the intervention periods the subjects received in random order fish oil or contral capsules. At the start of the study, the men filled in a food frequency questionnaire, which allowed us to estimate their energy and nutrient intakes. Based on these results, they were instructed by an experienced dietician to change their eating pattern to a recommended diet throughout the study. This diet provided 30-35 percent of energy (EN\%) of fat, while the maximum intake from saturated plus trans fatty acids was 10 EN\%. The amount of carbohydrates was 55 EN\% at an intake of mono- and disiaccharides below $25 \mathrm{EN} \%$. The daily intake of cholesterol was less than $33 \mathrm{mg} / \mathrm{MJ}$ and of fibre $3 \mathrm{~g} / \mathrm{ML}$ or more.

The odorless purified fish oil supplement (Marinol C45, Loders Croklaan, Wormerveer, the Netherlands) contained $45 \%$ omega- 3 fatty acids, mainly EPA (C2O:5 n-3; 20\%) and DHA (C22:6n-3; 17\%). The control capsules contained high-oleic sunflower oil, which contained mainly oleic acid (C18:1 n-9; 80\%). subjects were instructed to take three capsules with a cold drink in the morning before breakfast and three capsules in the evening before dinner. In this way, subjects consumed $1.35 \mathrm{~g}$ omega- 3 fatty acids per day from the supplements during the fish oil period. Subjects visited the department every week and were then provided with more capsules than needed for that period. Returned capsules were counted to check compliance. 
Fasting blood samples were taken in weeks $0,3,5$ and 6 of each period. Body weights were recorded at each visit. Body composition was determined at the end of the first period using a dual-energy $X$-ray bone densitometer (DEXA) (Hologic QDR 4500 Elite, Hologic Europe Services, Zaventem, Belgium). Subjects recorded in diaries any signs of illness, medication used and any deviations from the protocol.

At the end of each intervention period of six weeks, subjects had to fill in a food questionnaire and a day of measurements took place. After an overnight fast of at least 12 hours, subjects arrived at the laboratory at 8 a.m. Subjects had to lay down and a cannula was inserted into the left dorsal hand vein, which was warmed in a hot-air box, circulating at $60^{\circ} \mathrm{C}$, for at least 30 minutes before the sampling of arterialized venous blood. Arterialized blood instead of venous blood was sampled to determine arterio-venous differences, which will be described elsewhere. After superficial skin anesthesia (EMLA, AstraZeneca, Zoetermeer, The Netherlands), a microdialysis catheter (CMA 60, CMA microdialysis, Solna, Sweden) with a semipermeable polyamide membrane was inserted into the periumbilical subcutaneous adipose tissue $5-8 \mathrm{~cm}$ left of the umbilicus. Probes consisted of a dialysis tubing ( $30 \times 0.6 \mathrm{~mm}, 20 \mathrm{kDa}$ cut-off) fasted to the end of a double lumen polyamide cannula. The perfusion fluid entered the probe through the inner cannula, passed down to the tip of the probe, streamed upwards in the space between inner cannula and outer dialysis membrane and left the probe through the outer cannula via a side arm from which it was collected. The catheters were connected to a microinfusion pump (Harvard Apparatus, South Natick Mass, USA) and were continuously perfused with Ringer's solution (147 mmol// $\mathrm{Na}^{+}, 4 \mathrm{mmol} / / \mathrm{K}, 2.20 \mathrm{mmol} / \mathrm{l} \mathrm{Ca}{ }^{2+}, 156 \mathrm{mmol} / / \mathrm{Cl}$ (Baxter, Uden, The Netherlands)) at a flow rate of $0.3 \mu \mathrm{l} / \mathrm{min}$. In adipose tissue, ${ }_{100-150 \mu l}{ }^{133} \mathrm{Xe}$ with a maximum of $20 \mathrm{MBq}$, was injected percutaneously with a very fine needle into the subcutaneous tissue in the abdominal side next to the microdialysis catheter to measure the blood flow in the adipose tissue. After a 45 minutes equilibration period, disappearance of ${ }^{133} \mathrm{Xe}$ was monitored continuously with a Csl crystal detector (Oakfield Instruments, Eynsham, UK). This $\gamma$-counter collected continuous 20 sec readings (22).

After a 60 minutes equilibration period, three fasting blood samples were taken within half an hour ( $t=-30, t=-15$ and $t=0 \mathrm{~min}$ ) before a standardized meal. A fasting diallysate sample was taken at $t=-15$ min. After the third fasting blood sample at $t=0$ min subjects were given a milkshake, which they had to drink within 10 minutes. The shake provided $3.0 \mathrm{MJ}$ of which $32.6 \mathrm{EN} \%$ from carbohydrates, $5.1 \mathrm{EN} \%$ from protein, and $62.3 \mathrm{EN} \%$ from fat $(40.0 \mathrm{EN} \%$ saturated fat, 40.4 EN\% monounsaturated fat, 19.6 EN\% polyunsaturated fat and no fish oil). Thereafter, every 30 minutes arterialized and deep venous blood samples were drawn for determinations of insulin, NEFA, TG, TC, 
glucose, and free glycerol during a five-hour period. Dialysate samples were collected in the middle of each 30 -minute collection period for glycerol determinations.

\section{Weight reduction study}

After the fish oil study eight subjects continued with the weight reduction study that lasted eight weeks. During the first four weeks of the diet period the subjects followed a very low calorie diet (VLCD) (Modifast Novartis, Breda, The Netherlands) of $2 \mathrm{M} / \mathrm{day}$. This energy-restricted formula diet provided daily $52 \mathrm{~g}$ protein. $50 \mathrm{~g}$ carbohydrate, $7 \mathrm{~g}$ fat and $1.3 \mathrm{~g}$ sodium and a micronutrient content that meets the Dutch recommended daily intakes. Besides the shakes, the men were allowed to eat $250 \mathrm{~g}$ of vegetables and fruits (except of bananas) each day. In the fifth and 5 ixth weeks, subjects consumed an energy-restricted diet of approximately $4.2 \mathrm{MJ} / \mathrm{day}$ with a recommended composition (23). During weeks seven and eight subjects returned to weight-stable conditions. Body composition was determined using DEXA. At the end of the intervention period (week 8) a day of measurements, as described above, took place.

\section{Laboratory measurements}

EDTA plasma was used to measure TC and TG concentrations, (triglyceride, Boehringer Mannheim, Germany). Plasma concentrations of glucose (glucose, WAKO, Neuss, Germany), plasma NEFA concentrations (NEFA C, WAKO, Neuss, Germany) and plasma glycerol concentrations (glycerol, Boehringer, Mannheim, Germany) were measured with commercially avallable kits. Insulin concentrations were determined with a sensitive ELISA kit with crossreactivity with C-peptide and proinsulin less than $0.01 \%$ (Insulin ELISA, Mercodia, Uppsala, Sweden). Microdialysate glycerol to examine interstitial glycerol concentrations was measured with an enzymatic colorimetric method as described (24). Except for capsule count, the fatty acid profile of plasma phospholipids was determined to check compliance (25). Glycerol release across adipose tissue as a measure of subcutaneous adipose tissue lipolysis was calculated according to Fick's equation as described before (26). Conversion of interstitial into capillary venous plasma substrate concentration was performed using the equation previously reported by Blaak et al (27), where a permeability surface product area for glycerol of $5 \mathrm{ml} / \mathrm{min} / 100 \mathrm{~g}$ is used. The rate of disappearance of ${ }^{133} \mathrm{Xe}$ was determined over 45 minutes of fasting and during 20 minutes after each blood sampling as described (28). The adipose tissue blood flow (ATBF) was calculated by multiplying the slope of the decay pattern times the partition coefficient for 
the distribution of Xenon between the adipose tissue and blood. The partition coefficient was calculated according to a previously reported equation (28).

\section{Statistical analysis}

A Kolmogorov-Smirnov test was performed to test normality of the data. ATBF, glycerol release and insulin concentrations were not normally distributed, and were therefore log transformed for statistical analysis.

Fasting effects of fish oil and weight reduction were compared with control values using a paired t-test. The values obtained during the control period were used as baseline values for the weight reduction study. To compare responses between and within interventions, a three-way analysis of variance (ANOVA) with diet, time and subject number as factors was performed. For the fish oil study, the presence of carry-over effects was tested as described by Pocock et al (29). For the weight reduction study, this was tested by including a factor of the last treatment during the fish oil study (fish or control) into the model. Carry-over effects could not be demonstrated. A p-value of $p<0.05$ was regarded as statistically significant. All analyses were performed using SPSS; release 10.0.

\section{Results}

\section{Effects of the meal}

Results from the control period showed that insulin, glucose, NEFA and TG concentrations changed significantly in response to the meal $(p<0.001)$. Insulin concentrations increased sharply during the first hour of the experiment and gradually decreased during the last 3 hours (table 5.2 and 5.4).

Table 5.1:

Characteristics of the study population after the control and fish oil period $(n=11)$

\begin{tabular}{lccc}
\hline \multicolumn{1}{c}{} & control & fish oil & Pvalue \\
\hline Weight $(\mathrm{kg})$ & $96.7 \pm 8.72$ & $96.5 \pm 8.59$ & 0.654 \\
BMI $\left(\mathrm{kg} / \mathrm{m}^{2}\right)$ & $31.3 \pm 2.08$ & $31.3 \pm 1.82$ & 0.301 \\
Waist to hip ratio & $1.05 \pm 0.04$ & $1.05 \pm 0.03$ & 0.484 \\
Dietary intake (M/day) & $9.80 \pm 2.22$ & $9.70 \pm 1.51$ & 0.426 \\
\hline
\end{tabular}

Data are mean \pm SD. Statistical differences for diet were analyzed with paired $t$-test. 


\section{Figure 5.1:}

Interstitial and arterialized glycerol concentrations, adipose tissue blood flow, and glycerol release across adipose tissue in the fasting and postprandial period after fish oil and control supplementation

A

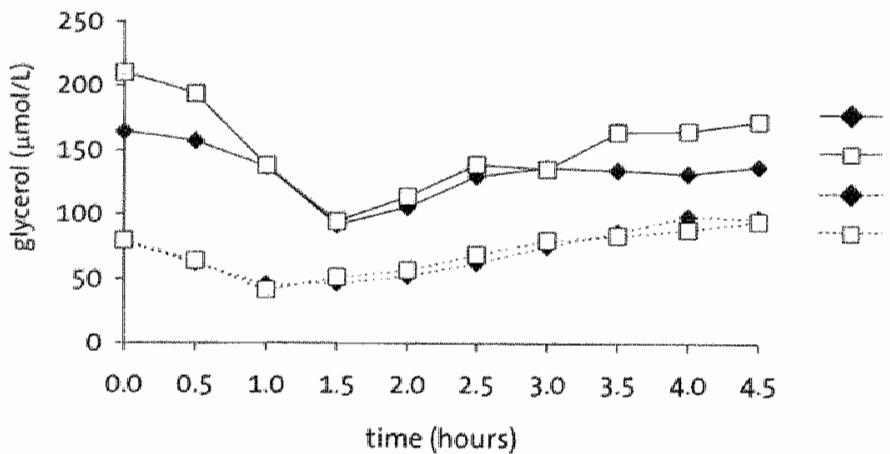

interstitivil control interstitial fish oil arterialized control arterialized fish oil

B time (hours)

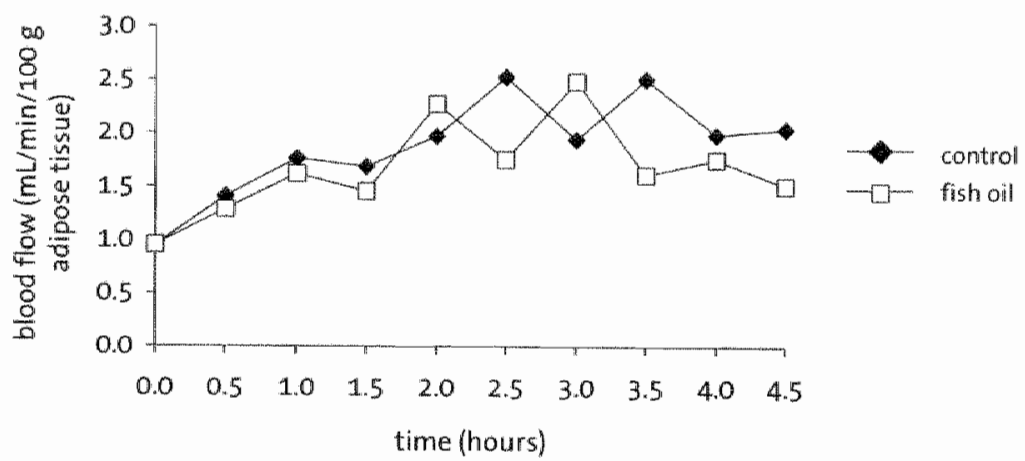

C

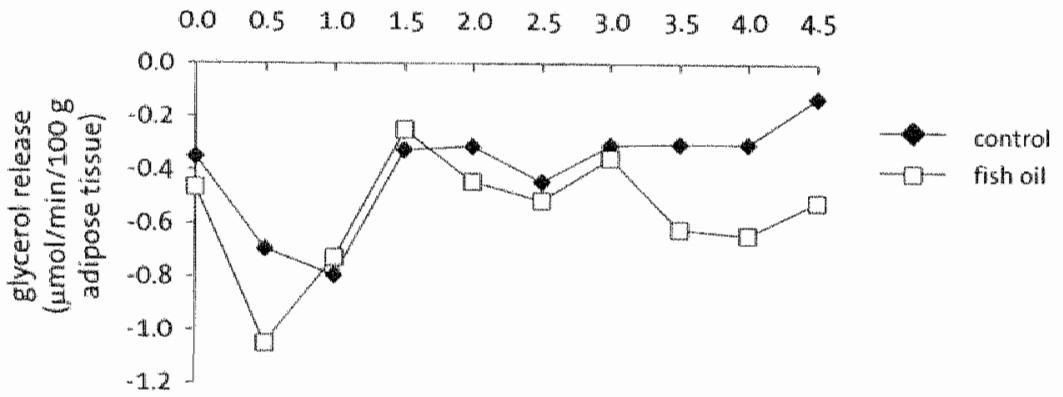

time (hours)

The meall was given immediately after $t=0$. Statistical differences between time points were analyzed with ANOWA based on data from the control group $(n=11)$. 5tatistical differences for diet and diet $x$ time were also analyzed with ANOWA. 


\section{Table 5.2:}

Effects of fish oil on postprandial arterialized insulin, glucose, NEFA and TG concentrations between fish oil and control supplementation $(n=11)$

\begin{tabular}{|c|c|c|c|c|c|c|c|c|}
\hline \multirow{2}{*}{ time } & \multicolumn{2}{|c|}{ Insulin (pmol/l) } & \multicolumn{2}{|c|}{ glucose (mmolll) } & \multicolumn{2}{|c|}{ NEFA (GMMOII) } & \multicolumn{2}{|c|}{$10(m m o l l)$} \\
\hline & control & fish & control & fish: & control & fish & control & fish \\
\hline 0.0 & $54 \pm 30$ & $49 \pm 23$ & $6.27 \pm 1.43$ & $6.22 \pm 1.14$ & $619 \pm 161$ & $605+165$ & $1.24 \pm 0.72$ & $1.12 \pm 0.47$ \\
\hline 0.5 & $235 \pm 169$ & $248 \pm 186$ & $7.13 \pm 1.52$ & $7.07 \pm 1.36$ & $558+134$ & $577 \pm 161$ & $1.28+0.74$ & $1.13 \pm 0.47$ \\
\hline 1.0 & $216 \pm 120$ & $225 \div 145$ & $7.32 \pm 1.86$ & $7.26 \pm 2.00$ & $398 \pm 119$ & $399 \pm 114$ & $1.41+0.74$ & $1.30 \div 0.49$ \\
\hline 1.5 & $195 \pm 97$ & $176 \pm 141$ & $7.41 \pm 2.06$ & $7.14 \pm 2.11$ & $328 \pm 94$ & $336 \pm 89$ & $1.66 \pm 0.75$ & $1.48+0.53$ \\
\hline 2.0 & $158 \pm 97$ & $155+111$ & $7.20 \pm 1.88$ & $7.36 \pm 1.72$ & $35.4 \pm 93$ & $376 \pm 102$ & $1.96 \pm 0.87$ & $1.78 \pm 0.62$ \\
\hline 2.5 & $164 \pm 118$ & $167 \pm 77$ & $7.25 \pm 1.49$ & $7.53 \pm 1.24$ & $450 \pm 117$ & $448 \pm 125$ & $2.32 \pm 0.90$ & 2.0510 .67 \\
\hline 3.0 & $141 \pm 86$ & $124 \pm 41$ & $7.35 \pm 1.31$ & $7.35 \pm 1.09$ & $536 \pm 173$ & $521 \pm 165$ & $2.52 \pm 0.95$ & $2.18 \pm 0.86$ \\
\hline 3.5 & $132 \pm 62$ & $117 \pm 43$ & $6.91+1.22$ & $6.78 \pm 1.36$ & $585 \pm 173$ & $546 \pm 132$ & $2.40 \pm 1.02$ & $2.12 \pm 0.97$ \\
\hline 4.0 & $123 \pm 53$ & $111 \pm 59$ & $7.61 \pm 1.40$ & $7.12 \pm 1.30$ & $634+177$ & $572 \pm 124$ & $2.60 \pm 1.32$ & 2.2150 .91 \\
\hline 4.5 & $97 \pm 40$ & $82 \pm 40$ & $7.04 \pm 1.41$ & $6.66 \pm 1.55$ & $641 \pm 134$ & $615+136$ & $2.44 \pm 1.26$ & $2.14+1.06$ \\
\hline $\begin{array}{l}\mathrm{pu} \\
\text { value }\end{array}$ & & 0.064 & & 0.384 & & 0.281 & & $<0$ \\
\hline
\end{tabular}

Data are means \pm SD. Pualues indicate statistical differences for diet and were analyzed with ANOVA with time, diet and subject number as factors.

After 4.5 hours, however, concentrations had not returned to baseline levels. Glucose and TG levels also increased in response to the meal with a peak level after respectively 1 and 3 hours. NEFA concentrations decreased after the meal and had returned, after a nadir at 1.5 hours, to baseline levels at the end of the experiment. Interstitial and arterialized glycerol concentrations significantly decreased in response to the meal ( $p<0.001$; figures $5.1 \mathrm{~A}$ and 5.2A). For interstitial glyceral, the lowest concentration was reached after 1.5 hours and for arterialized glycerol after 1 hour. ATBF significantly increased in response to the meal $(p=0.002$; figures $5.1 B$ and $5.2 B)$ and leveled off 2.5 hours after the meal. Glycerol release increased immediately after the meal, although the differences between the various time points did not reach statistically significance $(p=0.150$; figures $5.1 C$ and $5.2 C)$.

\section{Fish oil study}

The mean daily intake of the capsules, which were well tolerated, was $92.9 \%$ (range: 77-100\%) during the control period and 94.0\% (range: 83-101\%) during the fish oil period. Compliance was further confirmed by the increases in plasma phospholipids of EPA from $10.8 \mathrm{mg} / \mathrm{L}(0.79 \%)$ during the control period to $26.8 \mathrm{mg} / \mathrm{L}(2.10 \%)$ during the fish oil period $(p<0.001)$ and of DHA 
from $42.1 \mathrm{mg} / \mathrm{L}(3.12 \%)$ to $58.4 \mathrm{mg} / \mathrm{L}(4.56 \%)$ ( $p<0.001)$. Characteristics of the subjects during both periods are summarized in table 5.1. At the start of the fich oil period the subjects weighed $97.0 \pm 8.64 \mathrm{~kg}$ and at the end $96.5 \pm 8.59$ $\mathrm{kg}(p=0.350)$. In the control period subjects weighed $97.0 \pm 8.22 \mathrm{~kg}$ at the beginning and $96.7 \pm 8.72 \mathrm{~kg}$ at the end $(p=0.572)$. There were no significant changes in body weight between both periods ( $p=0.654)$. The mean daily energy intake was $9.70 \pm 1.51 \mathrm{MJ} /$ day during the control period and $9.8 \pm 2.24$ M/day during the fish oil period $(p=0.426)$. In addition, the mean daily nutrient intake did not significantly differ between the fish and contral period. Inspection of diaries did not reveal any deviations from the protocol during the entire study. Insulin, glucose, NEFA and TG concentrations in arterialized blood throughout the experiment are presented in table 5.2 . Although fasting TG concentrations tended to be lower $(p=0.172)$, fish oil did not favorably affect any of the parameters in the fasting state. Changes relative to fasting concentrations were not significantly different between the two supplementation periods. When postprandial values were included however, insulin concentrations tended to be consistently lower after fish oil supplementation ( $p=0.064)$, while TG concentrations were consistently decreased ( $p<0.001)$.

No differences in fasting interstitial glycerol values $(p=0.159)$ and in arterialized glycerol concentrations $(p=0.870)$ were observed after consumption of the fish oil or control capsules (figure 5.1A), although interstitial glycerol concentrations were consistently higher after fish oil supplementation after inclusion of postprandial values $(p=0.005$; figure 5.1A). ATBF during the postprandial study was not affected by the type of supplementation ( $p=0.756$, figure 5.1B). Glycerol release across the adipose tissue however was significantly increased after fish oil supplementation $(p=0.005$; figure $5.1 C)$, which was especially obvious 3 to 4.5 hours after the meal.

Table 5.3:

Characteristics of the study population before and after weight loss $(n=8)$

\begin{tabular}{lccc}
\hline & Before & After & p value \\
\hline Weight $(\mathrm{kg})$ & $94.0 \pm 8.64$ & $84.6 \pm 7.33$ & $<0.001$ \\
BMl $\left(\mathrm{kg} / \mathrm{m}^{2}\right)$ & $31.0 \pm 1.96$ & $27.9 \pm 1.45$ & $<0.001$ \\
Waist to hip ratio & $1.07 \pm 0.03$ & $1.02 \pm 0.04$ & $<0.001$ \\
Body fat $(\%)$ & $28.3 \pm 2.80$ & $24.6 \pm 2.99$ & $<0.001$ \\
\hline
\end{tabular}

Data are mean +50 . Statistical differences for diet were analyzed with paired t-test. 
Table 5.4:

Arterialized insulin, glucose, NEFA, and TG concentrations before and after weight loss $(n=8)$

\begin{tabular}{|c|c|c|c|c|c|c|c|c|}
\hline \multirow[t]{2}{*}{ time } & \multicolumn{2}{|c|}{ Insulin (pmol/4) } & \multicolumn{2}{|c|}{ clucose (mmol/l) } & \multicolumn{2}{|c|}{ NEFA (umoll) } & \multicolumn{2}{|c|}{ To (mmolll) } \\
\hline & before & after & before & after: & before & after & before & after \\
\hline 0.0 & $56 \pm 30$ & $42 \pm 24$ & $6.20 \div 1.35$ & $5.91+0.82$ & $625 \pm 164$ & $541+138$ & $1.29 \pm 0.84$ & $0.71 \pm 0.47$ \\
\hline 0.5 & $270 \pm 182$ & $247 \pm 151$ & $7.05 \pm 1.37$ & $7.12 \pm 0.74$ & $575+130$ & $483 \pm 105$ & $1.35 \pm 0.87$ & $0.70 \pm 0.44$ \\
\hline 1.0 & $241 \pm 126$ & $208 \pm 88$ & $7.28 \pm 1.83$ & $7.88 \pm 1.84$ & $398 \pm 126$ & $313 \pm 88$ & $1.46 \pm 0.86$ & $0.86 \pm 0.38$ \\
\hline 1.5 & $202 \pm 103$ & $241 \pm 119$ & $7.18 \div 2.04$ & $7.82 \pm 1.79$ & $316 \pm 95$ & $265 \pm 82$ & $1.72 \pm 0.88$ & $1.02 \pm 0.37$ \\
\hline 2.0 & $176 \pm 95$ & $168 \pm 99$ & $7.12 \pm 1.92$ & $7.51 \pm 1.42$ & $352 \pm 107$ & $295 \pm 128$ & $2.05 \pm 1.01$ & $1.15+0.39$ \\
\hline 2.5 & $187 \pm 130$ & $147 \pm 69$ & $7.21 \pm 1.54$ & $7.05 \pm 1.22$ & $462 \pm 132$ & $387 \pm 194$ & $2.44 \pm 1.04$ & $1.28+0.43$ \\
\hline 3.0 & $164 \pm 92$ & $112 \pm 69$ & $7.46 \pm 1.41$ & 6.7711 .10 & $556 \pm 196$ & $473 \pm 223$ & $2.66 \pm 1.08$ & 1.3440 .52 \\
\hline 3.5 & $1.45 \pm 618$ & $99+59$ & $6.99 \pm 1.32$ & $6.15 \pm 0.64$ & $602 \pm 195$ & $532+192$ & $2.69 \pm 1.26$ & $1.35 \pm 0.57$ \\
\hline 4.0 & $126 \pm 59$ & $86 \pm 57$ & $7.65 \pm 1.57$ & $6.27 \pm 0.90$ & $648 \pm 199$ & $590 \pm 191$ & $2.72 \pm 1.54$ & $1.36 \pm 0.65$ \\
\hline 4.5 & $98 \pm 47$ & $67 \pm 43$ & $7.08 \pm 1.57$ & 5.9010 .60 & $656 \pm 139$ & $609 \pm 1.41$ & $2.53 \pm 1.48$ & $1.31 \pm 0.73$ \\
\hline $\begin{array}{l}\mathrm{p}- \\
\text { value }\end{array}$ & & $<0.001$ & & 0.001 & & $<0.001$ & & $<0.001$ \\
\hline
\end{tabular}

Data are means \pm SD. P-values indicate statistical differences for diet and were anallyzed with ANOVA with time, diet and subject number as factors.

\section{Weight reduction study}

The characteristics of the subjects before and after weight loss are given in table 5.3. Subjects lost on average $9.36 \pm 2.02 \mathrm{~kg}$ during the weight loss period. This resulted in a significant decrease in BMI of on average $3.09 \mathrm{~kg} / \mathrm{m}^{2}$ $\pm 0.66 \mathrm{~kg} / \mathrm{m}^{2}$ and in waist to hip ratio of $0.04 \pm 0.03$. Fat mass reduced with $3.72 \pm 0.54 \mathrm{~kg}$. About $63 \%$ of the loss in body weight was due to a decrease in fat mass and $37 \%$ in fat free mass. Body weight was $84.6 \pm 7.78$ in week 7 and $84.6 \pm 7.33$ in week $8(p=0.481)$ of the intervention period, which suggests that subjects were in weight stable conditions at the time of the postprandial test. No differences in EPA and DHA concentrations were observed before and after weight loss $(p=0.177$ and $p=0.1 .72)$. After weight loss, fasting insulin, NEFA, and TG concentrations were significantly lower $(p=0.030,0.054$, and $p=0.028$ respectively), but fasting glucose concentrations were not significantly decreased ( $p=0.156)$. Arterialized insulin, glucose, NEFA and TG concentrations throughout the experiment are presented in table 5.4. After weight reduction, increases in glucose concentrations in response to the meal were less ( $p$ for interaction $=0.007$ ), while those in $T G$ concentrations just did not reach statistical significance ( $p$ for interaction $=0.062$ ). 
Figure 5.2:

Interstitial and arterialized glycerol concentrations, adipose tissue blood flow, and glycerol release across adipose tissue in the fasting and postprandial period before and after weight loss

A

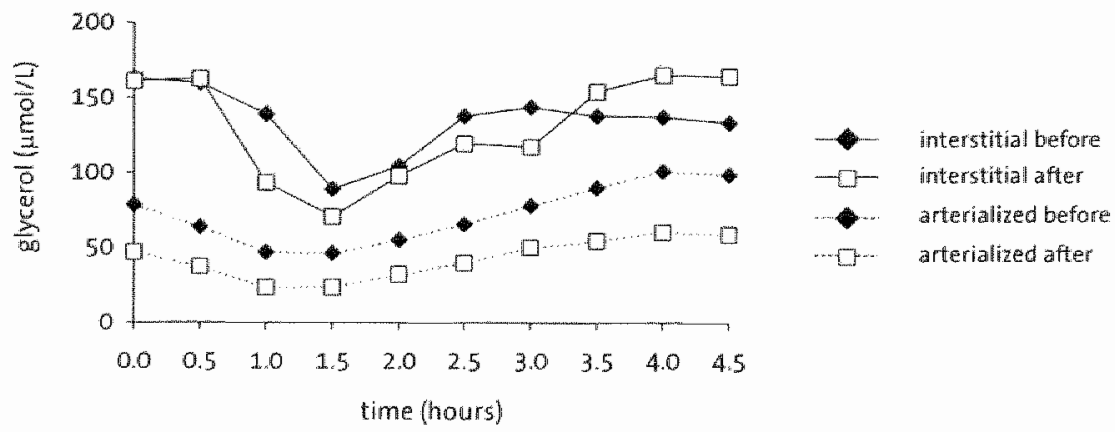

B

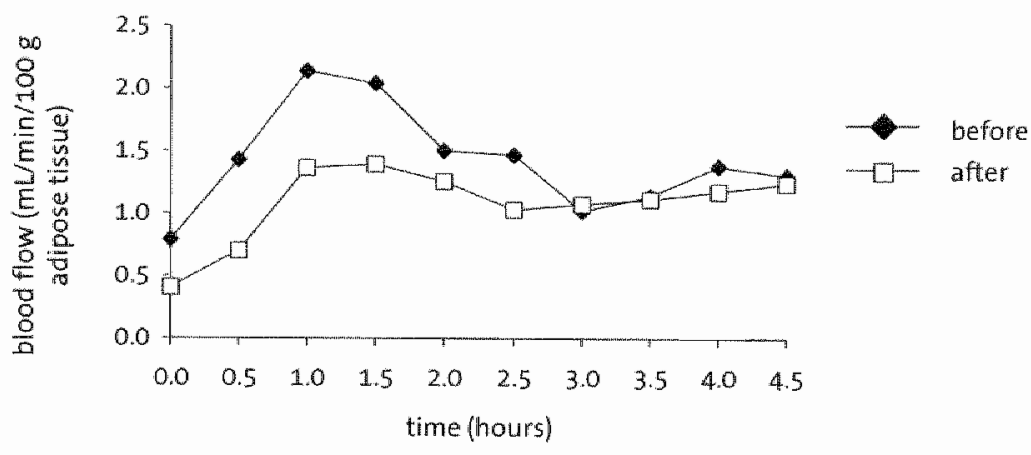

C

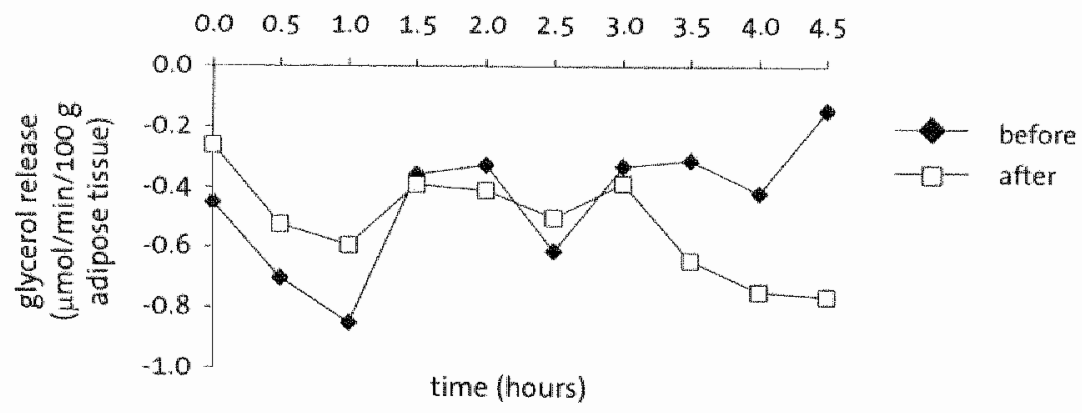

The meal was given immediately after $t=0$. Statisitical differences between time points were analyzed with ANOVA based on data from the control group ( $n=11$ ). Statistical differences for diet and diet $x$ time were also analyzed with ANOVA. 
During the postprandial phase, insulin and NEFA concentrations were consistently decreased after weight loss compared with values before weight loss ( $p=0.022$ and $p<0.001$ respectively).

Interstitial and arterialized glycerol concentrations before and after weight loss are summarized in figure 5.2A. There was no difference in interstitial glycerol concentrations before and after weight loss $(p=0.548)$, but arterialized glycerol concentrations were consistently decreased as a consequence of weight reduction ( $p<0.001$ ). Adipose tissue blood flow was also consistently lower $(p=0.007)$, especially during the first three hours after the meal (figure 5.2B). There was a diet-dependent change over time in glycerol release ( $p$ for interaction $=0.044$; figure $5.2 C$ ). After weight reduction, subcutaneous adipose tissue lipolysis tended to be lower initially, but was significantly increased during the late postprandial period.

\section{Discussion}

Insulin resistance may increase adipose tissue lipolysis, which is thought to be related to the metabolic disturbances as observed in obese subjects $(4,30)$. As weight reduction and possibly fish oil improve insulin resistance and postprandial metabolism, we hypothesized that these two interventions will decrease subcutaneous adipose tissue lipolysis in the postprandial period. We did not find, however, that fish oil suppressed subcutaneous adipose tissue lipolysis (per unit tissue mass). In fact, subcutaneous adipose tissue lipolysis was increased during the late postprandial period. After weight reduction, subcutaneous adipose tissue lipolysis tended to be lower initially, but was significantly increased during the late postprandial period.

\section{Effects of a meal}

It is well known that insulin inhibits HSL activity (4). This suggests that subcutaneous adipose tissue glycerol release will decrease immediately after a meal due to postprandial increase in insulin concentrations. On the control diet, however, subcutaneous adipose tissue glycerol release was increased during the first 30 minutes after the meal and was decreased to a minimum between 1.5 and 3 hours after the meal, although the results were not statistically significant. This is in line with the results of Coppack et al (6), who observed an increase in HSL activity immediately after a meal in obese, but not in lean subjects. This suggests that, especially in the obese, insulin is not the only determinant of HSL activity in response to a meal. Results for the other parameters were as expected. After an initial decrease, NEFA 
concentrations started to return to fasting levels two hours after the meal possibly due to the insulin-stimulated increase of LPL-activity (31). Like in other studies $(32,33)$, a peak in TG concentrations was seen approximately 4 hours after the meal. Also the observed increase in ATBF in response to the meal has been reported before (34). Glucose concentrations increased in response to the meal and had not returned to baseline at the end of the experiment. This is most probably related to the relatively high fat load.

\section{Effects of fish oil}

As compared with the control period, fish oil supplementation increased subcutaneous adipose tissue lipolysis in particular during the late postprandial state. A possible mechanism for this effect may be through effects on gene expression. Price et al (35) have suggested that n-3 LCPUFA downregulate the expression of lipogenic genes in the liver and adipose tissue. At the same time, however, the expression of genes involved in lipid oxidation in the liver and skeletal muscle are upregulated. This suggests that n-3 fatty acids may shift the balance from fat storage towards fat mobilization and oxidation, which is in line with several studies (36-38). At this time, however, precise mechanisms are not known and require further study.

After fish oil supplementation, insulin concentrations tended to be lower, suggestive of improved insulin sensitivity. This is in line with animal and epidemiological studies $(39,40)$. As already discussed, subcutaneous adipose tissue lipolysis was increased after fish oil supplementation. This suggests that a better capacity of insulin to suppress subcutaneous adipose tissue lipolysis is not a major mechanism underlying the reduced TG concentrations after fish oil consumption. Possible effects of fish oil on insulin sensitivity however may be tissue specific. In studies with rats, Storlien et al (40) indeed showed increased insulin sensitivity in skeletal muscle of rats, but not in white adipose tissue after fish oil supplementation. In addition, differential effects of insulin on lipolysis may exist between abdominal subcutaneous and visceral adipose tissue $(41,42)$.

The consistently reduced TG concentrations after fish oil supplementation of about $8 \%$ were as expected (18). This reduction however may not only be the result of a decreased synthesis, but also from an increased clearance of TGrich lipoproteins from plasma. This may be caused by increased LPL activity after fish oil supplementation as observed by Kasim-Karakas et al (43). The increase in LPL activity correlated inversely with plasma TO concentrations in this study, which indeed suggests a possible increase in clearance of TG. However, we did not observe a decreased postprandial response after fish oil supplementation. Data obtained from previous studies with a comparable fish 
oil dose in the background diet on postprandial TG response are also not convincing (44).

\section{Effects of weight loss}

Decreased circulating NEFA and glycerol concentrations after weight loss suggest decreased whole-body lipolysis both during fasting and postprandial conditions. This may be due to a reduction in fat mass or increased insulin sensitivity. Weight reduction did not suppress abdominal subcutaneous adipose tissue lipolysis to a greater extent during the fasting or postprandial period. Results of earlier studies on the effects of weight reduction have found both an increase (45) and decrease (46) in fasting subcutaneous abdominal adipose tissue lipolysis. Kolehmainen et al (47) have suggested that this controversy may be partly explained by the fact that body weight of the subjects was not stable at the time of the measurements, which may have affected the basal level of mobilization of fatty acids from adipose tissue. In our study, however, body weights did not change two weeks prior to the day of measurements, suggesting that subjects were weight stable. Our late postprandial differences in glycerol release before and after weight loss may possibly be related to an altered activity of the sympathetic nervous system. Previous studies have observed an increased $\beta$-adrenergically mediated lipolysis (46) and thermogenesis (48) after weight reduction. It is thought that the effect of insulin in response to a meal overrules the effect of the sympathetic nervous system (49). However, as insulin affects HSL activity especially in the first hour after a meal (42), $\beta$-adrenergical sensitivity may affect lipolysis in the late postprandial phase.

In conclusion, a decreased subcutaneous abdominal adipose tissue lipolysis during the postprandial phase can not explain the effects of fish oil and weight loss on lipid and glucose metabolism. In fact, subcutaneous abdominal adipose tissue lipolysis was increased in the late postprandial period, although insulin sensitivity seemed to be improved.

\section{Acknowledgements}

The study was supported by a grant from the Netherlands Organization for Scientific Research, grant number 980-10-006, Nutrition and Chronic Diseases. We are indebted to E. Molenaar, A. van Rees, J. Senden, M. Mensink, J. Stegen, F. Cox and M. Kunen for their laboratory and clinical assistance. We are grateful to Drir P. Zock for providing us with the oil capsules. 


\section{References}

1.

3.

Frayn $K M$. Role of non-esterified fatty acids in the metabolic changes in obesity. Int I Obes Rel Metab Dis 1996;20(supp/4):7-10.

Frayn KN, Whliams CM. Amer P. Are increased plasma non-esterified fatty acid concentrations a risk marker for coronary heart disease and other chronic diseases? Clin Sci 1996:90:243-253.

Bonadonna RC, Bonora E. Glucose and free fatty acid metabolism in human obesity: Relationships to insulin resistance. Diabetes Reviews 1997:5:21-51.

Coppack SW, Jensen MD, Miles JM. In wivo regulation of lipolysis in humans. I Lipid Res $1994: 35: 177-193$

Frayn KN. Adipose tissue and the insulin resistance syndrome. Proc Nutr Sor $2001 ; 60 \times 375-380$.

Cappack SW, Evans RD, Fisher RM, et al. Adipose tissue metabolism in obesity: lipase action in viwo before and after a mixed meal. Metabolism 1992:41:264-272.

Riccardi $G$. Rivellesse AA. Dietary treatment of the metabolic syndrome-the optimal diet. Br J Nutr 2000;83 Suppl 1:5143-148.

Dattilo AM, Kris-Etherton PM. Effects of weight reduction on blood lipids and lipoprotelns: a meta-analysis. Am J Clin Nutr 1992:56:320\%328.

Bang HO, Dyerberg J. Plasma lipids and lipoproteins in Creenlandic west coast Eskimos. Acta Med Scand 1972;192:85-94.

Gibson RA. The effect of diets containing fish and fish oils on disease risk factors in humans. Aust iN Z I Med 1988;18:713-722.

1. Norell $S E$, Ahlbom A, Feychting M, Pedersen NL. Fish consumption and mortality from coronary heart disease. Br Med J (Clin Res Ed) 1986;293:426.

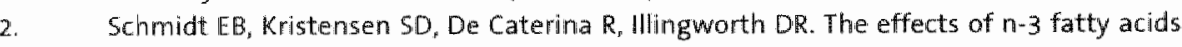
on plasma lipids and lipoproteins and other cardiovascular risk factors in patients with hyperlipidemia. Atherosclerosis 1993;103:107-121.

3. Nordoy A, Hatcher L, Goodnight S, Fitzgerald GA, Conner WE. Effects of dietary fat content, saturated fatty acids, and fish oil on eicosanoid production and hemostatic parameters in normal men. I Lab Clin Med 1994:123:914-920.

4. Roche HM, Gibney MJ. Postprandial triacylglycerolaemia: the effect of low-fat dietary treatment with and without fish oll supplementation. Eur I Clin Nutr 1996;50:617-624.

Agren JJ, Hannimen O, Julkunen $A_{\text {, }}$ et al. Fish diet, fish oll and docosahexaenoic acid rich oll lower fasting and postprandiath plasma lipid levels. Eur I Clin Nutr 1996:50:765-771.

6. Bordin P. Bodamer OA, Venkatesan S, Gray RM, Bannister PA, Halliday D. Effects of fish oil supplementation on apolipoprotein B100 production and lipoprotein metabolism in nomolipidaemic males. Eur / Clin Nutr 1998;52:104-109.

7. Harris WS. n- 3 fatty acids and serum lipoproteins: human studies. Am I Clin Nutr 1997:65:16455-165:45.

8. Roche HM, Gibney M. Effect of long-chain n-3 polyunsaturated fatty acids on fasting and postprandial triacylglycerol metabolism. Am J Clin Nutr 2000;71:2325-2375.

Vessby B. Dietary fat and insulin action in humans. Br I Nutr 2000;83 Suppl 1:S91-96. Bolinder I, Kerckhoffs DA, Moberg E, Hagstrom-Toft E, Arner P. Rates of skeletal muscle and adipose tissue glycerol release in nonobese and obese subjects. Diabetes. 2000:49:797-802.

Behandeling en preventie van coronaire hartziekten door verlaging van de plasmacholesterolconcentratie (treatment and prevention of coronary heart diseae by 
lowering plasma cholesterol concentrations). Utrecht: Centraal Begeleidingsongaan voor de lintercollegiale Toetsing in samenwerking met de Nederlandse Hartstichting (in Dutch), 1998.

22. Samra JS, Frayn KN, Giddings JA, Clark ML, Macdonald IA. Modification and vallidation of a commercially available portable detector for measurement of adipose tissue blood flow. Clin Physiol 1995:15:241-248.

23. Voedingsraad. Advies richtilinen goede voeding: advies opgesteld door de Commissie Richtlijnen Goede Voeding van de Voedingsraad. Den Haag: Voedingsraad, 1.986.

24. Hagstram-Toft E. Enoksson 5, Moberg E, Bolinder J, Arner P. beta-Adrenergic regulation of lipolysis and blood flow in human skeletal muscle in viva Am I Physiol 1998:275:E909-916.

25. Otto S, wan Houwellingen AC, Lopez-laramillo P, Hornstra G. Effects of pregnancyinduced hypertension on the essential fatty acid statuses of Ecuadorian and Dutch women. Am \Obstet Gynecol 1999;180:1185-1190.

26. Jansson PA, Larsson A, Smith $U$, Lonnroth $\mathbb{P}$. Glycerol production in subcutaneous adipose tissue in lean and obese humans. I Clin Invest 1992;89:1610-1617.

27. Blaak EE, Kemerink GJ, Pakbiers MT, Wolffenbuttel BH, Heidendal GA, Saris WH. Microdialysis assessment of local adipose tissue lipolysis during beta- adrenergic stimulation in upper-body-obese subjects with type $\mid$ diabetes. Clin Sci (Colch) 1999:97:421-428.

28. Blaak EE, van Baak MA, Kemerink GJ, Pakbiers MT, Heidendal GA, Saris WH. Total forearm blood flow as an indicator of skeletal muscle blood flow: effect of subcutaneous adipose tissue bllood flow. Clin Sci (Colch') 1994:87:559.5.66.

29. Pocock SJ. Cinical trials: a practical approach. Chichester: Wiley \& Sons, 1983.

30. Després J-P. Abdominal obesity as important component of insulin-resistance syndrome. Nutrition 1993;9:452-459.

31. Sadur CN, Eckel RH. Insulin stimulation of adipose tissue lipoprotein lipase. Use of the euglycemic clamp technique. J Clin invest 1982;69:1119-1125.

32. Summers LK, Barnes SC, Fielding BA, et al. Uptake of individual fatty acids into adipose tissue in relation to their presence in the diet. Am J Clin Nutr 2000;71:1470-1.477.

33. Potts $\mathrm{U}$, Coppack SW, Fisher RM, Humphreys $S M_{i}$ Gibbons GF, Frayn KN Impaired postprandial clearance of triacylglycerol-rich lipoproteins in adipose tissue in obese stubjects. Am \& Physiol 1995;268:E588-594.

34. Summers LK, Callow I, Samra IS, Macdonald IA, Matthews DR, Frayn KN. The effect on adipose tissue blood flow of isoenergetic meals containing different amounts and types of fat. Int l Obes Relat Metab Disord 2001:25:1294-1299.

35. Price PT, Neison CM. Clarke 5D, Omega-3 polyunsaturated fatty acid regulation of gene expression. Curr Opin Lipidol 2000;11:3-7.

36. Couet C, Delarue 1, Ritz P, Antoine I-M, Lamisse F. Effect of dietary fish oil on body fat mass and basal fat oxidation in healthy aduits. international joumal of obesity 1997:21:637-643.

37. Raclot $T$, Oudart $\mathrm{H}$. Selectivity of fatty acids on lipid metabolism and gene expression. Proc Nutr 5oc 1999:58:633-646.

38. Delarue 1, Couet $C_{r}$ Cohen $R$ Brechot If, Antoine JM, Lamisse F. Effects of fish oil on metabolic responses to oral fructose and glucose loads in healthy humans. Am I physiol $1996 ; 270$ E $353-362$.

39. Feskens EJ, Bowles CH, Kromhout D. Inverse association between fish intake and risk of glucose intolerance in normoglycemic elderly men and women. Diabetes Care 1.991:14:935-941. 
40. Storlen $L H$, Kraegen EW, Chisholm DJ, ford GL, Bruce DG, Pascoe WS. Fish oil prevents insulin resistance induced by high-fat feeding in rats. Science $1987: 237: 885-888$.

41. Arner P. Regulation of lipolysis in fat cells. Diabetes Rev 1996;4:450-463.

42. Large V, Arner P. Regulation of lipolysis in humans. Pathophysiological modulation in obesity, diabetes, and hyperlipidaemia. Diabetes and Metabolism 1998;24:409-418.

43. Kasim-Karakass SE, Herrmann $R$, Almaria R. Effects of omega-3 fatty acids on intravascular lipolysis of very-low-density lipoproteins in humans. Metabolism 1995:44:122\%-1230.

44. Williams CM. Postprandial lipid metabolism: effects of dietary fatty acids. Proc Nutr Sac $1997 \% 56: 679-692$.

45. Stich V, Harant I, De Glisezinski, et al. Adipose tissue lipolysis and hormone-sensitive lipase expression during very-low-calorie diet in obese female identical twins. I Clin Endocrinol Metab 1997;82:739-744.

46. Reymisdottir 5, Langin D, Carlstrom K, Holm C, Rossner S, Arner P. Effects of weight reduction on the regulation of lipolysis in adipocytes of women with upper-body obesity. Clin Sci (Lond) 1995;89:421-429.

47. Kolehmainen $M_{3}$ Vidal $H_{3}$ Ohisalo J, Pirinen E, Alhava E, Uusitupa MI. Hormone sensitive lipase expression and adipose tissue metabolism show gender difference in obese subjects after weight loss. Int 1 Obes Relat Metab Disord 2002;26:6-16.

48. Blaak EE, van Baak MA Kester AD, Saris WH. Beta-adrenergically mediated thermogenic and heart rate responses: effect of obesity and weight loss. Metabolism 1995:44:520524.

49. Patel JN, Eisenhofer $G$, Coppack SW, Miles JM. Norepinephrine spillover in forearm and subcutaneous adipose tissue before and after eating. J Clin Endocrinol Metab $1999 ; 84: 2815-2819$. 


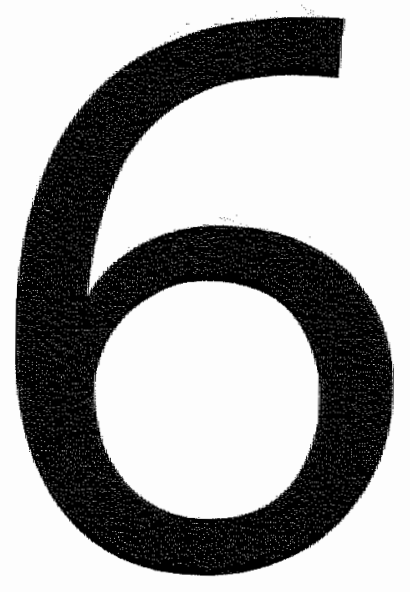

Effects of fish oil and weight loss on inflammatory parameters and PAI-1 antigen concentrations in obese men during the fasting and postprandial state

Annemarie Jellema ${ }^{1}$, Ronald P. Mensink ${ }^{1}$

1. Department of Human Biology, University of Maastricht, Maastricht, The Netherlands

Submitted 


\section{Abstract}

Background: Excretion of regulatory factors by adipose tissue may be changed by fish oil and weight loss. Results, however, are conflicting and effects have hardly been studied during the postprandial phase. The aim of this study was to compare in obese subjects the in vivo effects of fish oil and weight loss on circulating concentrations of pro-inflammatory cytokines and plasminogen activator inhibitor 1 (PAI-1) antigen in the fasting and postprandial state.

Methods: Eleven obese men (BMI: $30-35 \mathrm{~kg} / \mathrm{m}^{2}$ ) received for six weeks in random order fish oill or control capsules. During the fish oil period, subjects consumed daily $1.35 \mathrm{~g}$ omega-3 fatty acids. The two periods were interrupted by a wash-out period. Eight subjects continued with a weight reduction study that lasted eight weeks. Mean weight loss was $9.36 \mathrm{~kg}$. At the end of each intervention period a postprandial study was performed.

Results: When subjects consumed the control capsules, interleukin-6 (IL-6) levels increased with $75 \%$ two hours and with $118 \%$ four hours after the meal. In contrast, PAI-1 antigen concentrations were decreased with respectively $26 \%$ and $53 \%$. Changes in tumor necrosis factor- $\alpha$ (TNF- $\alpha$ ) and in soluble TNFreceptor concentrations (STNF-R60 and STNF-R80) did not reach statistical significance. Absolute IL-6, PAI-1 antigen, STNF-R-60, and STNF-R80 concentrations were not statistically different between the fish oil and control period, but were significantly decreased after weight reduction. Changes relative to fasting concentrations, however, were not significantly affected by fish oil or weight reduction.

Conclusions: In contrast to fish oil, weight loss leads to reduced concentrations of IL-6, PAl-1 antigen, sTNF-R60, and sTNF-R80. 


\section{Introduction}

A growing body of evidence suggests that adipose tissue plays a key role in the control of many different metabolic pathways (1). In fact, it secretes many regulatory factors like TNF- $\alpha$ and $\mathrm{IL}-6$, two pro-inflammatory cytokines, and PAl-1, a fibrinolytic regulator (2). A decrease in fat mass therefore reduces the risk to develop metabolic disturbances, as demonstrated by the decreases in plasma TNF- $\alpha$ and IL- 6 concentrations (3), and PAI- 1 activity (4) after weight loss. However, sustained weight loss is difficult to achieve and more insight into the effects of diet on these regulatory factors in overweight and obese subjects is needed. In this respect, fish oill deserves attention.

Fish oil is rich in eicosapentaenoic acid (EPA; C20:5n-3) and docosahexaenoic acid (DHA; $C 22: 6 n-3)$. These two fatty acids may have anti-inflammatory effects, as suggested by a reduction in TNF- $\alpha$ production by mononuclear cells after consumption of fish oil supplements (5). Blok et al (6), however, did not observe any beneficial effects of fish oil on circulating TNF- $\alpha$ concentrations and on ex vivo TNF-a production. Effects of fish oil on PAl-1 activity or PAI-1. antigen concentrations are also controversial. One study has reported unfavorable effects of $n-3$ fatty acids on PAI-1 activity (7), but this was not confirmed by other studies (8-10). In addition, most of these studies (7-10) have been carried out in the fasting state, although a large part of the day is spent in the postprandial period. The aim of the present study was therefore to compare in obese subjects the in vivo effects of fish oil and weight reduction on circulating concentrations of pro-inflammatory cytokines and PAl-1. Effects were not only studied in the fasting state, but also during the postprandial period.

\section{Subjects and methods}

\section{Subjects}

Eleven obese men with a body mass index between 30 and $35 \mathrm{~kg} / \mathrm{m}^{2}$ participated in the fish oil study, while eight of them also participated in the weight reduction study. None of the men had lost or gained more than $3 \mathrm{~kg}$ of weight during the three months preceding the study. Before the start of the study, the men were invited for two screening visits. At that time, mean $( \pm S D)$ total cholesterall (TC), high density lipoprotein cholesterol (HDL-C) and triglyceride (TG) concentrations were respectively $5.72 \pm 0.93 \mathrm{mmol} / \mathrm{L}$, $1.00 \pm 0.19 \mathrm{mmol} / \mathrm{L}$ and $1.53 \pm 0.60 \mathrm{mmol} / \mathrm{L}$. Their mean age was $59 \pm 9 \mathrm{yr}$. The 
men did not have any indication for treatment with cholesterol-lowering drugs according to the Dutch Cholesterol Consensus (11) and did not use any other medication known to influence the measurements. Their systolic and diastalic blood pressures were respectively below $160 \mathrm{mmHg}$ and $95 \mathrm{mmHg}$. The participants were asked not to change their physical activity and smoking habits during the study. Two of the men smoked. The subjects were given a detailed description of the study before they gave their informed consent. The study was approved by the Ethics Committee of the University of Maastricht.

\section{Clinical measurements}

\section{Fish oil study}

The fish oil study had a double-blind cros5-over design, which consisted of two intervention periods of six weeks, interrupted by a wash-out period of at least two weeks. At the start of the study, all subjects filled in a food frequency questionnaire, consisting of 100 items, to estimate their habitual energy and nutrient intakes. Food frequency lists were checked by a dietician immediately in the presence of the subjects. Items were coded and the composition of the diets was calculated using the Dutch food composition table (12). Based on these results the men received guidelines from the dietician for a diet that met the Dutch dietary guidelines (13): 30-35 energy percent (EN\%) from fat (a maximum of 10 EN\% from saturated fat) and 55 EN\% from carbohydrates (a maximum of 25 EN\% of mono- and disaccharides). Cholesterol intake was below $33 \mathrm{mg} / \mathrm{MJ}$ of cholesterol and fiber intake was $3 \mathrm{~g} / \mathrm{MJ}$ or more. They were not allowed to consume fish during the whole study.

During the intervention periods, subjects received in random order fish oil or control capsules. The oval shaped capsules contained $500 \mathrm{mg}$ oil and were made from gelatin, glycerol and purified water. They were colored with food grade titaniumdioxide. Subjects were instructed to take three capsules with a cold drink in the morning before breakfast and three capsules in the evening before dinner. The odorless purified fish oil supplements (Marinol C45, Loders Croklaan, Wormerweer, the Netherlands) contained approximately $45 \%(\mathrm{w} / \mathrm{w})$ omega-3 fatty acids. The main omega-3 fatty acids in the supplements were EPA $(20 \% w / W)$ and DHA $(17 \% w / w)$. During the fish oil period, subjects consumed each day $1.35 \mathrm{~g}$ amega-3 fatty acids from the supplements. The control capsules contained a high-oleic $(80 \% \mathrm{w} / \mathrm{w})$ sunflower oil. Subjects were provided with more capsules than needed for that period. Left-overs had to be returned and were counted to check compliance.

Body weights were recorded at each visit. Body composition was determined at the end of the first period of the fish oil study using a dual-energy $X$-ray absorptiometer (DEXA) (Hologic ODR 4500, Hologic Europe Services, 
Zaventem, Belgium). The subjects recorded any signs of illness, medication used, and any deviations from the protocol in diaries. At the end of each period food intake of the subjects was recorded with the food frequency questionnaire.

Fasting blood samples were taken at weeks $0,3,5$ and 6 of each period. In addition, a postprandial study took place at the end of each period. After an overnight fast, subjects arrived at the laboratory at $8 \mathrm{a} . \mathrm{m}$. The men were investigated in supine position. A cannula was inserted into the left dorsal hand vein, which was warmed in a hot-air box with circulating air at $60^{\circ} \mathrm{C}$ heated for at least 30 minutes for the sampling of arterialized blood. Arterialized blood instead of venous blood was sampled to determine also arterio-venous differences, which will be described elsewhere. After 60 minutes of rest, three fasting blood samples were taken within 30 minutes. Subjects were then given a standardized meal in the form of a milkshake, which provided 32.6 EN\% from carbohydrates, 5.1 EN\% from protein, and 62.3 EN\% from fat $(40.0$ EN\% from saturated fat, 40.4 EN\% from monounsaturated fat, 19.6 EN\% from polyunsaturated fat). The amount of energy was $3.0 \mathrm{MJ}$ and of cholesterol was $26 \mathrm{mg} / \mathrm{MJ}$. The shakes did not contain fish oil. The men were asked to consume the drink within ten minutes. Blood samples were collected two and four hours after the meal.

\section{Weight reduction study}

After the fish oil study, eight subjects were willing to continue with the weight reduction study that lasted eight weeks. During the first four weeks the subjects were provided with a very low calorie diet (VLCD) based on shakes (Modifast Nutrition, Breda, The Netherlands) supplying $2 \mathrm{MJ} /$ day. Besides the shakes, the men were allowed to eat $250 \mathrm{~g}$ of vegetables and fruits (except of bananas) each day. In the fifth and sixth weeks, subjects consumed an energy-restricted diet of $4.2 \mathrm{MJ} /$ day with a recommended composition (13). During weeks seven and eight, subjects were instructed to consume a diet to maintain body weight. Fasting blood samples were taken in weeks 0,7 and 8 . At the end of the intervention period, a postprandial study and body composition measurement took place as described above. In the last week, food intake was estimated using the food frequency questionnaire.

\section{Laboratory measurements}

Arterialized blood was sampled in tubes containing EDTA or citrate. Before analyzing, the three fasting baseline samples were pooled. Concentrations of sTNF-R60 and sTNF-R80 (14) and IL-6 (Quantikine HS kit, R\&D systems, Minneapolis, USA) were measured in EDTA plasma and those of PAI-1 antigen 
(PAl-ag; Zymutest, Hyphen Biomed, Andrésy, France) and TNF- $\alpha$ (Quantikine HS kit, R\&D systems, Minneapolis, USA) in citrate plasma. EDTA plasma was also used to measure glucose, TC, and TC concentrations by enzymatic methods (Boehringer Mannheim, Germany; Roche Diagnostica, Basel, Switzerland and WAKO, Neuss, Germany). Insulin concentrations in EDTA plasma were determined with a sensitive ELISA kit with crossreactivity with Cpeptide and proinsulin less than $0.01 \%$ (Insulin ELISA, Mercodia, Uppsala, Sweden). All samples from the same subject were analyzed in the same analytical run. The plasma phospholipid fatty acid composition in fasting samples at the end of each period was analyzed as described (15).

\section{Statistical analysis}

Based on previous studies $(3,16,17)$, the statistical power to detect a true difference of at least $10 \%$ in fasting TNF- $\alpha, \mathrm{LL}-6$ and PAl-1 antigen concentrations was for both studies more than $80 \%(\alpha=0.05)$. Data from the control period of the fish oil study were used as control data for the weight reduction study.

Using the data from the control period of the fish oil study, postprandial effects were examined by analysis of variance (ANOVA) with time and subject number as factors. Effects of fish oil supplementation or weight reduction were investigated with diet, time, and subject number as factors. The interaction term diet $x$ time was used to investigate if changes during the postprandial phase did depend on the type of intervention. If this interaction term did not reach statistical significance $(p<0.05)$, it was omitted from the model. Fasting levels between interventions were compared with a paired sample t-test.

For the control period, Pearson correlation coefficients were calculated between fasting concentrations of the inflammatory markers and PAI-1 antigen on the one hand the percentage of body fat, BMI, waist to hip ratio, insulin, and TG levels on the other hand. Pearson correlation coefficients were also calculated between changes in insulin and TG over time on the one hand and changes in IL-6, TNF- $\alpha$, PAII-1 antigen and STNF-receptors over time on the other hand. Changes over time were defined as the differences between two or four hour values with fasting values.

Variables are presented as means \pm standard deviation (SD). A two-tailed value of $p<0.05$ was considered to be statistically significant. All statistical analyses were performed with SPSS; PC (release 10). 


\section{Results}

None of the subjects experienced adverse effects of the fish oil or control capsules. The mean daily energy intake was $9.70 \pm 1.51 \mathrm{MJ} / \mathrm{day}$ during the control period and $9.80 \pm 2.22 \mathrm{MJ} /$ day during the fish oil period $(p=0.426$ ). Compliance with the treatments was good, as indicated by the mean calculated daily capsule intake of $5.57 \pm 0.45$ capsules $(92.9 \%)$ during the control period and of $5.64 \pm 0.35$ capsules $(94.0 \%)$ during the fish oil period $(p=0.677)$. Further, EPA in plasma phospholipids increased from $10.8 \mathrm{mg} / \mathrm{L}$ $(0.79 \%)$ during the control period to $26.8 \mathrm{mg} / \mathrm{L}(2.10 \%)$ during the fish oil period ( $p<0.001$ ) and DHA from $42.1 \mathrm{mg} / \mathrm{L}(3.12 \%)$ to $58.4 \mathrm{mg} / \mathrm{L}(4.56 \%)$ $(p<0.001)$. Body weight did not change during the fish oil study. Fish oil supplementation did not affect any of the parameters in the fasting state (table 6.1), although TG concentrations were somewhat lower $(p=0.172)$.

During the weight loss study, subjects lost on average $9.36 \pm 2.02 \mathrm{~kg}$ of weight. This resulted in a reduced fat mass of $3.72 \pm 0.54 \mathrm{~kg}$. The amounts of EPA and DHA in plasma phospholipids during the control period did not differ from those after weight loss. Body weight was $84.6 \pm 7.78 \mathrm{~kg}$ in week 7 and $84.6 \pm 7.33 \mathrm{~kg}$ in week $8(p=0.481)$, indicating that body weight was stable in week 8. After weight loss, there was a significant decrease in BMI, waist to hip ratio, insulin, TG and TC concentrations as compared with values during the control period (table 6.1).

On the control diet, fasting PAl-1 antigen concentrations correlated significantly with insulin $(r=0.68 ; p=0.022)$ and $T 0$ concentrations $(r=0.62$; $\mathrm{p}=0.041)$. Other correlations did not reach statistical significance.

\section{Table 6.1:}

Effects of fish oil and weight reduction on fasting anthropometric and metabolic parameters

\begin{tabular}{llll}
\hline & Control & Fishoil & Weight loss \\
\hline BMi $\left(\mathrm{kg} / \mathrm{m}^{2}\right)$ & $31.3 \pm 2.08$ & $31.3 \pm 1.82$ & $27.9 \pm 1.45^{\circ}$ \\
Waist to hip ratio & $1.05 \pm 0.04$ & $1.05 \pm 0.03$ & $1.02 \pm 0.04^{\circ}$ \\
Glucose (mmol/L) & $6.26 \pm 1.40$ & $6.21 \pm 1.1 .3$ & $5.92 \pm 0.80$ \\
Insulin (pmol/L) & $52.4 \pm 27.5$ & $48.6 \pm 21.3$ & $40.2 \pm 21.6^{\circ}$ \\
TG (mmol/L) & $1.24 \pm 0.72$ & $1.11 \pm 0.47$ & $0.70 \pm 0.47^{\circ}$ \\
$\mathrm{TC}(\mathrm{mmol} / \mathrm{L})$ & $5.10 \pm 0.71$ & $5.18 \pm 0.96$ & $4.54 \pm 0.48^{\circ}$ \\
\hline
\end{tabular}

Values are means \pm 50 . Statistical differences for diet were analyzed with paired thtest for the fish oil study ( $(n=11)$ and weight loss study $(n=8)$ separately, whereby *indicates $p<0.05$. 


\section{Postprandial effects}

The concentrations of TNF- $\alpha$, IL-6, PAI-1 antigen, STNF-R60, and STNF-R80 at different time points are presented in table 6.2. When subjects consumed the control capsules, $14-6$ levels increased after the standardized meal with $75 \%$ after two hours and with $118 \%$ after four hours (p<0.001 for differences between the three time points). In contrast, there was a decrease in PAl-1 antigen concentrations of $26 \%$ two hours and of $53 \%$ four hours after the meal ( $p<0.001$ ). Postprandial reductions in sTNF-R80 concentrations during the control period were not significantly different from each other, but there was a clear reduction over time when the data of the fish oil period were also included ( $p=0.002)$. TNF-a and STNF-R60 concentrations did not change after the meal.

During the control period, changes in insulin concentrations four hours after the meal correlated significantly with those in PAl-1 antigen ( $r=0.84 ; p=0.001)$ and STNF-R80 concentrations $(r=0.61 ; p=0.046)$. Two hours after the meal the TNF- $\alpha$ response correlated significantly with fat mass $(r=0.66 ; p=0.029)$, while the response after four hours was related to $B M I(r=0.73 ; p=0.011)$.

\section{Table 6.2:}

IL-6, TNF- $\alpha$, PAl-1 antigen, and STNFweceptor concentrations during the postprandial study

\begin{tabular}{|c|c|c|c|c|c|c|c|}
\hline & & \multicolumn{3}{|c|}{ time (hr) } & \multicolumn{3}{|c|}{ pralue } \\
\hline & & 0 & 2 & 4 & time & diet & interaction \\
\hline \multirow{3}{*}{$\begin{array}{l}\| \mathrm{L} \cdots \\
(\mathrm{pg} / \mathrm{mL})\end{array}$} & Control & $3.57 \pm 1.30$ & $6.25 \pm 2.81$ & $7.76+3.09$ & $<0.001$ & & \\
\hline & Fish oil & $4.98 \pm 3.66$ & $6.20 \pm 3.18$ & $7.45 \pm 3.92$ & & 0.518 & 0.372 \\
\hline & Weight loss & $2.97 \pm 1.01$ & $4.60 \pm 1.84$ & $6.30+2.97$ & & 0,001 & 0.388 \\
\hline \multirow{3}{*}{$\begin{array}{l}\text { TNF-a } \\
(\mathrm{mg} / \mathrm{mL})\end{array}$} & Control & $1.11 \pm 0.64$ & $1.31 \pm 0.57$ & 1. $37 \pm 0.68$ & 0.330 & & \\
\hline & Fistrof & $1.09 \pm 0.54$ & $1.39 \pm 0.78$ & $1.10 \pm 0.65$ & & 0.465 & 0.299 \\
\hline & Weight loss & $0.95 \pm 0.32$ & $1.10 \pm 0.47$ & $1.25 \pm 0.58$ & & 0.094 & 0.807 \\
\hline \multirow{3}{*}{$\begin{array}{l}\text { PAl-1 } \\
(\mathrm{ng} / \mathrm{mL})\end{array}$} & Control & $20.2 \pm 9.97$ & $150 \pm 10.8$ & $9.48 \pm 5.05$ & $<0.001$ & & \\
\hline & Fish oil & $23.5 \pm 20.0$ & $14.7 \pm 12.1$ & $11.5 \pm 8.10$ & & 0.323 & 0.645 \\
\hline & Weight loss & $11.9 \pm 5.83$ & 8.65 .5 .116 & $6.12 \pm 3.50$ & & 0.001 & 0.198 \\
\hline \multirow{3}{*}{$\begin{array}{l}\text { STNF-RGO } \\
(\mathrm{ng} / \mathrm{mL})\end{array}$} & Control & $0.95 \pm 0.13$ & $0.93+0: 14$ & $0.92 \pm 0.16$ & 0.451 & & \\
\hline & Fish oil & $0.93 * 0.14$ & $0.93 \pm 0.15$ & $0.96 \pm 0.19$ & & 0.794 & 0.718 \\
\hline & Weight loss & $0.90+0.20$ & $0.82 \pm 0.11$ & $0.82 \pm 0.08$ & & 0.003 & 0.420 \\
\hline \multirow{3}{*}{$\begin{array}{l}\text { STNF-R80 } \\
(\mathrm{ng} / \mathrm{mL})\end{array}$} & Control & $1.54 \pm 0.57$ & $1.46 \pm 0.48$ & 1. $38 \pm 0.47$ & 0.108 & & \\
\hline & Fish oil & $1.60 \pm 0.52$ & $1.40+0.41$ & $1.36 \pm 0.37$ & & 0.835 & 0.110 \\
\hline & Weight loss & $1.35+0.43$ & $1.21 \pm 0.36$ & $1.15 \pm 0.37$ & & 0.003 & 0.290 \\
\hline
\end{tabular}

Values are means $\$$ SD. Statistical differences between time points were analyzed with ANOVA based on data from the control group ( $n=11)$. Statistical differences for diet and diet time were analyzed with ANOVA for the fish oil study $(n=11)$ and weight loss study $(n=8)$ separately. 


\section{Figure 6.1:}

Changes in $\| L-6, T N F-\alpha, P A l-1$ antigen, and sTNF-receptor concentrations after a meal

A

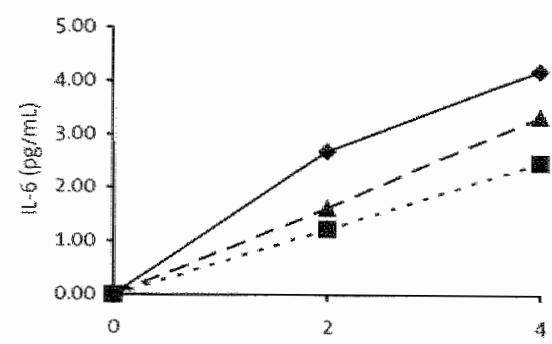

C

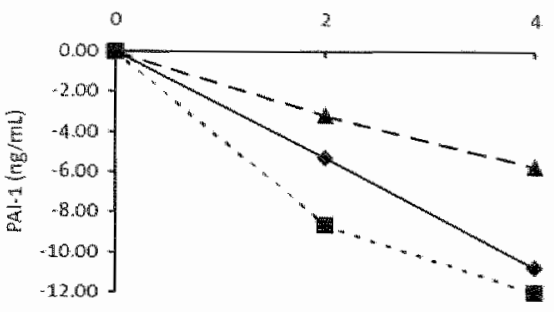

hime thours

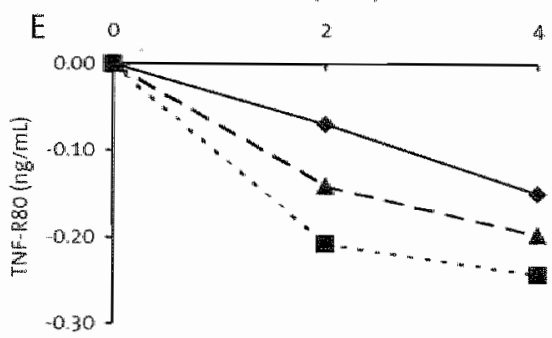

thme (hours.

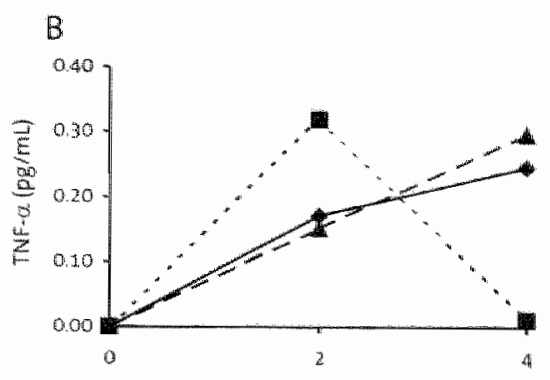

D

time thours

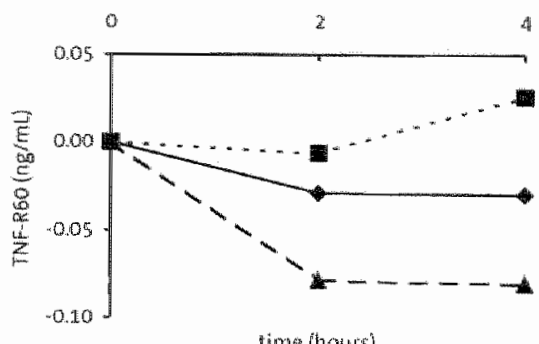

Fithent?

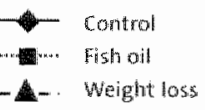

Values are means adjusted for fasting walues. Statistical differences between time points were anallyzed with ANOWA based on data from the control group $(n=1,1)$. Statistical differences for diet and diet $x$ time were analyzed with ANOVA for the fish oil studly $(n=11)$ and weight loss study $(n=8)$ separately.

\section{Effects of fish oil and weight reduction on postprandial effects}

During the postprandial study, $\mathbb{L}-\sigma_{\text {; }}$ PAl-1 antigen, sTNF-R60, and STNF-R80 concentrations were not statistically different between the fish oil and control period, but were significantly decreased after weight reduction (table 6.2). 
TNF- $\alpha$ concentrations were slightly, but not significantly, lowered after weight reduction.

Changes relative to fasting concentrations during the postprandial phase were not significantly affected by fish oil or weight reduction (figure 6.1, table 6.2 ), as evidenced by the $p>0.05$ for the interaction term diet $x$ time. After four hours, however, TNF $\alpha$ concentrations had nearly returned to fasting concentrations after the fish oil period, but not after the control or weight lass period.

\section{Discussion}

in this study with slightly obese men, we have compared the effects of fish oil and weight loss on inflammatory parameters and PAl-1 antigen concentrations during the fasting and postprandial state. in the fish oil study, the men consumed daily $1.35 \mathrm{~g}$ of omega-3 fatty acids from supplements, which can be provided by a daily consumption of about $70 \mathrm{~g}$ of fatty fish (12). Our data suggest that weight reduction resulted in reduced IL-6, PAI-1 antigen, and STNF-R concentrations and tended to decrease TNF- $\alpha$ concentrations. Fish oil supplementation did not affect $\mid L-6$, TNF- $\alpha, P A \mid-1$ antigen, STNF-R60 and STNF-R80 concentrations in the fasting or postprandial state. Changes relative to fasting concentrations during the postprandial phase were not significantly affected by fish oil or weight reduction.

\section{Effects of a meal}

IL- 6 concentrations increased in response to a meal. This extends the findings of Nappo et al (16), who studied in diabetic patients and healthy controls the effects of a high fat and a high carbohydrate meal on IL-6 concentrations. It was found that the high fat meal, but not the carbohydrate-rich meal, increased $1 \mathrm{~L} .6$ concentrations in healthy and diabetic subjects. This suggests that fat rather than carbohydrates increases postprandial IL.-6 concentrations. It should be realized however, that this increase in $\mathrm{L}-\mathrm{-6}$ concentrations not necessarily reflects an inflammatory response, as $\mathrm{IL}-6$ may also have a role in the regulation of satiety and thermogenesis (18).

Nappo et al (16) also observed increased TNF $\alpha$ concentrations in response to a high fat meal. However, in our study with obese subjects, the increase in TNF- $\alpha$ concentrations did not reach statistical significance, although the energy and fat contents of our standardized meal were comparable with those of Nappo et al (16). 
As opposed to TNF $\alpha$, the STNF-R8O concentration tended to decrease in response to a meall. The function of these sTNF-R is still largely unknown. STNF R are derived from two different membrane bound TNF-receptors (MTNF-R60 and MTNF-R8O) that become inactive upon shedding their TNFbinding domains as STNF-R. STNF-R may be involved in the inactivation of circulating TNF- $\alpha$ by binding TNF- $\alpha$ and competing with MTNF-R $(19,20)$. On the other hand, it has also been suggested that STNF-R serve as binding proteins to carry TNF- $\alpha$ from the side of production or act as a reservoir of bioactive TNF- $\alpha$ (19). Increased STNF-R concentrations have been related to the symptoms, clinical findings, and prognosis of infectious diseases, cancer, liver diseases and auto-immune diseases (21).

The observed decrease in PAI-1 antigen concentrations in response to a meal has also been found in other studies, but is hard to explain $(22,23)$. It is established that insulin, glucose, and very low density lipoprotein (VLDL) concentrations increase the secretion of PAl-1, suggesting an increase in PAl-1 secretion in response to a meal (24).

Postprandial studies in general can be difficult to interpret, as it is not always possible to disentangle circadian fluctuations from those of the response to the meal. Andreotti et al (25), for example, have reported an increase in PAI. 1 antigen levels during night hours. Further, Liebmann et al (20) observed that also concentrations of STNF-R80, but not of STNF-R60, exhibited a circadian rhythm and peaked at about 8 a.m., which may explain our decrease in STNF$\mathbb{R} 80$ concentration over time. On the other hand, if no meal is provided effects may be confounded due to a negative energy balance during a prolonged period of fasting. IL-6 concentrations may also differ over time due to sleepwake behavior with a peak IL-6 concentration at 6 a.m. and a nadir at 3 p.m. (26). This suggests that the increase in $1 \mathrm{~L}-6$ concentrations we observed in response to a meal was not due to circadian fluctuation. On the other hand, it is known that plasma $\quad$ L-6 concentrations may increase due to catheterinduced local IL-6 production (27).

\section{Effects of weight loss}

Synthesis and secretion of TNF- $\alpha$, STNF-R, IL-6 and PAI-1 antigen may all, at least in part, be regulated by adipose tissue $(17,28)$. Moreover, production of these substances is increased in obese subjects (29-32). Indeed, we observed a significant correlation between the percentage of body fat with IL-6 and PAI-1 antigen concentrations, but not with TNF- $\alpha$ or its soluble receptors. This finding suggests that higher proportions of circulating IL-6 and PAL-1 antigen concentrations are synthesized by adipose tissue as compared with the proportion of TNF- $\alpha$. In support, by measuring arterio-venous differences across a subcutaneous adipose tissue bed. Mohamed-Ali et al (33) could not 
demonstrate a signaficant contribution of adipose tissue to the serum concentrations of TNF- $\alpha$. After weight loss, we observed reduced concentrations of $1 \mathrm{~L}-6$, and PAl- 1 antigen and a trend towards reduced TNF- $\alpha$ concentrations, which corresponds with earlier studies (3, 4, 17). As metabolism of these substances is regulated by adipose tissue, a decrease after weight reduction may be caused by a decrease in fat mass. The reduction in STNF-R concentrations after weight reduction extends the results of Hauner et al (29), who found 30 to $40 \%$ higher circulating levels of both soluble receptor types in obese compared to lean subjects.

\section{Effects of fish oil}

As fish oil may have anti-inflammatory effects, we hypothesized that a fish oil intervention may be a possible dietary component in reducing metabolic risk factors in obese subjects. We did, however, not observe any beneficial effects during the fasting and postprandial phase on any of the inflammatory markers or on PAl-1 antigen concentrations. With respect to effects of fish oil on fasting inflammatory parameters, results are conflicting. Decreased levels of TNF- $\alpha$ and IL-1 after fish oil supplementation have been observed in an earlier in vitro study (5) with a dose of fish oil which was about five times higher ( $2.75 \mathrm{~g}$ EPA/day and $1.85 \mathrm{~g}$ DHA/day) as compared with the dose used in our study which provided daily $0.60 \mathrm{~g}$ EPA and $0.51 \mathrm{~g} \mathrm{DHA.} \mathrm{In} \mathrm{vitro} \mathrm{and} \mathrm{in}$ vivo studies are conflicting, as other in wivo studies with daily intakes of $n-3$ long chain polyunsaturated fatty acids ( $\mathrm{n}-3$ LCPUFA) varying from 1 to $3.5 \mathrm{~g}$ also did not find an effect of fish oil on inflammatory parameters $(6,34,35)$. However, the sensitivity of a person to suppressive effects of fish oil may be linked to the intrinsic level of production of the cells before supplementation and other individual factors, such as genetic wariation (35). Urfortunately, our sample is too small to stratify for intrinsic concentrations.

We observed no adverse effects of fish oil supplementation on PAI-1 antigen concentrations. The effects of fish oil on PAl-1 activity, which correlates with PAI-1 antigen concentrations (36), have been a matter of controversy. Barcelli et al (37) observed decreased PAl-1 activity after fish oil supplementation. However, other studies have reported no (8) or even increasing PAl-1 activity levels (7). Hansen et al (8) pooled data from 17 studies with a daily dose of $n-3$ fatty acids varying from $1.6 \mathrm{~g}$ to $7.7 \mathrm{~g}$. Only two of these studies reported an increase in PAl-1 activity after fish oil supplementation that differed from the control group. Additionally, the increase in EPA and DHA during fish oil treatment did not correlate with changes in PAI-1 activity, suggesting that there is no evidence for a direct influence of EPA and DHA on plasma PAI-1 activity. 


\section{Conclusion}

In contrast to fish oil supplementation, weight loss leads to reduced IL-6, PAI-1 antigen, and STNF-R and possibly to reduced TNF- $\alpha$ concentrations during the fasting and postprandial state. Changes from fasting to postprandial period concentrations were not affected by either weight loss or fish oil. We therefore concluded that, unlike weight reduction, a modest but realistic increased intake of fish oil is not a powerful intervention to lower the increased concentrations of inflammatory parameters and PAl-1 antigen concentrations as observed in obese subjects.

\section{Acknowledgements}

The study was supported by a grant from the Netherlands Organization for Scientific Research (NWO), grant number 980-10-006, Nutrition and Chronic Diseases. We are grateful to the members of our dietary and technical staff for their excellent support and to all subjects for their cooperation and interest. We are grateful to Dr ir P. Zock (Wageningen Centre for Food Sciences, Wageningen, the Netherlands) for providing us with the oil capsules. 


\section{References}

1. Mohamed-Ali $\mathrm{V}$, Pinkney $\mathrm{HH}$, Coppack SW. Adipose tissue as an endocrine and paracrine argan. Int J Obes 1998;22:1145-1158.

2. Cigolini $M$, Tonoli $M$, Borgato $L$, et al. Expression of plasminogen activator inhibitor-1 in human adipose tissue: a role for TNF-alpha? Atherosclerosis 1999;143:81-90.

3. Ziccardi P. Nappo F, Giugliano $G$, et al. Reduction of inflammatory cytokine concentrations and improvement of endothelial functions in obese women after weight loss over ane year. Circulation 2002; 105:804-809.

4. Rissamen $P$, Vahtera $E$, Krusius $T$, Uusitupa M, Rissanen A. Weight change and blood coagulability and fibrinolysis in healthy obese women. Int 1 Obes Relat Metab Disord $2001: 25: 212-218$

5. Endres 5 , chorbani $R$, Kelley VE, et al. The effect of dietary supplementation with $n-3$ polyunsaturated fatty acids on the synthesis of interleukin-1 and tumor necrosis factor by mononuclear cells. N Engl I Med 1989:320:265-271.

6. Blok WL, Deslypere J-P, Demacker PNM, et al. Pro- and anti-infilammatory cytokines in healthy wolunteers fed various doses of fish oll for 1 year. Eur I clin invest 1997:27:1003-1008.

7. Emeis Il, wan Houwelingen AC, van den Hoogen CM, Hornstra G. A moderate fish intake increases plasminogen activator inhibitor type-1 in human volunteers. Blood $1989: 74: 233-237$.

8. Hansen J, Grimsgaard $S_{*}$ Nordoy A, Bonaa K.H. Dietary supplementation with highly purified eicosapentaenoic acid and docosahexaenoic acid does not influence PAl-1. activity. Thromb Res 2000,98:123-132.

9. Dumstan DW, Mori TA, Puddey $\mathbb{B}_{\text {, }}$ et al. A randomised, controlled study of the effects of aerobic exercise and dietary fish on coagulation and fibrinolytic factors in type 2 diabetics. Thromb Haemost 1999:81:367 372.

10. Eritsland J, Arnesen $\mathrm{H}$, Seljeflot 1 , Kierulf $\mathrm{P}$. Long-term effects of $n-3$ polyunsaturated fatty acids on haemostatic variables and bleeding episodes in patients with coronary artery disease. Blood Coagull Fibrinolysis 1995:6:17-22.

11. Behandeling en preventie van coronaire hartziekten door werlaging van de plasmacholesterolconcentratie (treatment and prevention of coronary heart diseae by lowering plasma cholesterol concentrations). Utrecht: Centraal Begeleidingsorgaan voor de Intercollegiale Toetsing in samenwerking met de Nederlandse Hartstichting (in Dutch), 1998.

12. NEvO tabel. Nederlands yoedingstoffenbestand (Dutch food composition table). Den Haag: Stichting NEVO, Voorlichtingsbureau van de voeding (in dutch), 1998.

13. Nederlandse woedingsnormen 1989 (Dutch dietary guidelines 1989). Den Haag: Commissie Voedingsinormen, Voedingsraad, Voorlichtingsbureau voor de voeding (in dutch), 1992.

14. Leeuwenberg JF, Jeunhomme TM, Buurman WA. Slow release of soluble TNF receptors by monocytes in vitro. I mmunal 1994:152:4036-4043.

15. Otto 5I, van Houwelingen AC. Badart-Smook A. Hornstra $G$. Changes in the maternal essential fatty acid profile during early pregnancy and the relation of the profile to diet. Am J Clin Nutr 2001;73:302-307.

16. Nappo F. Esposito $K$, Cioffi $M$ et al. Postprandial endothelial activation in healthy subjects and in type 2 diabetic patients: role of fat and carbohydrate meals. I Am Coll Cardiol 2002;39:1145-1150. 
17. Bastard JP, Jardel $C$. Bruckert $E$, et al. Elevated levels of interleukin $G$ are reduced in serum and subcutaneots adipose tissue of obese women after weight loss. I Clith Endocrinol Metab 2000;85:3338-33:42.

18. Rothwell NJ. CNS regulation of thermogenesis. Crit Rev Neurobiol 1994:8:1-10.

19. van Greevenbroek MM, wan der Kallen CJ, Geurts JM, Janssen RG. Buurman WA, de Bruin TW. Soluble receptors for tumor mecrosis factor-alphal (TNF-R P55 and TNF-R P75) in familial combined hyperlipidemia. Atherosclerosis 2000;153:1-8.

20. Liebmann PM, Reibnegger $G$, Lehofer $M$, et al. Circadian rhythm of the soluble p75 tumor necrosis factor (STNF-R75) receptor in humans-a passible explanation for the circadian kinetics of TNR-alpha effects. Int Immunol 1998;10:1393-1396.

21. Diez-Ruiz A. Tilz GP, Zangerle R, Baier-Bitterlich $G$, Wachter $H$, Fuchs $D$. Soluble receptors for tumour necrosis factor in clinical laboratory diagnosis. Eur $J$ Haematol 1995:5:4:1-8

22. Tholstrup T. Marckmann P. Hermansen J. Holmer $G$, Sandstrom B. Effect of modified dairy fat on fasting and postprandial haemostatic variables in healthy young men. $\mathrm{Br}$ if Nutr 1999:82:105-113.

23. Salomaa $V$, Rasi $V$, Pekkamen J, et al. The effects of saturated fat and $n-6$ polyunsaturated fat on postprandial lipemia and hemostatic activity. Atherosclerosis 1993:103:1-11.

24. Nordt TK, Peter K, Ruef J, Kubler W, Bode C. Plasminogen activator inhibitor type-1 (PAI. 1) and its role in cardiovascular disease. Thromb Haemost 1999;82 Suppl 1:14-18.

25. Andreotti F, Davies G. Hackett DR, et al. Major circadian fluctuations in fibrinolytic factors and possible relevance to time of onset of myocardial infarction, sudden cardiac death and stroke. Am I Cardiol 1988;62:635-637

26. Undar $L$, Ertugrul $C$, Altumbas $H$, Akca 5. Circadian variations in natural coagulation inhibitors protein $C$, protein 5 and antithrombin in healthy men: a possible association with interleukin-6. Thromb Haemost 1999;81:571-575.

27. Haack $M$, Kraus $T$, Schuld $A$, Dafal $M$, Koethe $D$, Pollmacher $T$. Diurnal variations of interleukin-6 plasma levels are confounded by blood drawing procedures. Psychoneuroendocrinology 2002;27:921.

28. Juhar-Vague 1. Alessi MC. PAl-1, obesity, insulin resistance and risk of cardiovascular events. Thromb Haemost 1997:78:656-660.

29. Hauner $H$, Bender $M_{2}$ Haastert $B$. Hube F. Plasma concentrations of soluble TNF-alpha receptors in obese subjects. Int 1 Obes 1998:22:123911243.

30. Hotamisligil GS. The role of TNF-a and TNF receptors in obesity and insulin resistance. I Intern Med 19:99:245:621-625.

31. Mutch N: Witson HM, Booth NA. Plasminogen activator inhibitor-1 and haemostasis in obesity. Proc Nutr 5oc 2001,60:341-347.

32. Yudkin JS, Kumari M, Humphries SE, Mohamed-Ali V. Inflammation, obesity, stress and coronary heart disease: is interleukin-6 the link? Atherosclerosis 1999:148:209-214.

33. Mohamed-Ali $V$, Goodrick $S$, Rawesh $A$, et al. Subcutaneous adipose tissue releases interleukin-6, but not tumor necrosis factor-alpha, in viwo. 1 Clin Endocrinol Metab 1997:82:4196-4200.

34. Chan DC, Watts GF, Barrett PH, Beilin U. Mori TA. Effect of atorvastatin and fish oil on plasma high-5ensitivity C-reactive protein concentrations in individuals with visceral obesity. Clin Chem 2002; $48: 877-883$.

35. Grimble RF, Howell WM, O'Reilly $G$, et al. The ability of fish oil to suppress tumor necrosis factor alpha production by peripheral blood mononuclear cells in healthy men is associated with polymorphisms in genes that influence tumor necrosis factor alpha production. Am J clin Nutr 2002;76:454-459. 
36. Leng HM, Browwers E, Knockert!, Declerck PJ. Immunoassays for the quanttation of porcine PAl antigen and activity in biological fluid samples. Thromb Haemost $2000 ; 84: 1082-1086$.

37. Barcelli $U$, Glas-Gileenwalt $P$, Pollak VE. Enhancing effect of dietary supplementation with omega-3 faty acids on plasma fibrinolysis in nomal subjects. Thromb Res $1985: 39 \times 307-312$ 


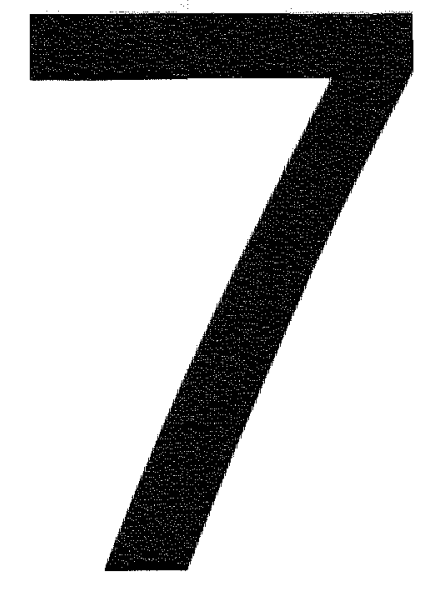

General discussion 
The main objectives of the studies described in this thesis were to evaluate the interrelationships between body mass index, genetic background and dietary interventions on metabolic risk markers, related to lipid and glucose metabolism. For this, we have compared in a cross-sectional study the associations between the insulin receptor substrate-1 (IRS-1) Gly972Arg polymorphism and metabolic risk markers in subjects with a high body mass index (BMI) (mean BMI $31.2 \mathrm{~kg} / \mathrm{m}^{2}$ ) or low BMI (mean BMI $21.9 \mathrm{~kg} / \mathrm{m}^{2}$ ). Since an increased fat mass is known to decrease insulin action, we have examined if these relationships were more pronounced in subjects with a high BMI than in subjects with a low BMI. In addition, we examined the impact of the Gly972Arg variant on the prevalence of type 2 diabetes by means of a metaanalysis. Further, relationships between two other polymorphisms, the tumor necrosis factor- $\alpha$ (TNF- $\alpha$ ) G308A and the interleukin-6 (IL-6) G174C polymorphism, and metabolic risk markers were studied in subjects with a high and low BMI. Finally, the effects of fish oil supplements and weight reduction on lipid and glucose metabolism and on inflammatory markers were explored in an intervention study with obese subjects. Especially, the effects of these interventions on subcutaneous adipose tissue metabolism and inflammatory responses were addressed during both the postabsorptive and postprandial phase.

\section{Main findings}

In a cross-sectional study, relationships between fasting metabolic risk markers and the Gly972Arg polymorphism in the IRS-1 gene were examined in a high BMI group (BMI $26-40 \mathrm{~kg} / \mathrm{m}^{2} ; n=304$ ) and a low BMI group (BMI 18 $\left.24 \mathrm{~kg} / \mathrm{m}^{2} ; n=296\right)$. In all subjects together, the IRS-1 972Arg variant was associated with higher insulin and lower triglyceride (TG) concentrations (chapter 2). Although the differences were more pronounced in the high BMI group, the impact of BMI was less pronounced than hypothesized before (1, 2). In our meta-analysis (chapter 3), we found that the IRS-1 972Arg variant was associated with a $25 \%$ higher risk for type 2 diabetes. Thus, based on the results of chapter 2 and 3 , it can be speculated that the IRS-1 972Arg variant is related to metabolic disturbances.

In chapter 4 , we found that the GG variant of the TNF- $\alpha$ G308A polymorphism was associated with higher TG and high density lipoprotein cholesterol (HDLC) concentrations in subjects with a high BMI. The GG variant of the IL-6 G174C polymorphism was related to a higher waist to hip ratio in the high $\mathrm{BMI}$ group. These relationships were not found in the low BMI group.

In chapter 5, the impact of fish oil and weight reduction on subcutaneous adipose tissue lipolysis has been studied, which is positively related to insulin 
resistance $(3,4)$. As weight reduction and possibly fish oil decrease insulin resistance, we hypothesized that these two interventions decrease subcutaneous adipose tissue lipolysis in the fasting and postprandial period. To examine this, eleven obese men with a BMI between 30 and $35 \mathrm{~kg} / \mathrm{m}^{2}$ received for two periods of six weeks in random order control capsules or fish oil capsules that provided daily $0.60 \mathrm{~g}$ eicosapentaenoic acid (EPA; C20:5n-3) and $0.51 \mathrm{~g}$ docosahexaenoic acid (DHA; C22:6 $\mathrm{n}$-3). Eight of them also participated in a weight reduction study, in which the men received first a very low calorie diet (VLCD) for four weeks followed by an energy-restricted diet for two weeks, and a diet to maintain body weight for another two weeks. Subjects lost on average $9.36 \mathrm{~kg}$ of body weight. At the end of each period, a postprandial test took place, during which subcutaneous abdominal adipose tissue lipolysis was measured with the microdialysis technique. In contrast to our hypothesis, subcutaneous abdominal adipose tissue lipolysis was increased in the late postprandial period after fish oil supplementation and weight reduction, although insulin sensitivity was improved. In chapter 6, the effects of these two interventions on circulating concentrations of proinflammatory cytokines and plasminogen activator inhibitor-1 (PAl-1) antigen, which are all secreted by adipose tissue (5), were examined. It was found that weight loss reduced IL-6, PAI-1 antigen, and soluble TNF-receptors (sTNF-R) and tended to reduce TNF- $\alpha$ concentrations during the fasting and postprandial state. Fish oil supplementation did not change any of these parameters.

\section{Methodological considerations in studying adipose tissue}

Adipose tissue plays a central role in the studies described in this thesis. Firstly, polymorphisms in three genes that are expressed by adipose tissue have been studied. Secondlly, the effects of fish oil and weight reduction on adipose tissue metabolism were determined.

Adipose tissue is a heterogeneous organ with varying metabolic activities in the different fat depots (6). For instance, lipolysis and secretion of substances between visceral and subcutaneous adipose tissue differ. The lipolytic activity is higher in the visceral compared with the activity in the abclominal subcutaneous area. Further, the lipolytic action of catecholamines is greatest in the visceral area, while the antilipolytic action of insulin is more pronounced in the abdominal subcutaneous depot. This suggests that the rate of lipolysis is higher in visceral compared with that in abdominal adipose tissue. The expression of inflammatory markers also differs between fat 
depots. Whereas subcutaneous adipose tissue has higher MRNA TNF-a levels than visceral adipose tissue (7), the opposite is true for IL-6 and PAI-1 $(8,9)$. Both subcutaneous and visceral adipose tissue increase with increasing weight in both sexes (10), but the amount of visceral fat rather than the amount of abdominal subcutaneous fat seems to be correlated with complications of obesity (11).

For ethical and practical reasons it is hardly possible to directly study the rate of lipolysis in visceral adipose tissue with current techniques. We therefore studied the effects of fish oil supplementation and weight reduction on subcutaneous adipose tissue lipolysis. However, due to the heterogeneity of adipose tissue, it remains to be determined if these results cam be extrapolated to visceral adipose tissue.

Another methodological consideration is that adipose tissue secretes components with a local function, like TNF- $\alpha$. The concentrations of TNF-a are not increased in venous blood draining the subcutaneous adipose tissue (12), suggesting that TNF- $\alpha$ has an autocrine or paracrine function (13). We did mot observe significant effects of fish oil and weight reduction on circulating arterialized TNF- $\alpha$ concentrations, although TNF- $\alpha$ concentrations tended to be reduced after weight loss. Possibly, the effect of both interventions on TNF- $\alpha$ expression in adipose tissue is not reflected by changes in circulating concentrations. In future intervention studies, it may be interesting to compare the effects of circulating concentrations with measurements in adipose tissue itself.

\section{Impact of polymorphisms}

A polymorphism arises as a result of mutation. For a polymorphic locus, the most common variant among them occurs with less than $99 \%$ frequency in the population at large (e.g. if the locus is biallelic, the rarer allele must occur with a frequency greater than $1 \%$ in the population) (14). An important question is how many genes, with what sizes of effects, are responsible for heritability of phenotypic expression and indirectly complex diseases, such as obesity, type 2 diabetes, and coronary heart disease (CHD) (15). 50 far, mutations in candidate genes can explain only a few rare cases of monogenic forms of obesity, CHD, and type 2 diabetes, for example Prader-Willi syndrome (16), familial combined hyperlipidemia (FCH) (17) or maturity-onset diabetes of the young (MODY) (18). A number of susceptibility gene variants has been identified, which by themselves are not sufficient to lead to complexes diseases, but do modulate the phenotypic expression of the disease. However, relationships between polymorphisms and phenotypes are complex and determined by interrelationships of a multitude of genetic and 
environmental factors (14). This multifactorial nature makes it difficult to pinpoint the contribution of one single individual factor to a phenotype, also because the effect of any factor may be obscured or modified by the effects of others.

The polymorphisms that we have studied, were associated with only a limited number of metabolic risk markers. The IRS-1 Glyg72Arg polymorphism was associated with higher insulin and lower TG concentrations. The TNF-0 G308A polymorphism and IL-6 G174C polymorphism were associated with TC and HDL-C concentrations and waist to hip ratio respectively. However, extrapolating these results to the general population, the impact of these polymorphisms on health may still be large. For example, the AA genotype of the TNF-a polymorphism was observed in only 20 subjects in our population (3.3\%), but this corresponds with approximately half a million men and women in the Netherlands. Based on our results, these subjects have $0.3-0.4$ mmol/L higher TG concentrations. Subjects with a high BMI even had 1.05 and $1.18 \mathrm{mmol} / \mathrm{L}$ higher TG concentrations compared with subjects with the GA and $G G$ variant. Results from a meta-analysis have now shown that an $1 \mathrm{mmol} / \mathrm{L}$ increase in TG concentrations was associated with a $32 \%$ increase in cardiovascular disease risk in men and a $76 \%$ increase in women (19).

Due to the low prevalence of several polymorphisms, such as the TNF- $\alpha$ polymorphism, the chance of a type 2 error in small studies is large. For example, the meta-analysis described in chapter 3 found a significantly higher risk in the prevalence of type 2 diabetes in carriers of the Arg972 variant, but a significant effect of this polymorphism was only found in two of the individual studies $(20,21)$ used in this meta-analysis. One way to reduce the chance of a type 2 error is by specific oversampling of the genotype with the lowest prevalence as described in this thesis (chapter 2).

As phenotypes are polygenic, analyzing gene-gene interactions is useful, but again the chance of type 2 errors can be large. The gene-gene interaction between the TNF $\alpha$ and $I L-6$ polymorphilsm on TG concentrations from chapter 4 , is illustrated in figure 7.1. Subjects with the IL-6 GG variant and the TNF- $\alpha$ AA variant had significantly higher TG levels compared with all other combinations. Although the number of subjects in each group was small, this example suggests that especially the combinations of various genotypes may rellate to metabolic risk markers.

To conclude, the number of statistically significant associations in this thesis between the three polymorphisms studied and metabolic risk markers was not large. However, unraveling the role of polymorphisms on key metabolic pathways in large databases is crucial to understand the impact of polymorphisms on health and disease. 


\section{Figure 7.1:}

Gene-gene interaction between the G174C LL-6 polymorphism and the G308A TNF-Q polymorphism on TG concentrations

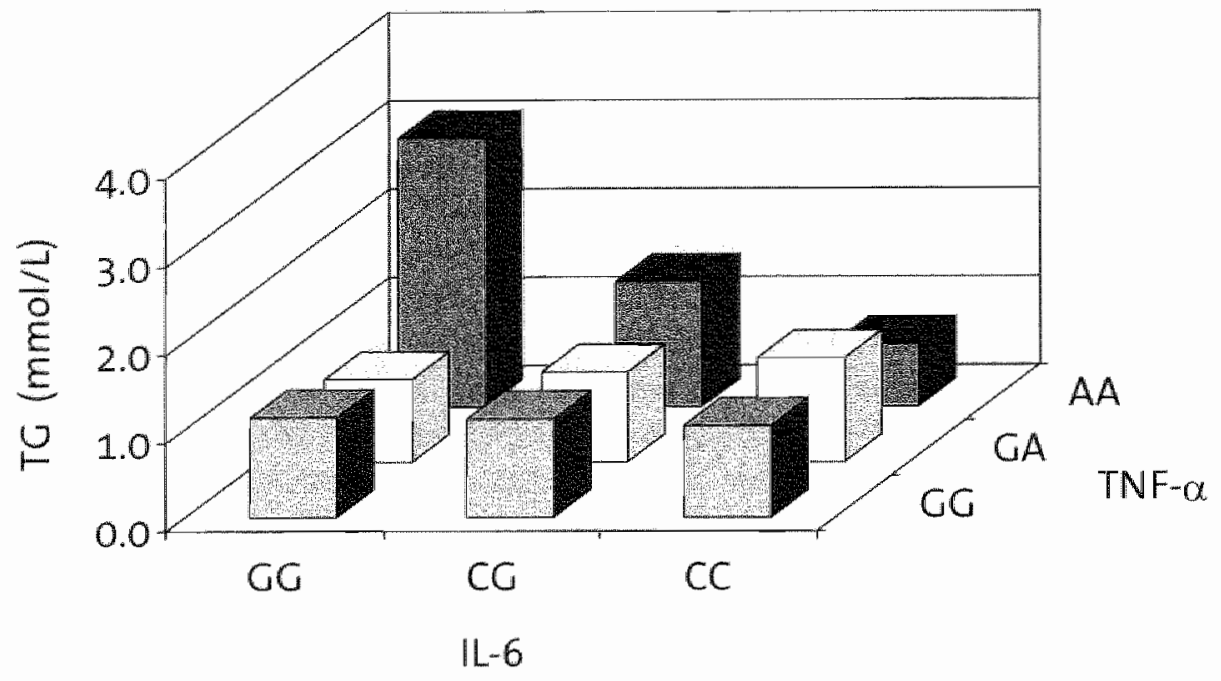

\section{Gene-environment interactions}

Gene-environment interactions arise when the response of a phenotype to environmental factors is modulated by the genotype of the individual (22). In the population there is a range of genetic risk profiles, with each individual occupying a position along the genetic risk spectrum (23). Similarly, individuals have a different position on the environmental spectrum of risk by the life style choices they make. However, in contrast to genetic factors, environmental risk factors are modifiable. In the cross-sectional studies described in chapters 2 and 4 we have examined whether BMI modified the relationship between genotype and metabolic risk markers. In chapter 2 we found that effects of the IRS-1 972Arg variant on insulin concentrations only reached statistical significance in the high BMI group. The difference in TG concentrations between carriers and non-carriers was significant in both the high and low BMI group. These findings suggest that for the IRS-1 polymorphism modification by BMI is smaller than suggested in previous studies $(1,2)$. The strength of the associations between polymorphisms in the TNF $\alpha$ and $\mid \mathrm{L}-6$ gene with TG concentrations and waist to hip ratio respectively, more clearly depended on BMI.

There are many other environmental variables that may modify the effects of polymorphisms on metabolic risk markers. We did some exploratory analyses 
and observed a gene-environment interaction between the Gly972Arg variant and the level of physical activity on HDL-C concentrations, which is shown in figure 7.2 .

Subjects heterozygous for the Gly972Arg variant and with a low physical activity level had significantly lower HDL-C concentrations compared with subjects without these variant or with a high physical activity level. This indicates the importance of studying gene-environment interactions in relation to metabolic disorders. The classical way to search for a geneenvironment interaction is to carry out an association study with stratification for the presence of an environmental factor as shown in figure 7.2 (24). A potentially more powerful approach is by a "genotype-stress" study, an intervention study in which the response of subjects with different genotypes to an environmental factor on metabolic risk markers is compared (for instance subjects with or without a Gly972Arg polymorphism on a fish oil diet). Once results have been confirmed by other independent studies, these findings may lead to genotype-specific life-style advices.

\section{Impact of dietary interventions}

Obesity has emerged as an epidemic in developed countries during the last quarter of the $20^{\text {th }}$ century (25) increasing between 1976 and 1997 from $4.9 \%$ to $8.5 \%$ among men and from 6.2 to $9.3 \%$ among women in the Netherlands (26). Although genetic susceptibility plays a role in the regulation of body weight, the rapid increase in the prevalence of overweight and obesity during the past two decades suggest that environmental factors are promoting, or at least favoring, the occurrence of abesity (27). As obesity is the consequence of a higher energy intake compared with energy expenditure, lowering energy intake ar increasing energy expenditure will reduce body weight. In this thesis we focused on the effects of energy restriction on metabolic risk markers. However, prolonged weight loss by energy restriction is difficult to achieve. In this respect, effects of dietary components on metabolic risk markers in overweight and obese subjects are of great interest. There is some evidence, for example, that decreasing saturated fatty acid and increasing monounsaturated fatty acid intakes, improve insulin sensitivity (28). Also, fish oil, which is rich in EPA and DHA, decreases metabolic risk markers, especially TG concentrations (29). 


\section{Figure 7.2:}

Relationship between the Gly972Arg variant of the IRS-1 polymorphism and the level of physical activity on HDL-C concentrations adjusted for age and sex

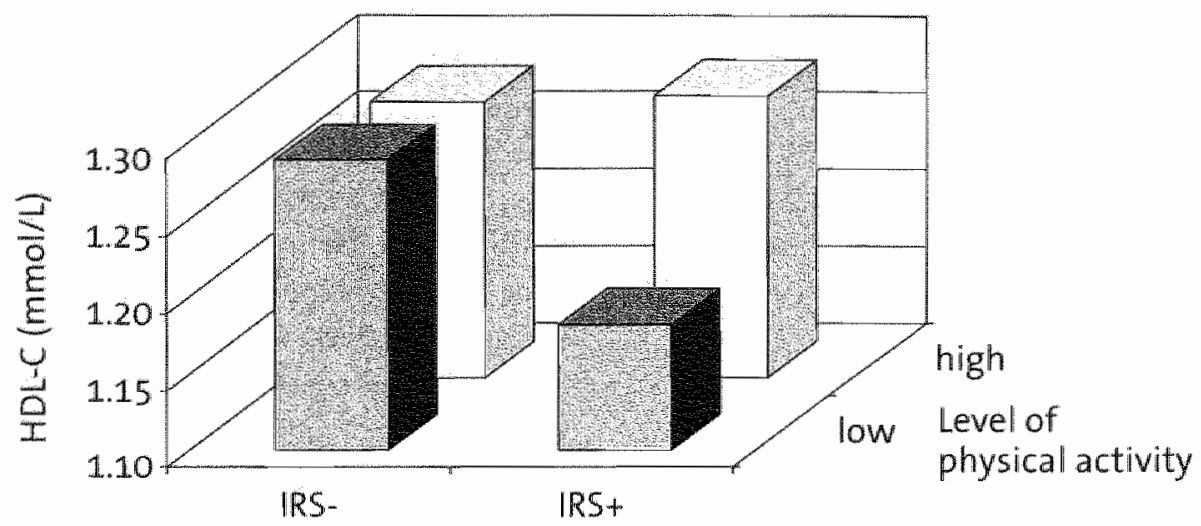

Gly972Arg variant

\section{Weight reduction}

Weight reduction is a powerful measure for the treatment of the metabolic syndrome (30). Weight reduction for instance improves an unfavorable lipoprotein profile (31), decreases basal lipolysis rate (32), and improves insulin sensitivity (33). In our study, subjects lost on average $10 \%$ of their initial weight (chapters 5 and 6 ), which already resulted in clinically relevant effects on for instance insulin, non-esterified fatty acids (NEFA) and TG concentrations. We also observed beneficial effects of weight reduction on inflammatory and fibrinolytic markers. Moreover, weight reduction resulted in an increased subcutaneous abdominal adipose tissue lipolysis during the late postprandial period, although insulin sensitivity was improved. This suggests that postprandial subcutaneous adipose tissue lipolysis may not be a major mechanism underlying the reduced TC concentrations after weight reduction.

In this thesis, subjects lost weight on a VLCD, which is very effective for the short-term treatment of obesity (34). The beneficial effects of weight reduction are usually preserved as long as weight is not regained (30). However, most subjects regain their lost weight (34). Weinstock et al (33) observed that only a partial regain already resulted in a marked increase in insulin levels. A VLCD in combination with active follow-up treatment, such as 
nutritional education, seems to be one of the better dietary treatment modalities for long-term weight maintenance success (34).

\section{Fish oil}

Several beneficial effects of fish oil on the risk for CHD have been observed (35). Depending on the dose of fish oil used, these have been explained by the effects of fish oil on platelet aggregation (36), blood pressure (37), TG concentrations (38) and reduction of arrhytmia (39). In addition, fish oil reduces dyslipidemia in visceral obesity (40) and is associated with a lower risk to develop type 2 diabetes (41).

However, the impact of short-term consumption of the low dose of fish ail on metabolic risk markers used in our study was only evident for a few parameters. Although a daily supplement of $1.35 \mathrm{~g}$ of fish oil reduced TG concentrations and tended to reduce insulin concentrations, it did not affect fasting TNF-a, IL-6, and PAl-1 concentrations.

As fisth oil may improve insulin resistance and postprandial metabolism, we hypothesized that this intervention would decrease subcutaneous adipose tissue lipolysis during the postprandial period. This was not observed. In fact, subcutaneous adipose tissue lipolysis (per unit tissue mass) was increased during the late postprandial period. A possiblle explanation for this effect may be through effects of fish oil on gene expression, downregulating the expression of lipogenic genes and at the same time upregulating the expression of genes involved in lipid oxidation (42). At this time, however, precise mechanisms are not known and require further study.

The dose of omega-3 fatty acid of $1.35 \mathrm{~g} /$ day $(0.60 \mathrm{~g} / \mathrm{day}$ of EPA and 0.51 g/day of DHA), can be achieved through a daily consumption of about $70 \mathrm{~g}$ of fatty fish. The dose of omega-3 fatty acids we have used was low compared with doses (>2 g/day) used in other intervention studies (43-45). This may have abscured some of the beneficial effects attributed to fish oil. However, low doses of omega-3 fatty acids may be preferable because of the prossible adverse effects of high doses ( $>3$ g/day). Negative health effects of high intakes of omega-3 fatty acid supplements have been reported on glycemic control in patients with diabetes (46), on bleeding tendencies (47), and on low density lipoprotein cholesterol (LDL-C) concentrations in hypertriglyceridemic patients (48). However, the safety of a lower intakes is not an issue.

\section{Combination of fish oil and weight reduction}

From this thesis it is clear that weight reduction of about $10 \%$ of body weight is a much more powerful intervention to improve metabolic risk markers and inflammatory factors than a low dose of fish oil. We did not study the 
combination of fish oll and weight reduction on ameliorating metabolic disturbances seen in obesity. Mori et al (49) reported that incorporating a daily fish meal into a weight loss regimen was more effective than either intervention alone in improving glucose-insulin metabolism and dyslipidemia. In contrast, Kriketos et al (50), however, observed no additional effect on blood pressure or the plasma lipid profile by the type of fatty acid consumed as part of an energy-restricted diet. There was a trend, however, for omega-3 fatty acids to have a protective effect on fat-free mass loss, and insulin sensitivity. Based on these findings a combination of both interventions seerns an interesting option for reducing metabolic risk markers in obese subjects.

\section{Postabsorptive and postprandial studies}

Most studies on the effects of dietary treatment on metabolic risk markers have been carried out in the fasting state. Only a few studies have been carried out during the postprandial phase. This is surprising as most people are in the postprandial state most of the day, while information obtained from postprandial studies may differ from fasting studies. At the same time, however, it should be acknowledged that postprandial studies are difficult to perform and to standardize. Many conditions may affect postprandial responses such as the composition of the test meal and the background diet (51). Another important aspect that complicates the interpretation of postprandial studies is the circadian cycle. For example, higher TG concentrations have been observed after a meal eaten at night than during the day (52).

Results from the control period of the intervention study, described in chapters 5 and 6 , showed that insulin, glucose, NEFA and TG concentrations changed significantly in response to the meal. After an initial decrease, NEFA concentrations started to return to fasting levels two hours after the meal possibly due to the insulin-stimulated increase of lipoprotein lipase (LPL) activity (53). A peak in TG concentrations was seen approximatelly 4 hours after the meal, which was also observed in other studies (54, 55). IL-6 concentrations significantly increased and PAl-1 concentrations significantly decreased in response to a meal. As for fasting values, weight reduction had a more pronounced effect on postprandial responses than fish oil. Compared with the control diet, there was a diet-dependent change in glycerol release and glucose concentrations after weight reduction, suggesting a change in postprandial response. Fish oil did not change the postprandial response significantly. Several earlier studies have found that fish oil lowered 
postprandial TG responses (56-58). It should be noted however that in these studies the dose of fish oil was 2-3 times higher compared with our study.

Such results provide insight into mechanisms, but in which way these effects relate to health is hardly known. Thus, although postprandial studies are essential to evaluate a subject's risk for metabolic disorders, more standardization between studies is needed for a proper interpretation of the results.

\section{Conclusions and future research}

Our results have shown that both genetic and environmental factors have important effects on metabolic risk markers, especially in subjects with an increased BMI. At the same time, it should be emphasized that one single polymorphism determines only in a small number of cases the difference between health and disease. In general, the genetic component of these markers is the result of polygenic interactions involving the simultaneous inheritance of several widespread mutations, each with subtle or minor effects on the development of the phenotypes. The sum of effects of these genetic variants is the basis on which environmental risk factors act (1).

In future research the impact of interactions between several genes and between genes and environment is important. For example, the most recent obesity gene map indicates that there are more than 300 genes or marker loci that have the potential to influence obesity (59). These rapid advances in genetics may present new and complex ethical issues for both the individual and society. Notwithstanding one can anticipate that major advances will occur in the coming years with respect to the identification of polygenetic causes of the susceptibility to metabolic risk markers, which may eventually cause complex diseases, including obesity, CHD and type 2 diabetes. 


\section{References}

1. Clausen 10, Hansen T, Bjprbaek $C$, et all. Insulin resistance: interactions between abesity and a common variant of insulin receptor substrate-1. Lancet 1995;346:397-402.

2. Baroni MG. Arca $M$, Sentinelli $F$, et al. The $G 972 R$ variant of the insulin receptor substrate-1 (IRS-1) gene, body fat distribution and insulin-resistance. Diabetologia 2001:44:367\%372.

3. Després J.P. Abdominal obesity as important component of insulin-resistance syndrome. Nutrition 1993;9:452-459.

4. Coppack $5 W_{i}$ Jensen MD, Miles $I M$. In wiwo regulation of lipolysis in humans. Il Lipid Res 1994:35:177 193.

5. Cigolini $M$, Tonoli M. Borgato $L$, et al. Expression of plasminogen activator inhibitor-1 in human adipose tissue: a role for TNF.alpha? Atherosclerosis 1999;143:81-90.

6. Arner P. Regulation of lipolysis in fat cells. Diabetes Rev 1996:4:450-463.

7. Hube F. Hauner $H$. The role of TNF $\alpha$ in human adipose tissue: prevention of weight gain at the expense of insulin resistance? Horm Metab Res 1999:31:626-631.

8. Fried SK, Bunkin DA, Greenberg AS. Omental and subcutaneous adipose tissues of obese subjects release interleukin 6 : depot difference and regulation by glucocorticoid. J Clin Endocrinol Metab 1998;83:847-850.

9. Biastard IP, Pieroni L, Hainque B. Rellationship between plasma plasminogen activator inhibitor 1 and insulin resistance. Diabetes Metab Res Rev 2000;16:192-201.

10. Wajchenberg BL. Subcutaneous and wisceral adipose tissue: their relation to the metabolic syndrome. Endocr Rev 2000;21:697-738.

11. Arner P. Regionall adipocity in man. J Endocrinol 1997;155:191-192.

12. Mohamed-Ali $V$, Goodrick $S$, Rawesh $A_{0}$ et al. Subcutaneous adipose tissue releases interleukin-6, but not tumor necrosis factor-allpha, in wivo. J Clin Endocrinol Metab 1997:82:41:96-4200.

13. Hotamisligil G5, Spiegelman BM. Tumor necrosis factor a: a key component of the obesity-diabetes link. Diabetes 1994:43:1271-1278.

14. Schork NJ, Fallin D, Lanchbury JS. Single nucleotide polymorphisms and the future of genetic epidemiology. Clin Genet 2000:58:250-264.

15. Keavney B. Genetic epidemiological studies of coronary heart disease. Int $J$ Epidemiol 2002:31:730-736.

16. Hitman GA. Molecular genetics of obesity. In: Kopelman PG, Stock MJ, eds. Climical Obesity. Oxford: Blackwell Science, 1998:73-85.

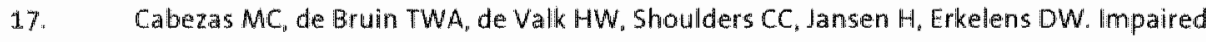
fatty acid metabolism in familial combined hyperlipidernia. J Clin Invest 1993:92:160168.

18. Winter WE, Silverstein JH. Molecular and genetic bases for maturity onset diabetes of youth. Curr Opin Pediatr 2000;12:388-393.

19. Hokanson JE, Austin MA. Plasma triglyceride level is a risk factor for cardiovascular disease independent of high-density lipoprotein cholesterol level: a meta-analysis of population-based prospective studies. 1 Cardiovasc Risk 1996;3:213-219.

20. Baroni MG. D'Andrea MP, Montali $A_{2}$ et al. A common mutation of the insulin receptor substrate-1 gene is a risk factor for coronary artery disease. Arterioscler Thromb Wasc Biol 1999; 19:2975-2980.

21. Rosskopf D, Frey U, Eckhardt $S$, et al. Interaction of the $G$ protein beta 3 subunit $T 825$ allele and the IRS-1. Arg972 varlant in type 2 diabetes. Eur J Med Res 2000;5:484-490. 
22. Clayton D, Mckeigue PM. Epidemiological methods for studying genes and enwironmental factors in complex diseases. Lancet 2001;358:1356-1360.

23. Stephens IW. Humphries SE. The molecular genetics of cardiovascular disease: timical implications. Interí Med 2003;25:120-127.

24. Humphries SE, Donati MB. Analysis of gere-environment interaction in coronary artery disease. ltal Heart $12002 ; 3: 3-5$.

25. Popkin BM, Doak CM. The obesity epidemic is a worldwide plrenomenon. Autr Rev $1998 ; 56: 106-114$.

26. Visscher $\mathrm{TL}$, Kromhout $\mathrm{D}$, Seidell JC. Long-term and recent time trends in the prevalence of obesity among Dutch men and Women. Int 1 Obes Rellat Metab Disord 2002;26:1218. 1224 .

27. Hill JO, Melanson EL, Wyatt HT. Dietary fat intake and regulation of energy balance: implications for obesity. IN Nutr 2000:130:2845-2885.

28. Vessby B, Unsitupa M. Hermansen $K$, al. Substituting dietary saturated for monounsaturated fat impairs insulin sensitivity in healthy men and women: The KANWU Study. Diabetologia 2001:44:312-319.

29. Roche HM, Gibney M. Effect of long-chain n-3 polyunsaturated fatty acids on fasting and postprandial triacylglycerol metabolism. Am J Clin Nutr 2000;71:2325-2375.

30. Riccardi $G_{*}$ Rivelhese AA. Dietary treatiment of the metabolic syndrome--the optimal diet. BrJ Nutr 2000;83 Suppl 1:5143-148.

31. Dattilo AM, Krism Etherton PM. Effects of weight reduction on blood lipids and lipoproteins: a meta-analysis. Am I Clin Nutr 1992:56:320-328.

32. Reynisdottir S, Langin D, Carlstrom K, Holm C, Rossner 5, Arner P. Effects of weight reduction on the regulation of lipolysis in adipocytes of women with upper-body obesity. Clin Sci (Lond) 1995:89:421\%429.

33. Weinstock R5, Dai H. Wadden TA. Diet and exercise in the treatment of obesity: affects of 3 interventions on insulin resistance. Arch Interin Med 1998;158:2477-2483.

34. Saris WH. Very-low-Calorie diets and sustained weight loss. Oben Res 2001:9 Suppl 4:2955-3015.

35. Kris-Etherton PM, Harris WS, Appel U. Fish consumption, fish oil, omegai-3 fatty acids. and cardiovascular disease, Circulation 2002;106:2747-2757.

36. Mori TA, Beilin $\omega$, Burke V, Morris J, Ritchie J. Interactions between dietary fat, Fish, and fish oils and their effects on platelet function in men at risk of cardiovascular disease. Arterioscler Thromb Vase Biol 1997;17:279-286.

37. Howe PR. Dietary fats and hypertension. Focus on fish oil Ann N $Y$ Acad $5 \mathrm{ci}$ $1997 ; 827: 339-352$.

38. Harris WS. n-3 fatty acids and serum lipoprotenins: human studies. Am 1 Oin Nutr $1997 ; 65: 16455-16545$.

39. Dietary supplementation with n-3 polyunsaturated fatty acids and vitamin $E$ aftier myacardial infarction: results of the GISSI-Prevenzione trial. Gruppo thaliano per lo Studio della Soprawivenza nell'infiarto miocardico. Lancet 1999;354:447-455.

40. Chan DC, Watts GF, Mori TA, Barrett PH, Beilin LI, Redgrave TG. Factorial study of the effects of atorvastatim and fish oil on dyslipidaemia in visceral obuesity. Eur I Clin Invest $2002 ; 32: 429-436$.

41. Goh YK, Jumpsen IA, Ryar EA, Clandinin MT. Effect of omega 3 fatty acid on plasma Iipids, cholesterol and lipoprotein fatty acid content in NDDM patients. Diabetologia $1997: 40: 45-52$.

42. Price PT, Nelson CM, Clarke SD. Omega-3 polyunsaturated fatty acid regulation of gene expression. Curr Opin Lipidol $2000 ; 11: 3-7$. 


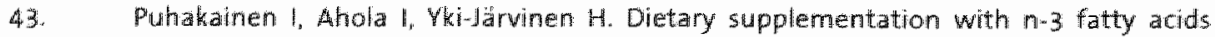
increases gluconeogenesis from glycierol but not hepatic glucose praduction in patients. with non- insulin-dependent diabetes mellitus. Am J Clin Nutr 1995;61:12:-126.

44. Kasim-Karakas SE, Hermann $R$, Almario $R$. Effects of omega- 3 fatty acids on intravascular lipolysis of very-low density lipoproteins in humans. Metabolism $1995: 44: 1223-1230$.

45. Christensen IH, Christensen MS, Dyerberg 1, Schmidt EB. Heart rate wariability and fatty acid content of blood cell membranes: a dose-response study with n-3 fatty acids. Am I Clin Nutr 1999;70:331-337.

46. Glawber $H$, Wallace P, Giver $k$ Brechtel $G$. Adverse metabolic effect of omega-3 fatty acids in non-insulin-dependent diabetes mellitus. Ann Interm Med 1988;108:663-668.

47. Goodnght StH, Jr., Harris WS, Connor WE. The effects of dietary omega 3 fatty acids on platelet composition and function in man: a prospective, controlled study. Blood $1981 ; 58: 880,885$

48. Harris WS, Dujowne $\mathrm{CA}_{4}$ Zucker M. Johnson B. Effects of a low saturated fat, low cholesterol fish oil supplement in hypertriglyceridemic patients. A placebo-controlled triall. Ann intarn Med 1988;109:465-470.

49. Mori TA, Bao DQ Burke V, Puddey IB. Watts GF, Beilin L. Dietary fish as a major component of a weight-loss diet: effect on serum lipids, glucase, and insulin metabolism in overweight hypertensive subjects. Am I Cllin Nutr 1999.70:817-825.

50. Kriketos AD, Robertson RM, Sharp TA, et al. Role of weight loss and polyunsaturated fatty acids in improving metabolic fitness in moderately obese, moderately hypertensiwe subjects. 1 Hypertens $2001 ; 19: 1745 * 1754$.

51. Williams CM. Postprandial lipid metabolism: effects of dietary faty acids. Proc Nutr 506 $1997,56: 679-692$.

52. Le Fur $C_{\text {, Romon }} M_{\text {. Lebel }}$. et al. Inftuence of mental stress and circadian cycle on postprandial lipemia. Am I Clin Nutr 1999;70:213-220.

53. Sadur CN, Eckel RH. Insulin stimulation of adipose tissue lipoprotein lipase. Use of the euglycemic damp technique. J Cin Invest 1982;69:1119-1125.

54. Summers LK, Biarnes, 5C, Fielding BA, et al. Uptake of individual fatty acids into adipose tissue in relation to their presence in the diet. Am J Clin Wutr 2000;71:1470-1477.

55. Potts J, Coppack SW, Fisher RM, Humphreys 5 M, Gibbons GF, Frayn KN. Impaired postprandial ciearance of triacylglycerolitich lipoptoteins in adipose tissue in obase subjects. Am I Physiol 1995,268:E588.594.

56. Leigh-Firbank EC, Minihane AM, Leake DS, et al. Eicosapentaenoic acid and dorosalrexatenoic acid from fish oils: differential associations with lipid responses. Br J Nutr $2002 \cdot 87: 435-445$

57. Zampelas A, Peel AS, Gould B., Wright d, Williams CM. Polyunsaturated fatty acids of the $n-6$ and $m-3$ series: effects on postprandial lipid and apolipoprotein levels in healthy men: Eur J Clin Nutr $1994: 48: 842-848$

58. Agren U, Hanminen 0 , Julkumen A, et all. Fish diet, fish oil and docosahexaenoic awid rich oll lower fasting and postprandial plasma Hipid levels. Eur J Clin Nutr 1996;50:765-771.

59. Chagnon VC, Ramkinen T, Snyder EE, Weisnagel 5J, Perusse L, Bouchard C. The Human Obesity Gene Map: The 2002 Update. Obes Res $2003 ; 11: 313 \times 367$. 
Summary 
The objectives of the studies described in this thesis were twofold. The first objective was to examine if relationships between selected genetic polymorphisms on metabolic risk markers depend on body fatnes5. The polymorphisms that we studied were from the genes coding for insulin receptor substrate-1 (IRS-1), tumor necrosis factor-a (TNF- $a$ ) and interleukin-6 (IL-6), which are all expressed in adipose tissue. The second objective was to compare side by side in obese males the effects of fish oil supplementation and weight loss, which may both reverse some of the metabolic disturbances seen in obesity. Especially, the effects of these two interventions on adipose tissue metabolism and inflammatory responses were examined.

IRS-1 occupies a key position in the insulin signaling pathway. An impaired IRS-1 function may therefore weaken insulin signaling and increase the risk to develop type 2 diabetes. An important polymorphism of the IRS-1 gene is the Gly972Arg polymorphism with a prevalence of about $10 \%$ in Western countries. In a large cohort of 600 subjects, selected according to body mass index (BMI) (BMI $26-40 \mathrm{~kg} / \mathrm{m}^{2}$ or BMI $18-24 \mathrm{~kg} / \mathrm{m}^{2}$ ) and IRS-1 genotype, associations between this polymorphism and metabolic risk markers were investigated (chapter 2). Subjects with the $972 \mathrm{Arg}$ variant had significantly higher insulin concentrations (4.08 pmol/L; $p=0.024)$ and lower triglyceride (TG) levels $(0.13 \mathrm{mmol} / L$; $p=0.001)$ compared with non-carriers when adjusted for age, sex, waist to hip ratio, BMI, alcohol consumption, physical activity and cigarette smoking. These associations were more pronounced in the high BMI group, although the interaction between genotype and BMI did not reach statistical significance.

Since the Gly972Arg polymorphism may impair insulin signaling, we were also interested in the relationship between this polymorphism and the risk to develop type 2 diabetes. This has already been examined in several casecontrol studies, but most studies had a limited power, which may explain the inconsistent results. We therefore decided to perform a meta-analysis (chapter 3). The summary risk ratio, based on 3,408 cases and 5,419 controls from 27 studies, was 1.25 (95\% Cl 1.05-1.48), suggesting that subjects with the Glyg72Arg polymorphism indeed had a higher risk to develop type 2 diabetes.

In chapter 4, associations between the $G 174 \mathrm{C}$ polymorphism in the IL-6 and the $6308 \mathrm{~A}$ polymorphism in the TNF- $\alpha$ gene with metabolic risk markers were examined. For the $\mathrm{LL}-6$ polymorphism, the waist to hip ratio in the high BMI group (BMI $26-40 \mathrm{~kg} / \mathrm{m}^{2}$ ) was significantly lower in $C C$ subjects than in $C G$ and $G G$ subjects $(0.91$ versus 0.94 and $0.95 ; \quad p=0.033)$ of the $L-6$ polymorphism. This relationship was not found in the low BMI group IBMI 18- 
$\left.24 \mathrm{~kg} / \mathrm{m}^{2}\right)$. For the TNF-a polymorphism, carriers of the AA variant had higher TG and lower high density lipoprotein cholesterol (HDL-C) levels compared with carriers of the $G A$ or $G G$ variant $(2.46 \mathrm{mmol} / \mathrm{L}$ versus 1.41 and 1.26 $\mathrm{mmol} / \mathrm{L} ; \mathrm{p}=0.001$ for $T G$ and $1.01 \mathrm{mmol} / \mathrm{L}$ versus 1.17 and $1.09 \mathrm{mmol} / \mathrm{L} ;$ $p=0.016$ for $H D L C$ ). Again, this relationship was only found in subjects with a high BMl. For both polymorphisms no other significant associations were observed. A gene-gene interaction between both polymorphisms was present with respect to TG concentrations. Subjects with the IL-6 GG variant and the TNF- $\alpha$ AA variant had significantly higher TG levels compared with all other combinations.

Besides genetic background, dietary interventions also affect metabolic risk markers related to lipid and glucose metabolism. In this thesis, a side by side comparison was made to study the effects of fish oil and weight loss on subcutaneous adipose tissue metabolism and inflammatory responses during the fasting and postprandial period in obese men. These two interventions were chosen because of their potential to decrease metabolic risk markers. Eleven obese individuals with a BMI between 30 and $35 \mathrm{~kg} / \mathrm{m}^{2}$ participated in the fish oil study, a double-blind cross-over study consisting of two periods of six weeks. Subjects received in random order fish oil capsules that provided daily $0.60 \mathrm{~g}$ eicosapentaenoic acid (EPA; C20:5 $\mathrm{n}-3$ ) and $0.51 \mathrm{~g}$ docosahexaenoic acid (DHA; C22:6 n-3) and control capsules, containing high oleic sunflower oil. Eight of the subjects also agreed to participate in the weight reduction study, in which the men received first a very low calorie diet (VLCD) for four weeks followed by an energy-restricted diet for two weeks, and a diet to maintain body weight for another two weeks. Subjects lost on average $9.36 \mathrm{~kg}$ of body weight during this intervention.

In chapter 5 , the effects of these two dietary interventions on subcutaneous adipose tissue lipolysis, as measured with the microdialysis technique in the fasting and postprandial state, were studied. Glycerol release across the adipose tissue was significantly increased after fish oil supplementation compared with control supplementation ( $p=0.005$ ), suggesting an increased subcutaneous abdominal adipose tissue lipolysis. Weight reduction decreased circulating glycerol and NEFA concentrations ( $p<0.001$ ), indicating a decreased whole body lipolysis during basal and postprandial conditions. Fasting glycerol release seemed to be decreased after weight loss, although this was not statistically significant. However, 3 to 4.5 hours after the meal glycerol release was statistically increased after weight loss. Thus, a decreased subcutaneous adipose tissue lipolysis during the postprandial phase cannot explain the effects of fish oil and weight loss on lipid and glucose metabolism. In fact, 
subcutaneous abdominal adipose tissue lipolysis was increased in the late postprandial period, although insulin sensitivity seemed to be improved.

The in vivo effects of both fish oil and of weight reduction on circulating concentrations of pro-inflammatory cytokines and plasminogen activator inhibitor-1 (PAI-1) antigen in the fasting and postprandial state were explored in thapter 6. IL-6, PAI-1 antigen, and soluble tumor necrosis factor receptor concentrations. (sTNF-R60 and STNF-R80) were not statistically different between the fish oil and control period, but were consistently lower after weight reduction $(p<0.01$ ). TNF $\alpha$ concentrations did not change after fish oil supplementation, but tended to reduce after weight reduction ( $p=0.094)$. Changes relative to baseline concentrations during the postprandial phase were not significantly affected by fish oill or weight reduction. We therefore concluded that, unlike weight reduction, a modest but realistic increased intake of fish oil is not a powerful intervention to lower the increased concentrations of inflammatory parameters and PAI-1 antigen concentrations as observed.

Our results clearly show that relationships between genetic factors and metabolic risk markers may depend on body fatness. At the same time, it should be recognized that reducing body weight has a much stronger impact on metabolic risk markers than the polymorphisms we have studied or than fish oil. It should further be emphasized that one single polymorphism determines only in a rare number of cases the difference between health and disease. In general, the genetic component of these markers is the result of polygenic interactions involving the simultaneous inheritance of several widespread mutations, each with subtle or minor effects on the development of the phenotypes. In future research the impact of interactions between several genes and between genes and environment will become more and more important. Such studies will possibly form the basis for genetic-based dietary advices. 
Samenvatting 
De doelstelling van dit proefschrift was tweeledig. Het eerste doel was onderzoeken of relaties tussen geselecteerde genetische polymorfismen en metabole risicofactoren afhankelijk zijn van de hoeveelheid lichaamsvet. De polymorfismen die we hebben bestudeerd zijn afkomstig van genen die coderen voor het insuline-receptor substraat-1 (IRS-1), tumor necrosis factor- $\alpha$ (TNF- $\alpha$ ) en interleukine-6 (IL-6), die allen tot uitdrukking komen in het vetweefsel. De tweede doelstelling was het vergelijken van zowel de effecten van visolie als van gewichtsreductie, die beide metabole verstoringen in obesitas kunnen verminderen. In het bijzonder wordt de invloed van deze twee interventies op het vetweefsel metabolisme en de inflammatoire respons beschreven.

IRS-1 vervult een sleutelrol in de insuline signalering. Een verstoorde IRS-1 functie kan daarom leiden tot een verslechterde insuline signalering met als gevolg een verhoogd risico op de ontwikkeling van type 2 diabetes. Een belangrijk polymorfisme van het IRS-1 gen is het Gly972Arg polymorfisme met een prevalentie van ongeveer $10 \%$ in Westerse landen. In een groot cohort van 600 personen, geselecteerd op basis van de quetelet index (OI) (OI 26 - 40 $\mathrm{kg} / \mathrm{m}^{2}$ of Q $18-24 \mathrm{~kg} / \mathrm{m}^{2}$ ) en het IRS-1 genotype, zijn associaties tussen dit polymorfisme en metabole risicofactoren bestudeerd (hoofdstuk 2). Personen met de $972 \mathrm{Arg}$ variant hadden significant hogere insuline concentraties $\left(4,08 \mathrm{pmol} / \mathrm{L}_{i} \quad \mathrm{p}=0,024\right)$ en verlaagde triglyceride (TG) concentraties $(0,13 \mathrm{mmol} / L ; p=0,001)$ vergeleken met personen die geen drager zijn van het polymorfisme na correctie voor leeftijd, geslacht, middel heup omtrek, $\mathrm{OI}$, alcohol consumptie, lichamelijke activiteit en roken. Deze associaties waren duidelijker annwezig in personen met een hoge $\mathrm{OI}$, alhoewel de interactie tussen genotype en $\mathrm{Q}$ I niet significant was.

Omdat het IRS-1 polymorfisme de insuline signalering kan verslechteren waren we ook geïnteresseerd in de relatie tussen dit polymorfisme en het risico op het ontwikkelen van type 2 diabetes. Deze relatie is al bestudeerd in verschillende patiënt-controle onderzoeken, maar de meeste studies hadden een gelimiteerde power, wat een mogelijke verklaring kan zijn voor de inconsistente resultaten. We hebben daarom besloten een meta-analyse uit te voeren (hoofdstuk 3). De gemiddelde OR, gebaseerd op 3.408 patienten en 5.419 controlepersonen uit 27 studies, was 1,25 (95\% B| 1,05-1,48), wat suggereert dat personen met het Gly972Arg polymorfisme een verhoogd risico op het ontwikkelen van type 2 diabetes hebben.

In hoofdstuk 4 worden associaties tussen het G174C polymorfisme in het IL-6 gen en het G308A polymorfisme in het TNF- $\alpha$ gen met metabole risicofactoren beschreven. Voor wat betreft het IL-6 polymorfisme was de 
middel heup omtrek in de hoge QI groep $\left(\mathrm{Q} / 26-40 \mathrm{~kg} / \mathrm{m}^{2}\right)$ significant lager in $C C$ dragers vergeleken met $C G$ en $G G$ dragers $(0,91$ ten opzichte van 0,94 en $0,95 ; p=0,033)$. Dit verband was niet aanwezig in de lage of groep (OI $18-24$ $\left.\mathrm{kg} / \mathrm{m}^{2}\right)$. Voor wat betreft het TNF- $\alpha$ polymorfisme bleken dragers van de AA variant hogere TG en lagere hoge dichtheid lipoproteine cholesterol (HDL-C) concentraties te hebben vergeleken met dragers van zowel de $G A$ als $G G$ variant $(2,46 \mathrm{mmol} / \mathrm{L}$ ten opzichte van 1,41 en $1,26 \mathrm{mmol} / \mathrm{L} ; \mathrm{p}=0,001$ voor TG en $1,01 \mathrm{mmol} / \mathrm{L}$ versus 1,17 en $1,09 \mathrm{mmol} / \mathrm{L} ; \mathrm{p}=0,016$ voor $\mathrm{HDL}-\mathrm{C})$. Opnieuw werd dit verband alleen gevonden in personen met een hoge $\mathrm{Q}$. Voor beide polymorfismen werden geen andere significante associaties gevonden. Een gen-gen interactie tussen beide polymorfismen was aanwezig ten aanzien van TG concentraties. Personen met de IL- 6 GG variant en de TNF- $\alpha$ AA variant hadden significant hogere $T G$ gehalten vergeleken met alle andere combinaties.

Naast genetische achtergrond hebben ook dieet interventies effect op metabole risicofactoren die verband houden met vet en glucose metabolisme. In dit proefschrift is het effect van zowel visolie als gewichtsreductie op het onderhuidse vetweefsel metabolisme en de inflammatoire respons gedurende de nuchtere en gevoede toestand bij obese mannen bestudeerd. Deze twee interventies zijn gekozen, omdat met behullp van beide interventies metabole risicofactoren verlaagd kunnen worden. Elf obese mannen met een $\mathrm{Q}$ l tussen de 30 en $35 \mathrm{~kg} / \mathrm{m}^{2}$ namen deel aan de visolie studie, een dubbelblinde gekruiste studie bestaande uit twee perioden van 6 weken. Personen ontvingen in willekeurige volgorde visolie capsules, die zorgden voor een dagelijkse inname van 0,60 g eicosapentaeenzuur (EPA; C20:5 n-3) en $0,51 \mathrm{~g}$ docosahexaeenzuur (DHA; $\mathrm{C} 22: 6 \mathrm{n}-3$ ), en controle capsules bestaande uit zonnebloemolie. Acht van de elf personen namen vervolgens deel aan de gewichtsreductie studie warin zij gedurende 4 weken een dieet met zeer weinig calorieën ontvingen gevolgd door een energie-beperkt dieet gedurende 2 weken en een dieet om gewichtsstabiel te blijven gedurende de 2 weken daaropvolgend. Deelnemers verloren gemiddeld $9,36 \mathrm{~kg}$ gedurende deze interventieperiode.

In hoofdstuk 5 worden de effecten van deze interventies op de subcutane vetweefsel lipolyse, gemeten met de microdialyse techniek in de nuchtere en gevoede toestand, beschreven. De glycerol afgifte over het vetweefsel was significant verhoogd na visolie supplementatie vergeleken met controle supplementatie $(p=0,005)$, wat een verhoogde subcutane vetweefsel lipolyse suggereert. Gewichtsreductie verlaagde de circulerende glycerol en vrije vetzuren concentraties $(p<0,001)$, wat een indicatie is voor een verlaagde totale lipolyse gedurende de nuchtere en gevoede toestand. In nuchtere 
toestand lleek de glycerol afgifte verlaagd te zijn, alhoewel dit niet significant was. Echter, 3 tot 4,5 uur na de maaltijd was de glycerol afgifte significant verhoogd na gewichtsreductie. Dit betekent dat een verlaagde subcutane vetweefsel lipolyse gedurende de gevoede toestand niet de effecten van visolie en gewichtsreductie op vet en glucose metabolisme kan verklaren. De subcutane vetweefsel lipolyse blijkt zelfs verhoogd te zijn gedurende de periode na de maaltijd, alhoewel de insuline gevoeligheid verbeterd is.

De in vivo effecten van zowel visolie als gewichtsreductie op circulerende concentraties van pro-inflammatoire cytokines en plasminogeen-activatorremmer-1 (PAl-1) antigeen in de nuchtere en gevoede toestand worden beschreven in hoofdstuk 6. IL-6, PAl-1 antigeen en oplosbare TNF receptor concentraties (sTNF-R60 en TNF-R80) waren niet verschillend tussen de visolie en controle periode, maar waren consistent lager na gewichtsreductie $(p<0,010)$. TNF- $\alpha$ concentraties waren niet veranderd na visolie supplementatie, maar leken te zijn verlaagd na gewichtsreductie $(p=0,094)$. Veranderingen ten opzichte van nuchtere waarden gedurende de periode na de maaltijd werden niet beînvloed door visolie of gewichtsreductie. We hebben daarom geconcludeerd dat, in tegenstelling tot gewichtsreductie, een gemiddelde inname van visolie niet leidt tot een verlaging van inflammatoire parameters en PAl-1 antigeen concentraties.

Onze resultaten laten duidelijk zien dat associaties tussen genetische factoren en metabole risicofactoren afhankelijk kunnen zijn van de hoeveelheid lichaamsvet. Tegelijkertijd moet gezegd worden dat gewichtsreductie een veel grotere invloed heeft op metabole risicafactoren dan de polymorfismen die wij bestudeerd hebben of dan visolie. Verder moet benadrukt worden dat een enkel polymorfisme alleen in een uitzonderlijk geval het verschil tussen gezondheil en ziekte verklaart. Over het algemeen is de genetische component van deze metabole risicofactoren het resultaat van polygene interacties betreffende de simultane overerving van meerdere mutaties, die elk een klein effect hebben op het fenotype. In toekomstig onderzoek zal de invloed van interacties tussen verschillende genen en omgevingsfactoren steeds belangrijker worden. Zulke studies zullen mogelijk de basis zijn van dieetadviezen gebaseerd op genetica. 
Abbreviations 
sane:

ACC:

ANOVA:

ATBF:

ATP:

BM:

CHD:

Cl

CRP:

DEXA:

DG:

DHA:

EN\%:

EPA:

FA:

FABP:

FAS:

$\mathrm{FCH}$ :

GLUT4:

GPDH:

GTT:

HDL $-\mathrm{C}$ :

HL:

HOMA

HSL:

IGF-1:

IL-6:

IRS-1:

LDL-C:

LPL:

MG:

MODV:

MORGEN:

MTNF-R60:

MTNF-R80:

n-3 LCPUFA:

NEFA:

NUTRIM:

NWO:

OR:

PAI-1:

PCR:

\section{Xenon}

acetyl-COA carboxylase

analysis of variance

adipose tissue blood flow

adenosine triphosphate

body mass index

coronary heart disease

confidence interval

creactive protein

dual-energy $x$-ray absorptiometer

diacylglycerol

docosahexaenoic acid

energy percent

eicosapentaenoic acid

fatty acids

fatty acid-binding protein

fatty acid synthase

familial combined hyperlipidemila

glucose transporter-4

glyceral phosphate dehydrogenase

glucose tolerance test

high density lipoprotein cholesterol

hepatic lipase

homeostasis model assessment for insulin resistance hormone sensitive lipase

insulin growth factor -1

interleukin-6

insulin receptor substrate-1

low density lipoprotein cholesterol

lipoprotein lipase

monoacylglycerol

maturity-onset diabetes of the young

monitoring Project on risk factors for chronic disease

membrane bound tumor necrosis factor receptor 60

membrane bound tumor necrosis factor receptor 80

n-3 long chain polyunsaturated fatty acids

non-esterified fatty acids

Nutrition and Toxicology Research Institute Maastricht

Netherlands organization for scientific research

odds ratio

plasminogen activator inhibitor-1

polymerase chain reaction 
PI:

SD:

SE:

SSCP:

STNF-R60:

STNF-R80:

$T C$ :

TG:

TNF- $\alpha$ :

TRL:

tPA:

VLAG:

VLCD:

VLDL:

WHO:

QI: phosphatidylinositol

standard deviation

standard error

single strand conformation polymorphism analysis

soluble tumor necrosis factor receptor 60

soluble tumor necrosis factor receptor 80

total cholesterol

triglyceride

tumor necrosis factor- $\alpha$

triglyceride-rich lipoproteins

tissue plasminogen activator

Food Technology, Agrobiotechnology, Nutrition and Health Sciences

very low calorie diet

very low density lipoprotein

World Health Organization

quetelet index 

Nawoord 
Het is weer vrijdag, mijn "proefschrift" "dag. Sinds ik werk bij de GGD heb ik deze dag vrij genomen om mijn proefschrift af te ronden. Vandaag heb ik weinig inspiratie. Het regent buiten en ik merk dat mijn rechterarm het layouten van het boekje niet leuk vindt. Bang voor RSI besluit ik een irritant antiRSI programmaatje te installeren. Op de momenten dat ik nu fanatiek werk, word ik geconfronteerd met micro-pauzes en allemaal ontspannende oefeningen. Eerst maar eens bedenken wat we gaan eten vanavond je moet je prioriteiten stellen, toch?). Terwijl ik door de receptenkaartjes van AH blader bedenk ik me dat mijn proefschrift ook een groot recept is. Ik brainstorm wat ik er allemaal voor nodig heb gehad. Na een flinke rekensom kom ik uit op zo'n 19,5 liter bloed, 640 voedingsvragenlijsten, 1.600 bloedbuizen, $47.360 \mathrm{~kg}$ op de weegschaal, 962 referenties in mijn Endnote bestand, $6,5 \mathrm{~m}$ pleisters, 217 uur videofilm, 5.400 polymorfisme bepalingen, 22 versies van het IRS-1 artikel, 41.765 woorden proefschrifttekst, 180 uur centrifugeren, 5.289 visolieen controlecapsules, enzovoort, enzovoort.

Ik bedenk me dat mijn lijst met ingrediënten veel verder gaat dan deze materialen. Ik had niks kunnen beginnen zonder de 600 vrijwilligers die in groten getale meededen aan de screening. De belangrijkste "ingrediënten" van de interventiestudie waren meneer Molin, In de Braek, Zegers, Kluten, Kurvers, Dilweg, Reinders, Leenders, Chambille, Kerkhofs en Schreurs. Urenlang hebben ze op bed gelegen tijdens de meetdagen met aan beide armen een infuus en aangesloten op de oxycon, microdialyse, spier- en vetbloedstroommeter. "Het moet geen pretje geweest zijn", bedenk ik me, terwijl zij de meting allemaal twee en de meesten zelfs drie keer zonder mopperen vervolgden.

"Als de proefpersonen en materialen de ingrediënten van mijn recept zijn, zou $i k$ dan iedereen die me geholpen heeft met dit proefschrift met de potten en pannen kunnen vergelijken of ga ik dan te ver?", brainstorm ik verder. Dan is Ronald de "wok", waar alle ingrediënten in samen komen. Hij heeft me tijdens de afgelopen vier jaar het meest geholpen met het opzetten en uitvoeren van alle metingen. Hij beantwoordde vragen door vragen terug te stellen, zodat ik zelf na ging denken. Op momenten dat ik het helemaal had gehad, was hij er altijd met advies en relativerende woorden. Als Ronald de wok is, is Edith de "braadpan", alleen noodzakelijk als je wlees gaat braden, maar dan ook onmisbaar. Door de afstand Bilthoven-Maastricht was het niet altijd handig voor praktische zaken een beroep op Edith te doen, maar af en toe een dagje samen was vreselijk nuttig. Niet alleen het proefschrift werd dan doorgenomen, ook minstens zo belangrijke onderwerpen als de stand van zaken in de politiek en vakantieplannen passeerden de revue. Als je eenmaal aan het vergelijken bent, slaat je fantasie op hol. Als ik Wim en Daan nu eens vergelijk met twee "groentepannen", op de achtergrond aanwezig op het vuur. Ze grepen in als het nodig was en bekeken kritisch het manuscript. Ook 
de leden van de beoordelingscommissie hebben als "keuringsdienst van waren" een kritische blik op mijn proefschrift geworpen.

Naast pannen zijn er meer benodigdheden voor het bereiden van een maaltijd. Mijn "keukengerei" was ook niet gering. Ik besluit de afgelopen jaren eens langs te lopen. Als eerste kom ik bij de mensen van de afdeling LEO van het RIVM, met name Barbara en Evert. Zij hebben me geholpen met de genotypering van de polymorfismen. Jaap en Jolanda hebben me het jaar op het RIVM geassisteerd op het moment dat Edith er niet was. Spike en Tim hebben me vervolgens bijgestaan bij het uitvoeren van de screening. De labanalyses waren nooit gelukt zonder de hulp van Frank, Jos, Maurice, Sjoerd en Wendy. Kees Kluft heeft voor de bepaling van CRP gezorgd. Loek en Paul zorgden voor het voortbestaan van mijn Imac. Ilona, Peggy, Claudia, Desiree, Truus en Mariëlle van het secretariaat hielpen me altijd met administratieve vragen. Arnold Kester was altijd bereid mee te denken over mijn statistische analyses. Maurice heeft me enthousiast gemaakt voor de meta-analyse en me de basisprincipes bijgebracht. Ellen heeft me geïntroduceerd in het wereldje van de microdialyse en bloedflowmeting. Van haar heb ik deze metingen geleerd en ze heeft me bijgestaan tijdens de eerste meetdagen. Peter Arner zorgde vervolgens voor analyse van alle microdialyse monsters. Tijdens de gehele interventiestudie was Esther mijn grote steun en toeverlaat. Samen hebben we de hele studie uitgevoerd met Angelina als troef die tijdens de meetdagen insprong waar nodig. Joan en Marco zorgden voor de vele infuzen, Mirjam voor de opvang van de proefpersonen in de winkel en de heerlijke shakes en de medewerkers van Nucleaire geneeskunde hielpen met het bereiden van de Xenon en het uitvoeren van de DEXA meting. Meneer Vandijck heeft me geholpen met het maken van de plaatjes op de voorkant van het proefschrift. Aldrik, Marian, Janneke en Joost hebben zich door het proefschrift geworsteld om de laatste fouten eruit te halen.

Met ingrediënten en keukengerei kom je in principe aardig ver bij de bereiding van je maaltijd, maar niks is zo ongezellig als alleen eten. Gelukkig had ik de afgelopen jaren genoeg "eters" tijdens en na thet werk. Om te beginnen bij mijn eerste AiO jaar waren dat de medewerkers van CZE, met name Rob en Caroline, die ik ook tijdens congressen en meetings nog geregeld tegenkwam. Marieke was een belangrijke "eter" tijdens mijn tweede Aio jaar. Volgens mij waren wij de enige AiO's bij Humane Bilologie die statistiek zo erg niet vonden. Wat waren we verontwaardigd en teleurgesteld dat we na een jaar niet meer bij elkaar op de kamer mochten zitten. Hoe kwamen ze erbij dat het te gezellig zou zijn op onze kamer? Ariënne, Angelina, Elke, Alexandra, Daniëlle, Maurice, Jogchum, Frank, Myriam, Mirjam, 5joerd en Julian waren mijn vaste lunchmaatjes de afgelopen jaren. Om klokslag twaalf uur rammelde mijn maag en was het tijd voor soep. Ariënne houdt me nu ook nog op de hoogte van het wel en wee van de vakgroep. De vele telefoongesprekken en e- 
mailtjes over en weer zorgen ervoor dat ik me nog een beetje bij de vakgroep voel horen. Voor de nodige afleiding zorgden ook andere (ex)collega's van Humane Biologie, zoals Tanja, Manuela, Lydia, Renate, Marleen, Freddy, Chris, Erwin, Joris, Gijs, Cyriel, Luc, Petra, Marco, Margriet, Eefje, Annemiek, Guy, Neeltje, Eva, Hasibe, Antoine, Freek, Michiel, Mirjam A. en natuurlijk Joost. Hij was er voor gezellige kletspraatjes, opbeurende praatjes, zeurpraatjes, roddelpraatjes en is ook nog mijn paranimf. Sander is mijn andere paranimf. Wij zijn als huisgenootjes tijdens onze studententijd in hetzelfde jaar van BGK begonnen en promoveren nu ook nagenoeg tegelijkertijd. Lekker om samen te praten over het wel en wee van AiO zijn. Jammer dat hij in Maastricht blijft, ik had hem graag in de Randstad gehad. Marian, Marieke W., Ilse, Nienke, Dewi, Nicole, Edwin, Volcmar, Judith, Wendy, Martine, Vanessa, Yvonne, Marjan, Fleur, Sanne, Sander T. en Akim hebben gezorgd voor de nodige ontspanning na het werk.

Ik eet het allerliefste thuis, lekker bij mem en Wim, samen met Janneke, Jachin, Sytske en Aldrik. Even niet denken aan het werk, maar genieten van de heerlijke gerechten die mem maakt (waarom heb ik die genen niet geërfd?), spelletjes Kolonisten na het eten en lachen, heel veel lachen.

Vanavond eet ik lekker samen met Aldrik, zoals gelukkig heel vaak het afgelopen jaar. Ik bedenk me dat hij de "keuken" was de afgelopen jaren, hij zorgde ervoor dat ik de ruimte kreeg om mijn proefschrift te maken. Hij had engelengeduld, beurde me op en relativeerde.

Ik kies uit de hoeveelheid kaartjes van $\mathrm{AH}$ de maaltijd die het snelst klaar is. Even geen uitgebreide recepten meer voor mij. 
List of publications 


\section{Full papers}

- Jellema A, Feskens EJM, Mensink RP, Saris WHM, Kromhout D. Metabolic risk markers in an overweight and normal weight population with oversampling of carriers of the IRS-1 972Arg variant. Accepted in Atherosclerosis

- Jellema A, Zeegers MPA, Feskens EJM, Dagnelie PC, Mensink RP. Glyg $72 \mathrm{Arg}$ variant in the insulin-receptor substrate-1 gene and association with type 2 diabetes: a meta-analysis of 27 studies. Diabetologia 2003:46:990-995.

- Jellema $A_{n}$ Feskens EJM, Mensink RP, Saris WHM, Kromhout D. Impact of polymorphisms of the IL- 6 and TNF- $\alpha$ genes on cardiovascular risk markers in a large population. Submitted

- Jellema A, Blaak EE, Mensink RP, Arner P, Kemerink GJ, Feskens EJM, Saris WHM. Effects of fish oil and weight reduction on subcutaneous adipose tissue lipolysis in the fasting and postprandial state. Submitted

- Jellema A, Mensink RP, Effects of fish oill and weight loss on inflammatory parameters and PAI-1 antigen concentrations in obese men during the fasting and postprandial state. Submitted

- Zeegers MPA, Jellema A, Ostrer, H: Empiric risk of prostate carcinoma for relatives of patients with prostate carcinoma, a meta-analysis. Cancer 2003;97:1894-1903.

\section{Abstracts}

- Jellema A, Feskens EJM, Mensink RP, Saris WHM, Kromhout D. Cardiovascular risk markers in an overweight and normal weight population with oversampling of carriers of the IRS-1 972 Arg variant. Atherosclerosis 2002;3(suppl 2):133.

- Jellema A, Feskens EIM, Mensink RP, Saris WHM, Kromhout D. Impact of polymorphisms of the IL-6 and TNF- $\alpha$ genes on cardiovascular risk markers in a large population. Atherosclerosis 2002;3(suppl 2):133. 
- Jellema A, Zeegers MPA, Feskens EJM, Dagnelie PC, Mensink RP: Metaanalysis of the Gly972Arg variant in the insulin receptor substrate-1 gene and association with type 2 diabetes. Diabetologia 2002;45(suppl 3)A123-4.

- Zeegers MPA, Jellema A, Ostrer, H: Empiric risk of prostate cancer for relatives of prostate cancer patient Am J Hum Gen 2002;71(suppl 4):239. 

Curriculum vitae 
Annemarie Jellema was born on March 16, 1975, in Grouw. She completed secondary school at Marianum in Groenlo in 1993. In the same year she started her academic education at the Maastricht University, where she studied Biological Health sciences until 1998. During her first internship in 1997, she examined the effect of quitting with growth hormone supplementation on body composition in children with growth hormone disorders. In 1998, she went to Denver for her second internship. During this internship, she studied the effect of high or low calorie drinks on satiety and eating pattern in children of different ages.

From November 1998 until December 2002 she was appointed as a PhD fellow to the department of Human Biology at the Maastricht University. During this period, she conducted a large cross-sectional study and two intervention studies in which she examined the effects of genetic polymorphisms and dietary interventions on metabolic risk markers and lipid metabolism. She participated in the educational epidemiology program and received her epidemiologist $A$ registration in 2003.

Since February 2003, she works as an epidemiologist at the local health institute GGD Noord-Kennemerland in Alkmaar. 


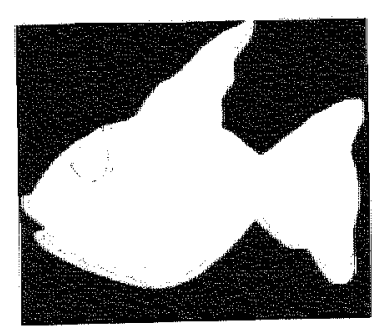

Picture back page 